\title{
Influence of As-cast Microstructure on Forging Behaviour of Magnesium Alloy AZ80
}

\author{
by \\ Jared Uramowski
}

A thesis

presented to the University of Waterloo

in fulfillment of the

thesis requirement for the degree of

Master of Applied Science

in

Mechanical Engineering

Waterloo, Ontario, Canada, 2021

(c) Jared Uramowski 2021 


\section{Author's Declaration}

I hereby declare that I am the sole author of this thesis. This is a true copy of the thesis, including any required final revisions, as accepted by my examiners.

I understand that my thesis may be made electronically available to the public. 


\begin{abstract}
Concerns over the environment and greenhouse gas emissions have incentivized the increased use of lightweight metals, such as magnesium alloys, to improve vehicle efficiency through a reduction in mass. While there are some current applications of magnesium alloys in the automotive industry, further adoption will see their use in areas with more structural components, such as chassis and suspension. To meet the strength and fatigue requirements of a structural automotive component however, the mechanical properties must be improved through hot forging. Research has shown the mechanical properties of forged magnesium to rely on the grain size, grain orientation, and internal defects, of the as-cast starting material.
\end{abstract}

The current research is part of a Natural Sciences and Engineering Research Council of Canada's Strategic Partnership Grant, and is conducted at the University of Waterloo. The intent of this project is to produce an automotive suspension control arm for a Ford Fusion car, through casting and forging of the AZ80 alloy. In this research, a spatially optimized forging pre-form shape will be cast, such that the forging process and mechanical properties will be optimized upon forging. Therefore, more consideration is given to the production of the AZ80 castings and their starting structure, as well as their forging behaviour.

This research focuses on the influence of the as-cast microstructure on the forging behaviour and microstructure evolution of the AZ80 magnesium alloy. Forging behaviour is evaluated by measuring the compressive stress, evolution of microstructure during deformation, and susceptibility to cracking during deformation. A particular emphasis is placed on the effect of the cooling rate during solidification on subsequent forgeability. Two casting moulds were used to produce material for this project: a wedge casting mould and a cylinder casting mould. The wedge casting enabled the study of the cooling rate, while the cylinder casting mould enabled the study of the homogenization treatment.

The microstructure effects of cooling rate, and its subsequent influence on the compressive stress and deformation behaviour, are explored. This includes effects of both grain size and morphology of the $\mathrm{Mg}_{17} \mathrm{Al}_{12}$ intermetallic phase. The use of a homogenization heat treatment to improve the forgeability of the AZ80 castings is also studied. In all cases, the hot compression behaviour was studied using a Gleeble ${ }^{\mathrm{TM}} 3500$ thermal-mechanical simulator, available at the University of Waterloo, by uniaxial compression testing. Samples were characterized primarily through optical microscopy analysis. 
The results show that the forging behaviour is dependent on the microstructure of the initial cast material. Samples cast with a higher cooling rate saw a more refined grain structure, inducing a higher peak stress during compression testing. The cooling rate is also found to influence the $\mathrm{Mg}_{17} \mathrm{Al}_{12}$ phase morphology. Slower cooling rates during the later stages of solidification showed a higher amount of precipitated $\mathrm{Mg}_{17} \mathrm{Al}_{12}$, and less of the eutectic $\mathrm{Mg}_{17} \mathrm{Al}_{12}$. The presence of these precipitates also has an influence on the forging behaviour, whereby more dynamic recrystallization may occur during deformation. A heat treatment of $420^{\circ} \mathrm{C}$, held for 24 hours, was sufficient for what is believed to be a near-full homogenization of the AZ80 microstructure. Homogenized samples retained their relative grain size effects on the compressive stress from the solidification cooling rate, however the amount of dynamic recrystallization which occurred during deformation was increased. This resulted in a high amount of dynamic softening following the peak compressive stress, which translates to a reduction in compressive stress at elevated strains, compared to the cast material. Finally, the porosity that is often inherent to castings was not found to significantly affect the compressive stress of the material. However, samples with a high amount of porosity had a higher tendency to crack under high strains, making them less suitable for forging. This knowledge will help to determine the optimal cast material structure that will enable structural components upon forging. 


\section{Acknowledgements}

While this thesis is comprised of research I have conducted in my time as a master's student, many of the following pages would be vacant if not for the contributions from those I have met and collaborated with along the way. I would like to take this opportunity to express my gratitude for the following people.

To begin, I would like to thank my supervisor, Dr. Mary Wells, for the opportunity to join this research group. The guidance which has been provided to me throughout this time has been invaluable, and I am grateful for all I have learned because of it. The freedom of curiosity, which I have been fortunate to enjoy as a master's student, has not come without encouragement and support from Dr. Wells.

To Dr. Hamid Jahed, Dr. Seyed Behzad Behravesh, and Dr. Ali Roostaei, thank you for your leadership roles in the SPG project. Your expertise in the field and familiarity with the project has been very helpful to directing my research and understanding the results. To my research colleagues Erfan Azqadan and Tharindu Kodippili, thank you for the assistance with the execution of my research and the analysis of results. To the remaining research colleagues in the SPG project, thank you for the continued feedback and criticism, it has always been helpful and constructive.

I am especially thankful for all the help provided by Renata Zavadil at CANMET Materials. While my in-person research activities at CANMET were short lived, I am lucky to have learned what I could about metallography preparation, most notably the importance of perfectionism. Further, and even more importantly, all the optical microscope images which are presented in the results of this thesis have been taken by her, as well as all the etching required prior to imaging. The detail in these images is outstanding, and I am fortunate to be able to include them in my thesis. Conducting research during a pandemic is difficult, even more-so when so much of it is reliant on access to off-campus laboratories such as CANMET, and I am grateful to have had Renata on the other end of this remote-work request scenario.

Also from CANMET, I would like to thank Peter Newcombe and Gabriel Birsan. Peter and Gabriel provided continual support and advice with my casting mould designs. Their help has significantly contributed toward the quality of the castings produced in this research. Thank you to Dr. Bruce Williams for welcoming me to CANMET, and for providing advice on my research, and helping to coordinate research remotely. 
Thank you to Mark Whitney for training me on the Gleeble and helping me diagnose both my test results, and any issues with the machine. I learned far more than just compression testing and am much more invested in my results because of it. Your camaraderie will be missed.

Thank you to Andy Georgiou, Mike Bruhn, Alex Duquette, and Tom Sparrow from Multimatic Technical Centre, for their first-hand knowledge in manufacturing, and advice on how to design casting moulds to be machinable.

Thank you to Dr. Paresh Prakash and Dr. Andrew Gryguc for your mentorship and guidance along the way. I have benefitted greatly from your expertise on magnesium alloys, and from your friendship.

Thank you to my partner, Claire, for being by my side, and for believing in me. Your encouragement and support helps me to strive for the greatest things in life.

Above all, thank you to my parents and my brother. Thank you for investing the time and effort to ensure that I could grow into a confident and inquisitive individual. You instilled in me at a young age a strong desire for knowledge; a passion for understanding how things work, and this holds true in all my pursuits. Your love, support, friendship, and encouragement has been the greatest source of reassurance, and I do not know who or where I would be without it. 


\section{Table of Contents}

List of Figures $\quad$ x

$\begin{array}{ll}\text { List of Tables } & \text { xvi }\end{array}$

\begin{tabular}{lll}
\hline & Introduction & 1
\end{tabular}

1.1 Background . . . . . . . . . . . . . . . . . . . . . 1

1.2 Research Objectives . . . . . . . . . . . . . . . . . . 3

1.3 Thesis overview . . . . . . . . . . . . . . . . . . . . 3

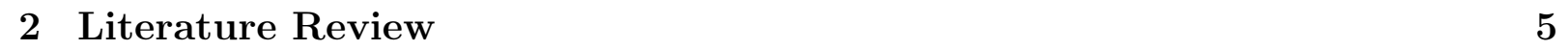

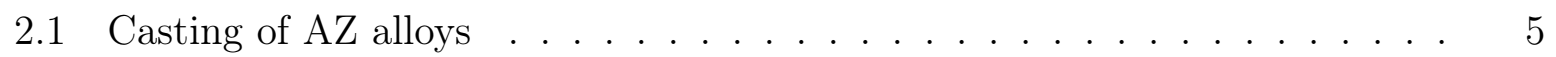

2.1.1 Microstructure and mechanical properties of cast AZ alloys . . . . . 5

2.1.2 Effect of aluminum content on AZ alloy microstructure and properties 8

2.1.3 Effect of solidification rate on AZ alloy microstructure and properties 11

2.2 Deformation and forging of AZ alloys . . . . . . . . . . . . . . . . . . . . . 12

$2.2 .1 \quad$ Deformation modes . . . . . . . . . . . . . . . . . . . . 12

$2.2 .2 \quad$ Effect of initial state on deformation behaviour . . . . . . . . . . . 14

$2.2 .3 \quad$ Effect of process parameters on deformation behaviour . . . . . . 19

2.3 Permanent mould design . . . . . . . . . . . . . . . . . . . . . . . . . 21

2.3 .1 Components of a casting mould . . . . . . . . . . . . . . . . 21

$2.3 .2 \quad$ Designing a mould to minimize defects . . . . . . . . . . . . . . 22

2.4 Casting process modelling . . . . . . . . . . . . . . . . . . . 24

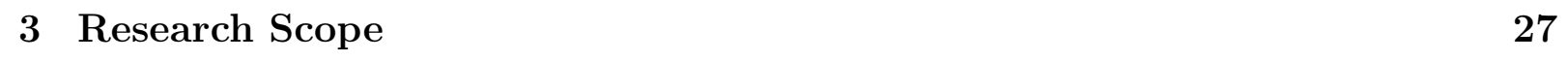


\begin{tabular}{lll}
\hline 4 & Methodology & 28
\end{tabular}

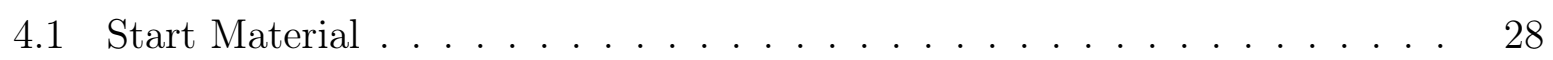

$4.1 .1 \quad$ Casting of Material . . . . . . . . . . . . . . . . . . 28

$4.1 .2 \quad$ Homogenization Treatment . . . . . . . . . . . . . . . . . 33

4.2 Uniaxial Compression Testing . . . . . . . . . . . . . . . . . . . . . . . 34

$4.2 .1 \quad$ Sample Geometry and Extraction from Starting Material . . . . . . 34

4.2 .2 Testing Procedure . . . . . . . . . . . . . . . . . . . . . 34

4.2 .3 Correction Methods. . . . . . . . . . . . . . . . . . 36

4.3 Characterization $\ldots \ldots \ldots \ldots$

$4.3 .1 \quad$ Optical Metallographic Sample Preparation . . . . . . . . . . . 38

$4.3 .2 \quad$ Metallography Analysis and Quantification . . . . . . . . . . 38

4.3 .3 Thermodynamic Property Measurements . . . . . . . . . . . . . 40

$4.3 .4 \quad$ Electrical Conductivity . . . . . . . . . . . . . . . . . . 41

4.4 Casting Experiment Simulation . . . . . . . . . . . . . . . . . . . . . 42

$4.4 .1 \quad$ Simulation Setup and Procedure. . . . . . . . . . . . . . . 42

$4.4 .2 \quad$ Boundary Conditions . . . . . . . . . . . . . . . . . 43

4.5 Permanent Mould Development . . . . . . . . . . . . . . . . . . . . . 45

$\begin{array}{lll}5 & \text { Results and Discussion } & 47\end{array}$

5.1 Cast Microstructure . . . . . . . . . . . . . . . . . . . . . . . . . . 47

$5.1 .1 \quad$ Effect of Cooling Rate $\ldots \ldots \ldots \ldots \ldots$

$5.1 .2 \quad$ Effect of De-gas Addition. . . . . . . . . . . . . . . . . . 49

$5.1 .3 \quad$ Casting Mould Design . . . . . . . . . . . . . . . 52

$5.1 .4 \quad$ Effect of Homogenization . . . . . . . . . . . . . . . 56

$5.2 \quad$ Hot Compression Behaviour $\ldots \ldots \ldots \ldots$. . . . . . . . . . . 6

5.2 .1 Typical Stress-Strain Curve $\ldots \ldots \ldots$. . . . . . . . . . 60

5.2 .2 Effect of Temperature $\ldots \ldots \ldots \ldots \ldots \ldots$

5.2 .3 Effect of Strain Rate . . . . . . . . . . . . . . . . . . . . . 62 
5.2 .4 Effect of Cast Cooling Rate $\ldots \ldots \ldots \ldots \ldots$

5.2 .5 Effect of Homogenization . . . . . . . . . . . . . . 72

5.2 .6 Evolution of Cast and Homogenized Microstructure . . . . . . . 77

6 Conclusions and Future Work 84

6.1 Conclusions . . . . . . . . . . . . . . . . . . . . . . . . . . 84

6.2 Future Work . . . . . . . . . . . . . . . . . . . . . . . 86

\begin{tabular}{lr}
\hline References & 88
\end{tabular}

\begin{tabular}{lr}
\hline APPENDICES & 96
\end{tabular}

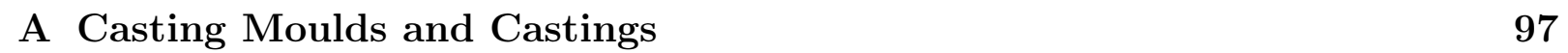

\begin{tabular}{ll}
\hline B Compressive Stress Curve Data & 99
\end{tabular}

\begin{tabular}{ll}
\hline C Metallographic Analysis & 102
\end{tabular} 


\section{List of Figures}

1.1 Specific strength and specific stiffness of Magnesium, Aluminum, and Iron. (Reproduced with permission from Springer Nature) [4] . . . . . . . . . . 2

2.1 Microstructure of as-cast AZ80: (a, b) Optical Microscopy and (c, d) SEM. (Reproduced with permission from Elsevier) [11] $\ldots . . . . . . .66$

2.2 Optical microscopy images of entrained oxide film and intermetallic cluster defects. (Reproduced with permission from Elsevier) [13] . . . . . . . . . . 7

2.3 The influence of $\mathrm{Al}$ content and drawing rate (cooling rate) on the eutectic morphology. The left column shows Mg-Al alloys at compositions of 3, 6, 10, and 15 weight percent $\mathrm{Al}$, drawn at $0.3 \mathrm{~mm} / \mathrm{s}$, and the right column shows $\mathrm{Mg}-\mathrm{Al}$ alloys with the same composition drawn at $3 \mathrm{~mm} / \mathrm{s}$. (Reproduced

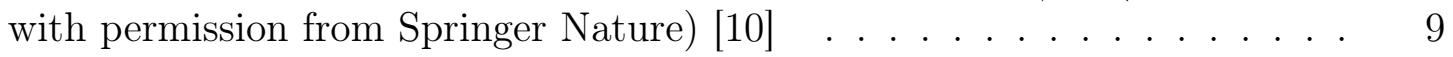

2.4 (a) and (b) Typical tensile stress-strain flow curves of Mg-Al alloys showing effects of alloy content and drawing rate. (Reproduced with permission from Springer Nature) $[10]$. . . . . . . . . . . . . . . . . . . 10

2.5 Major slip systems in magnesium alloys. . . . . . . . . . . . . . . . . . . . 12

2.6 Estimated CRSS of slip and twinning systems in Mg at 1\% strain. (Reproduced with permission from Elsevier) $[28] \ldots \ldots . . \ldots . . \ldots 13$

2.7 True stress-true strain curves of as-cast and pre-strained AZ80 alloy at strain rates of; (a) $0.01 / \mathrm{s}$ and (b) $0.1 / \mathrm{s}$. (Reproduced with permission from Else-

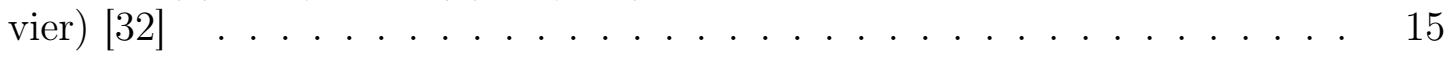

2.8 Microstructure after compression to a strain of 0.2 at $350^{\circ} \mathrm{C}$ and $0.01 / \mathrm{s}$ for (a) wrought AZ31 and (b) cast AZ31. (Reproduced with permission from Elsevier) [34] $\ldots \ldots \ldots \ldots \ldots \ldots$

2.9 Microstructure after 20 hour homogenization treatment at $420^{\circ} \mathrm{C}$ for (a) cast AZ80 by optical microscopy and (b) grain refined cast AZ80 by scanning electron microscopy. (Reproduced with permission from Elsevier) [11] . . . 18

2.10 Microstructure of samples deformed at a strain rate of $0.001 / \mathrm{s}$ to a strain of 0.15 at temperatures of (a) $300^{\circ} \mathrm{C}$ and (b) $400^{\circ} \mathrm{C}$. (Reproduced with permission from Author and UWSpace) [50] . . . . . . . . . . . . . . . . . 20

2.11 A schematic showing the components of a bottom-fed casting mould. (Reproduced with permission from Springer Nature) [51] . . . . . . . . . 21 
2.12 A sketch of a surface entrainment event in an aluminum alloy. (Reproduced with permission from Elsevier) $[52]$. . . . . . . . . . . . . . . . 22

$4.1 \quad$ The wedge casting mould, with attached water lines. . . . . . . . . . . . . 29

4.2 The locations of the thermocouples along the wedge. . . . . . . . . . . . . 30

4.3 The temperature recorded by thermocouple 4 and thermocouple 7 after filling, showing the temperature range over which the cooling rate was calcu-

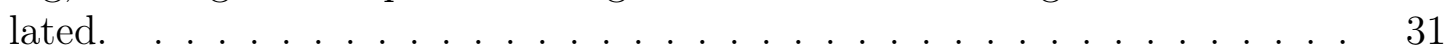

4.4 An exploded view of the cylinder casting mould. . . . . . . . . . . . . . . 32

4.5 A view of one half of the cylinder mould, showing the thermocouple loca-

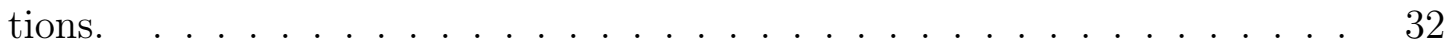

4.6 The fluidized alumina powder bath, and wire-mesh cage, used for homogenization treatment. . . . . . . . . . . . . . . . 33

4.7 Compression sample extraction from the a) wedge casting and b) cylinder

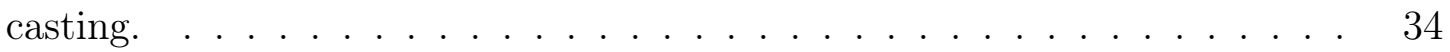

4.8 Plots showing the measured data for a) force and displacement, and calculated values for b) true stress and true strain. . . . . . . . . . . . . . 36

4.9 True stress-true strain curves of the uncorrected data, data with friction correction, and data with both friction and temperature correction. . . . . 37

4.10 An example showing the methods used to measure a) SDAS and b) grain

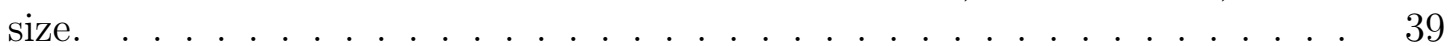

4.11 The voids within a polished sample selected for area fraction measurement. 40

4.12 An exploded view of the wedge mould components used in the ProCAST model. . . . . . . . . . . . . . . . . . . . 42

4.13 An exploded view of the wedge mould components used in the ProCAST model, including the partitions for variable heat transfer coefficient calculation. 44

4.14 The interface heat transfer coefficient, as a function of interface temperature, for the center partition of the wedge mould simulation, with liquidus and solidus temperatures labelled. . . . . . . . . . . . . . . . . 45

4.15 Details of the final mould design including a) the mould itself with important features labelled and b) the resulting cast part from the mould. Images courtesy of Peter Newcombe at CANMETMaterials. . . . . . . . . . . . . . 46 
5.1 Optical microstructure of wedge cast AZ80: a) High cooling rate (HCR), and b) Low Cooling Rate (LCR). . . . . . . . . . . . . . . . . . . 47

5.2 Optical microstructure of wedge cast AZ80: a) HCR, b) LCR, at higher

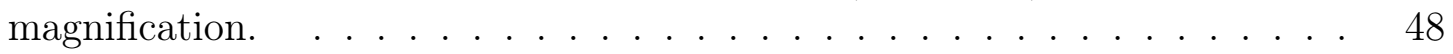

5.3 Temperatures recorded by thermocouple 4 (HCR) and thermocouple 7 (LCR) during solidification of the as-cast wedge casting, with measured liquidus $\left(\mathrm{T}_{\text {liq }}\right)$ and solidus $\left(\mathrm{T}_{\mathrm{sol}}\right)$ temperatures shown. . . . . . . . . . . 49

5.4 Optical microstructure of wedge cast AZ80 at high cooling rate: a) without addition of de-gas agent, b) with de-gas agent. $\ldots . . . . . . . .50$

5.5 Optical microstructure of wedge cast AZ80 at high cooling rate: a) without

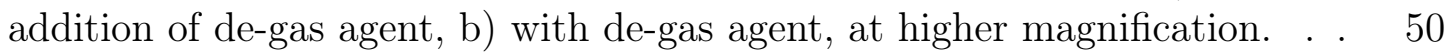

5.6 Temperatures recorded by thermocouple 4 during solidification for the wedge casting of as-cast and de-gas material. . . . . . . . . . . . . . 51

5.7 The percentage of pores on a 2D surface of HCR and LCR samples from both wedge casting trials, including the de-gas samples. . . . . . . . . . 52

5.8 The temperature recorded at each thermocouple in the cylinder casting mould for air and water cooled castings. . . . . . . . . . . . . . . . 53

5.9 Comparison of the cooling rate between the wedge casting and the permanent mould casting processes. . . . . . . . . . . . . . . . . 54

5.10 Optical microstructure of cast AZ80 from the a) air cooled cylinder casting, b) LCR wedge casting, and at 500x magnification from the c) air cooled cylinder casting, and d) LCR wedge casting. . . . . . . . . . . . . . . 55

5.11 Optical microstructure of air cooled cylinder cast AZ80 at 100x magnification: a) as-cast, prior to homogenization, b) after homogenization, and at 500x magnification: c) as-cast, prior to homogenization, and d) after

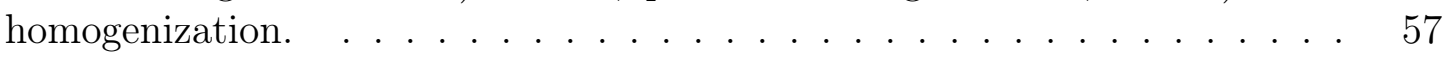

5.12 The DSC heat flux plotted with respect to temperature, during the heating \begin{tabular}{|l}
\hline and cooling stages, for the air cooled de-gas cylinder in both the as-cast and \\
\hline \hline homogenized state. . . . . . . . . . . . . . . . . . . . 58
\end{tabular}

5.13 The evolution of average electrical conductivity of AZ80 samples measured in \%IACS (percentage of international annealed copper standard), during homogenization treatment. . . . . . . . . . . . . . 59 
5.14 A typical measured compressive stress curve showing the calculated rate of work hardening. The sample in this example was a de-gas LCR wedge cast sample, compressed at $300^{\circ} \mathrm{C}$ and a strain rate of $1 \mathrm{~s}^{-1}$. . . . . . . . . . 60

5.15 Effect of deformation temperature on the compressive strength of de-gas LCR wedge cast AZ80 at a strain rate of $0.1 \mathrm{~s}^{-1} . \ldots \ldots . . \ldots 61$

5.16 Effect of strain rate on the compressive strength of de-gas LCR wedge cast

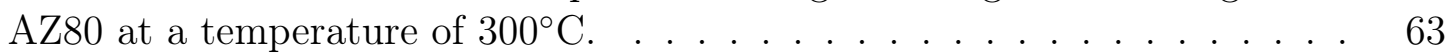

5.17 Optical microstructure of cylinder cast samples deformed at a temperature of $300^{\circ} \mathrm{C}$ at $500 \mathrm{x}$ magnification: a) 0.15 strain $0.01 \mathrm{~s}^{-1}$ strain rate, b) 0.4 strain $0.01 \mathrm{~s}^{-1}$ strain rate, c) 1.0 strain $0.01 \mathrm{~s}^{-1}$ strain rate, d) 0.15 strain $0.1 \mathrm{~s}^{-1}$ strain rate, e) 0.4 strain $0.1 \mathrm{~s}^{-1}$, and f) 1.0 strain $0.1 \mathrm{~s}^{-1}$. . . . . . . 64

5.18 Effect of strain on the percentage of area of DRX grains for strain rates of $0.1 \mathrm{~s}^{-1}$ and $0.01 \mathrm{~s}^{-1}$, at a deformation temperature of $300^{\circ} \mathrm{C} . \quad \ldots . . . .65$

5.19 Measured compressive stress-strain curves for as-cast LCR and HCR wedge cast samples, tested at $300^{\circ} \mathrm{C}$ and a strain rate of $1 / \mathrm{s} . \quad \ldots . . . . .666$

5.20 The compressive stress-strain curves of wedge cast samples comparing degas material to as-cast material, for a) HCR and b) LCR, at a strain rate of $1 \mathrm{~s}^{-1}$ and a temperature of $300^{\circ} \mathrm{C} . \quad \ldots \ldots \ldots$. . . . . . . . . 67

5.21 Measurements of (a) the peak stress and (b) the steady-state stress, for LCR and HCR castings of both as-cast and de-gas wedge cast samples. The error

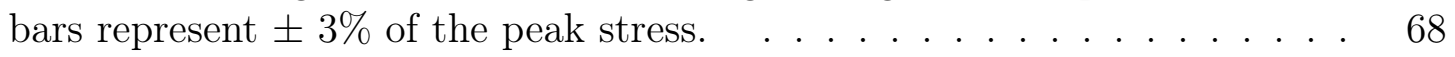

5.22 The natural logarithm of the calculated $\mathrm{Z}$ parameter plotted against the natural logarithm of the a) maximum true stress, and b) true stress at a strain of 0.7 , comparing results from the HCR and LCR wedge casting with values in literature. Data extrapolated from $[49,76]$. . . . . . . . . . . . . 70

5.23 Examples of a de-gas AZ80 HCR sample which did not experience surface cracking (left), and a de-gas AZ80 LCR sample which did show surface cracking (right), after compression at $300^{\circ} \mathrm{C}$ and a strain rate of $1 \mathrm{~s}^{-1}$ to a strain of 1.0. . . . . . . . . . . . . . . . . 71

5.24 True stress-true strain curves for as-cast and cast-homogenized air cooled cylinders, compressed at $300^{\circ} \mathrm{C}$ and a strain rate of $0.1 \mathrm{~s}^{-1}$. $\ldots . . . . .73$

5.25 The compressive true stress-true strain curves for as-cast and homogenized LCR and HCR material: a) $300^{\circ} \mathrm{C}$ and $1 \mathrm{~s}^{-1}$, b) $300^{\circ} \mathrm{C}$ and $0.1 \mathrm{~s}^{-1}$, and c) $300^{\circ} \mathrm{C}$ and $0.01 \mathrm{~s}^{-1} . \ldots \ldots \ldots \ldots 74$ 
5.26 The natural logarithm of the calculated $\mathrm{Z}$ parameter plotted against the natural logarithm of the a) maximum true stress, and b) true stress at a strain of 0.7 , for cast and homogenized LCR and HCR wedge cast material. 75

5.27 Optical microstructures of a) LCR as-cast wedge cast AZ80, and b) air cooled cylinder cast AZ80. $\ldots \ldots \ldots \ldots \ldots$. . . . . . . . . . . 75

5.28 Compressive true stress-true strain curves for the as-cast and homogenized samples of the LCR wedge and air cooled cylinder castings, deformed at a

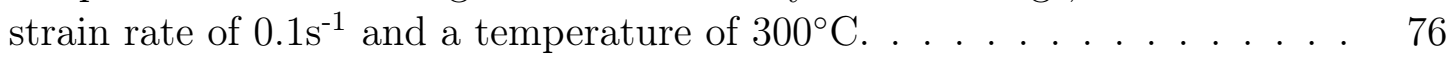

5.29 Compressive true stress-true strain curves for the as-cast and homogenized cylinder cast samples, compressed at a temperature of $300^{\circ} \mathrm{C}$ and a strain rate of $0.01 \mathrm{~s}^{-1}$. The strain at which each image is taken is shown by vertical dashed lines on the plot. . . . . . . . . . . . . 78

5.30 Optical microstructure of the cast deformed samples from the cylinder casting: a) 0.15 strain 100x magnification, b) 0.4 strain 100x magnification, c) 1.0 strain 100x magnification, d) 0.15 strain 500x magnification, e) 0.4 strain

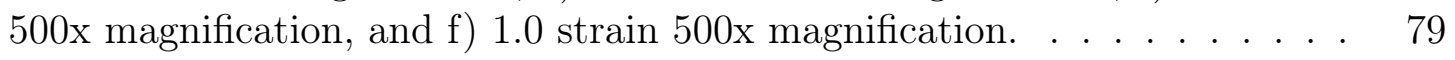

5.31 Optical microstructure of the homogenized deformed samples from the cylinder casting: a) 0.15 strain 100x magnification, b) 0.4 strain 100x magnification, c) 1.0 strain 100x magnification, d) 0.15 strain 500x magnification, e)

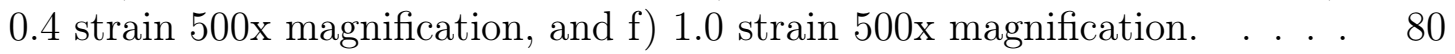

5.32 The percentage of area of DRX grains for cast and homogenized cylinder samples, at a deformation temperature of $300^{\circ} \mathrm{C}$ and a strain rate of $0.01 \mathrm{~s}^{-1}$. 81

5.33 The evolution of porosity volume estimated by measured 2D pore area with increasing strain, for both the cast and homogenized LCR cylinder samples, at strain rates of $0.01 \mathrm{~s}^{-1}$ and $0.1 \mathrm{~s}^{-1}$. . . . . . . . . . . . . . . . 82

A.1 Detailed images of the wedge casting mould, showing water cooling lines, thermocouples inside the mould, and the cast wedges. . . . . . . . . . . . . 97

A.2 Detailed images of the cylinder casting mould, showing water cooling lines, detailed mould geometry and approximate size, and the casting. Images courtesy of Peter Newcombe at CANMETMaterials. . . . . . . . . . . . . . 98

B.1 Compressive true stress-true strain curves for the as-cast material. . . . . . 99

B.2 Compressive true stress-true strain curves for the de-gas material. . . . . . 100 
B.3 Compressive true stress-true strain curves for the cast and homogenized cylinder material . . . . . . . . . . . . . . . . . . . . . . . 101

C.1 An example of the lines drawn on the sample images for grain size measurement. The sample is an as-cast LCR sample, at 50x magnification. . . . . . 102

C.2 An example of an image with a high amount of DRX grains, and how they appear after selection using ImageJ. . . . . . . . . . . . . . . . . . 103 


\section{List of Tables}

4.1 Composition of the as-received material, compared to the target range for the AZ80 alloy. . . . . . . . . . . . . . . . . . . . . . . 28

5.1 A summary of the qualitative surface crack evaluation, for as-cast and degas wedge cast material, of HCR and LCR conditions, for each temperature and strain rate tested. . . . . . . . . . . . . . . . . . 72

5.2 A summary of the qualitative surface crack evaluation, for de-gas and homogenized material, of HCR and LCR conditions, for each temperature and strain rate tested. . . . . . . . . . . . . . . . . . 77

C.1 The line length and grain boundary intercepts recorded, and calculated grain size, for the as-cast LCR wedge casting. . . . . . . . . . . . . . . . . . . . . 103 


\section{Introduction}

\section{$1.1 \quad$ Background}

In recent years, climate change, because of global human activity, has been highlighted as one of the most important concerns towards the quality of life for future generations. Acknowledgement of this, has brought about increased awareness of our carbon footprint and how making sustainable choices in our everyday lives can reduce the impact we make on the environment, setting the course towards a cleaner, healthier planet. One area that has been repeatedly called upon for change, is in the improvement of the fuel efficiency of automobiles. To address this, regulators have designed aggressive fuel economy targets for automakers such as the projected Corporate Average Fuel Economy (CAFE) requirement of a fleet average fuel economy of up to $49.7 \mathrm{MPG}(4.7 \mathrm{l} / 100 \mathrm{~km})$ by the year 2025 [1. While many improvements have been made in areas surrounding powertrain efficiency and aerodynamics, the inherent limitations of the internal combustion engine have driven automakers to develop alternate means of improving fuel efficiency. An effective solution can be found by reducing the gross vehicle mass, as every $10 \%$ reduction in mass can improve the vehicles efficiency by up to $7 \%$ [2]. To accomplish this, the use of greater amounts of lightweight materials is required in automobiles.

Among the advanced structural materials being developed for vehicle light weighting are metal foams, fiber reinforced composite materials, advanced high strength steels, and magnesium alloys [3]. Magnesium alloys are emerging as a popular contender, as magnesium is the least dense commercially available structural metal, with a density of only $1.74 \mathrm{~g} / \mathrm{cm}^{3}$, enabling between $22 \%$ and $70 \%$ reduction in weight over similar components made from aluminum and steel [4. It is well understood that the benefit of magnesium alloys is their excellent mechanical properties specific to their weight, promising comparable performance to other alloys in addition to a reduction of weight. These mechanical properties are further improved when alloying elements such as aluminum are used [3, 5]. Figure 1.1 shows a comparison of specific strength and stiffness between magnesium and more traditionally used aluminum and iron, illustrating that higher strength and comparable stiffness can be achieved alongside a reduction in weight when using magnesium.

Further, magnesium-aluminum alloys (AZ series alloys) exhibit good fluidity in the liquid state [4] and moderate contraction during solidification [6], giving them good castability. For this reason, the cast AZ alloys have been subject to much study over the past decade, particularly in the automotive sector. While the high specific strength of magnesium al- 


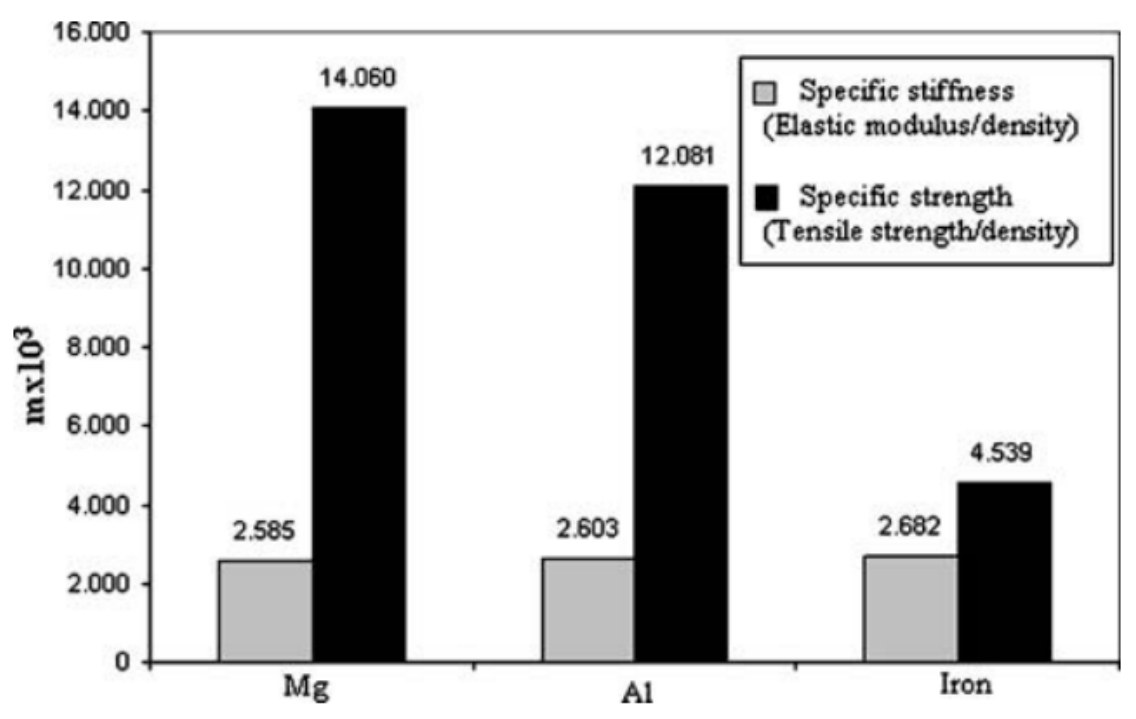

Figure 1.1: Specific strength and specific stiffness of Magnesium, Aluminum, and Iron. (Reproduced with permission from Springer Nature) [4]

loys shows potential in structural applications, much of the current use has been limited to non-load bearing components, such as instrument panel structures, seat frames, and pedal assemblies [3]. These components are primarily made from castings as the knowledge of wrought forming of magnesium alloys is limited. Cast magnesium alloys exhibit poor ductility and fatigue properties compared to their forged counterparts [7], and thus magnesium use in automotive applications is currently limited [3]. It is important to note that automotive components belonging to the body, chassis, and suspension are typically produced by sheet metal forming and forging, and it is uncommon to use casting to produce these structural components.

The focus of this work is on the AZ80 alloy, an AZ alloy containing approximately $8 \%$ aluminum by weight. Since AZ80 was developed specifically for forging applications, there is much promise of increased structural applications with a further understanding of its physical metallurgy [8]. With these advancements, there is promise that alloys such as AZ80 can be used to reduce the environmental impact of our transportation vehicles by improving their efficiency through a reduction of vehicle mass. 


\section{$1.2 \quad$ Research Objectives}

The research presented in this thesis is part of the Natural Sciences and Engineering Research Council of Canada's Strategic Partnership Grant (NSERC SPG). The industry partners and contributing organizations for this project consist of; the University of Waterloo, Multimatic Technical Centre, and CanmetMATERIALS. The SPG project aims to further extend the knowledge surrounding the forging of structural magnesium alloy components, particularly the automotive control arm for a Ford Fusion car that was explored in the earlier NSERC Automotive Partnership Canada (APC) grant. This project will focus on a hybrid manufacturing process which amalgamates knowledge of casting and forging processes through development of a process-structure-property relationship to cast a pre-form structure which will have optimal properties upon subsequent forging. Development of this manufacturing process requires several tasks; characterization of as-cast microstructure and mechanical properties, development of the relationship between cast and forged properties, optimization of cast pre-form geometry through an advanced neural network, and finally characterization of forged microstructure and mechanical properties. Based on the findings of the APC project, the magnesium alloy AZ80 was chosen due to its superior forgeability and its commercial availability.

The work in this thesis aims to study the hot deformation behaviour of the AZ80 alloy, by relating the as-cast microstructure to the compressive flow stress and microstructure evolution during hot deformation. The flow stress will be measured during uniaxial compression under various temperatures and strain rates. Differing initial microstructures are produced in the castings by different cooling rates during solidification, using a different casting process, and applying a homogenization heat treatment. At the project level, the observed and measured impacts of the starting microstructure will help to develop the relationship between cast structure and forged mechanical properties, and will be a valuable input toward the development of an optimal pre-form geometry for the forged control arm.

\subsection{Thesis overview}

The remainder of this thesis will be comprised of 5 sections as follows.

Chapter 2 reviews relevant literature related to casting of magnesium alloys, and the microstructure and mechanical properties that are attainable through both casting and forging processes. Since the AZ80 alloy is the focus of this research, literature surrounding 
magnesium-aluminum alloys and the effect of aluminum content in cast magnesium alloys is also explored. Available literature regarding the forging and deformation of $\mathrm{AZ}$ series alloys is summarized, focusing on the alloys in their as-cast state and any influence the initial microstructure may have on subsequent wrought forming.

Chapter 3 outlines the scope of this research.

Chapter 4 details the methodology used in experiments that fulfil the objectives described in Chapter 3. The casting process for producing compression testing samples is detailed, including validation through use of a commercial simulation software, followed by the process for the compression testing itself. Applicable microstructure examination and quantification techniques are disclosed. Finally, common practices for design of casting moulds relevant to this project are included.

Chapter 5 illustrates the correlations that can be found between the casting process and thermal history on its resulting microstructure. The effect that these differing casting processes and thermal processing histories have on the deformation behaviour, flow stress, and microstructure development during deformation is also shown. In addition to the effect of starting material, the effect of deformation parameters is also presented.

Chapter 6 presents the conclusions that can be drawn from the current research, and potential areas for further study. 


\section{Literature Review}

The following section is a review of previous research relevant to the casting and forging of structural magnesium alloys, with a focus on the magnesium alloy AZ80. Casting processes and the typical microstructures and defects that can form are discussed, including a more detailed summary of the microstructure and properties inherent to AZ alloys in their ascast state. Relevant works on forging of magnesium alloys and the influence of their initial state are explored, with a focus on the effect of the cast microstructure of AZ alloys on the compressive stress during forging. Finally, relevant permanent mould casting design principles for magnesium alloys will be reviewed.

\subsection{Casting of AZ alloys}

As is the case with most metals, there are many ways to produce AZ alloys by casting. The method most commonly used to produce complex cast magnesium components for the automotive industry is high pressure die casting (HPDC), which boasts very high cooling rates and a high amount of undercooling, enabling a very fine-grained cast structure which is great for mechanical properties. Casting methods such as sand casting or permanent mould casting often have much lower cooling rates, and so the grain size is comparatively larger. In this case, alternative means of grain refinement are required to obtain acceptable mechanical properties. The morphology of the eutectic phase of these alloys, affected by the cooling rate during solidification, is therefore also influenced by the casting process [9]. In addition to cooling rate, the chemical composition of the alloy can significantly alter the microstructure and subsequent mechanical properties of these alloys, both by changing the eutectic morphology [9] and the grain size [10].

\subsubsection{Microstructure and mechanical properties of cast AZ alloys}

Like other AZ series alloys, the microstructure of AZ80 consists mostly of a primary $\alpha-\mathrm{Mg}$ phase with a hexagon close packed crystal lattice structure, and a eutectic phase consisting of secondary $\mathrm{Mg}$, and intermetallic $\gamma-\mathrm{Mg}_{17} \mathrm{Al}_{12}$ phase with a cubic crystal lattice structure 8]. This second phase accounts for approximately $11-12 \%$ of the volume in AZ80 [11]. Diffusion of the aluminum during non-equilibrium solidification causes the eutectic to form as a two-phase $\gamma-\mathrm{Mg}_{17} \mathrm{Al}_{12}+\alpha$-Mg [8]. Upon solidification, AZ80 becomes a fully dendritic $\alpha-\mathrm{Mg}$ structure, with the eutectic $\gamma-\mathrm{Mg}_{17} \mathrm{Al}_{12}$ forming between the dendrite arms [8], shown in Figure 2.1 by both optical and scanning electron microscopy. The eutectic 

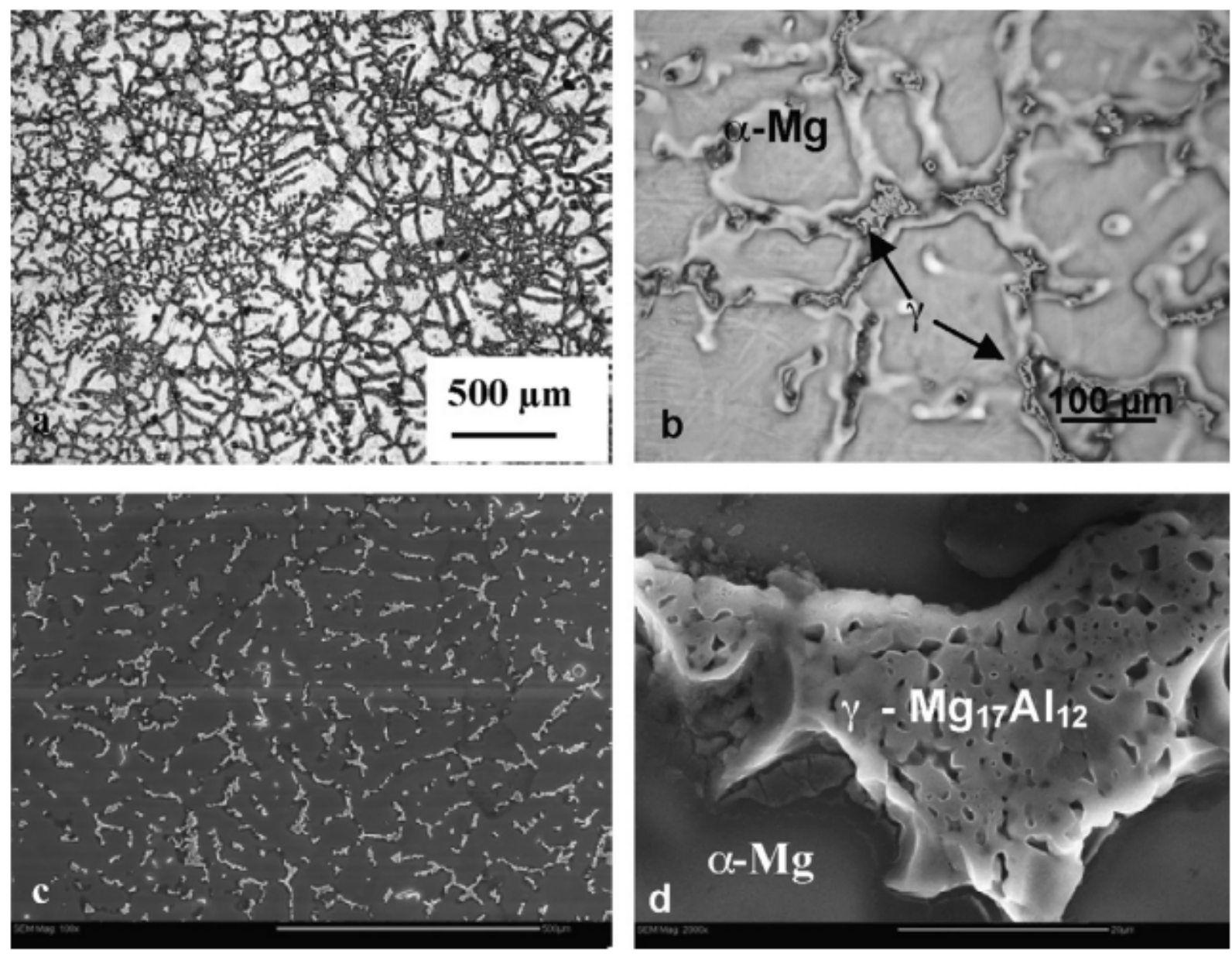

Figure 2.1: Microstructure of as-cast AZ80: (a, b) Optical Microscopy and (c, d) SEM. (Reproduced with permission from Elsevier) [11]

of these alloys in their cast form is typically characterized by either a partially or fully divorced morphology. Commercially produced cast AZ alloys (normally below 10\% Al by weight) typically have a divorced morphology, where the eutectic $\mathrm{Mg}$ and $\gamma-\mathrm{Mg}_{17} \mathrm{Al}_{12}$ are separate. The eutectic Mg surrounds the primary $\alpha$-Mg dendrites, and the intermetallic is present in large inter-dendritic regions (fully divorced), or is present in large inter-dendritic particles with some eutectic Mg solidified inside (partially divorced). For the AZ80 alloy shown in Figure 2.1, though mostly surrounded by the secondary Mg phase, the eutectic is not fully divorced as there are areas within some $\gamma-\mathrm{Mg}_{17} \mathrm{Al}_{12}$ particles which contain islands of secondary $\mathrm{Mg}$. This is especially clear in the optical microscope image in Figure 2.1b, 
where the $\gamma-\mathrm{Mg}_{17} \mathrm{Al}_{12}$ phase (shown by darker areas on the image) contains some lighter areas within, indicating a partially divorced morphology. The morphology of this second phase is influenced by the rate of solidification and the aluminum content, and has a strong effect on the mechanical properties [10]. Divorced morphologies are favored by lower alloy content ( $3 \% \mathrm{Al}$ by weight), and higher cooling rate processes such as HPDC. Regardless of the eutectic morphology, the ductility of alloys with inter-dendritic intermetallic phases is often poor, especially when the phase is partially continuous as in AZ80. Precipitation of the $\gamma-\mathrm{Mg}_{17} \mathrm{Al}_{12}$ phase as more finely dispersed and discontinuous precipitates can improve both the strength and ductility of the alloy $[12$. The ductility is also proportional to the volume fraction of the $\gamma-\mathrm{Mg}_{17} \mathrm{Al}_{12}$ phase; increasing as more eutectic is dissolved into the matrix [3, 11].

In addition to their structure, the mechanical properties of cast AZ-alloys are also limited by the defects which can result from the casting process, which often justifies further thermomechanical processing. Mackie et al. [13] studied the defect formation in DC cast AZ80, and found that the defects typically include entrained oxides and clusters of $\mathrm{Al}_{8} \mathrm{Mn}_{5}$ intermetallic particles, images of which are shown in Figure 2.2. Samples that included
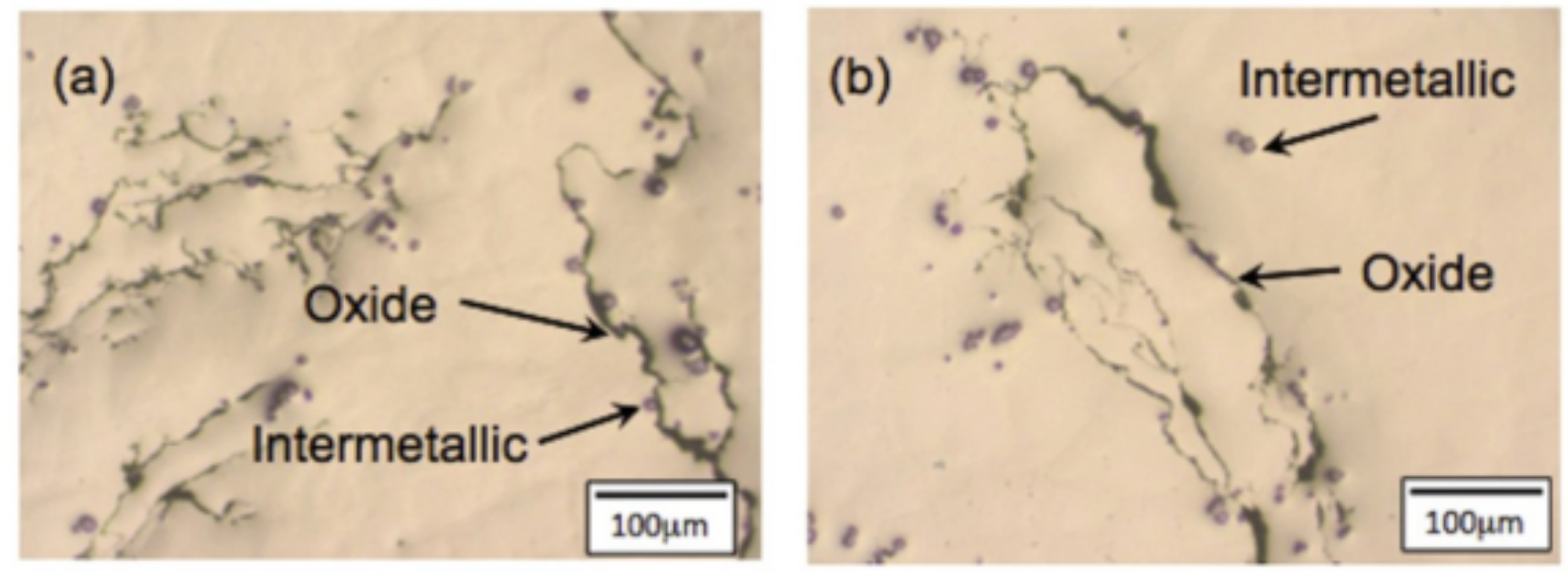

Figure 2.2: Optical microscopy images of entrained oxide film and intermetallic cluster defects. (Reproduced with permission from Elsevier) [13]

these defects saw a significant reduction in the ultimate tensile strength and elongation to failure in tension, compared to defect-free samples. Manganese is often added to AZ alloys to passivate any iron that may be present in the melt [14], however the presence of manganese in excess of its solubility limit (0.122 wt\% for AZ91) is what may lead to 
the formation of $\mathrm{Al}_{8} \mathrm{Mn}_{5}$ particles. Presence of these particles near the casting surface can also be detrimental to corrosion performance [15]. These $\mathrm{Al}_{8} \mathrm{Mn}_{5}$ particles are found to be larger in size at lower cooling rates, though in cases where the cooling rate is high as in permanent mold casting it is suggested that nucleation of $\alpha$-Mg grains prevails, preventing nucleation of these particles [15]. The effect of defects in cast magnesium alloys extends to the fatigue properties as well. Initiation of fatigue cracks would ideally form from slip bands during plastic deformation, however in the presence of casting defects such as porosity, micro-shrinkage within the dendritic structure, and oxide formation, the crack is more likely to initiate from these defects [16]. While the initiation stage of fatigue life is greatly reduced in the presence of these defects, the same effect is not seen with particle inclusions [16]. Fatigue properties have been studied for extruded and forged AZ80 alloys, where the fatigue response could be predicted using available fatigue life models, therefore suggesting little influence from initial casting defects once the alloy is in a wrought form [17, 18, 19].

\subsubsection{Effect of aluminum content on AZ alloy microstructure and properties}

The effect of microstructure on mechanical properties for AZ alloys was studied by Cao and Wessén, who found that the maximum ultimate tensile strength was achieved at 8 percent aluminum by weight, corresponding to the AZ80 alloy [10]. At this composition, the $\gamma$ $\mathrm{Mg}_{17} \mathrm{Al}_{12}$ phase provides ample strengthening, while the surrounding ductile $\alpha$-Mg phase resists any brittle fracture due to crack propagation through the $\gamma-\mathrm{Mg}_{17} \mathrm{Al}_{12}$ phase. This ductile matrix helps provide good forgeability, while maintaining a high strength through the presence of the intermetallic phase. While AZ80 does provide a good combination of strength and forgeability, efforts by Fujita et al. to develop a more forgeable magnesium alloy showed that the elongation of AZ80 is poor at high strain rates [20]. This led to a study on the effect of aluminum content on toughness, measured by impact testing, where the toughness of the alloys showed a decrease with increasing aluminum content. They proposed that a magnesium alloy with 7 percent aluminum by weight would be optimal for forgeability and post-forged properties. For AZ alloys with lower aluminum contents (3, 4, and 6 percent by weight) Cao and Wessén saw a higher elongation to failure than with AZ80, however a significantly lower ultimate strength, owing to the dispersed eutectic morphology and its lower volume fraction [10]. Microstructures of die cast AZ alloys with aluminum contents of 3, 6, 10, and 15 percent by weight are shown in Figure 2.3. This shows that AZ alloys with aluminum contents below 10 percent by weight have a more evenly dispersed eutectic throughout the $\alpha-\mathrm{Mg}$ phase, and in the $\mathrm{Mg}-3 \mathrm{Al}$ sample, the eutectic appears to be fully divorced. 

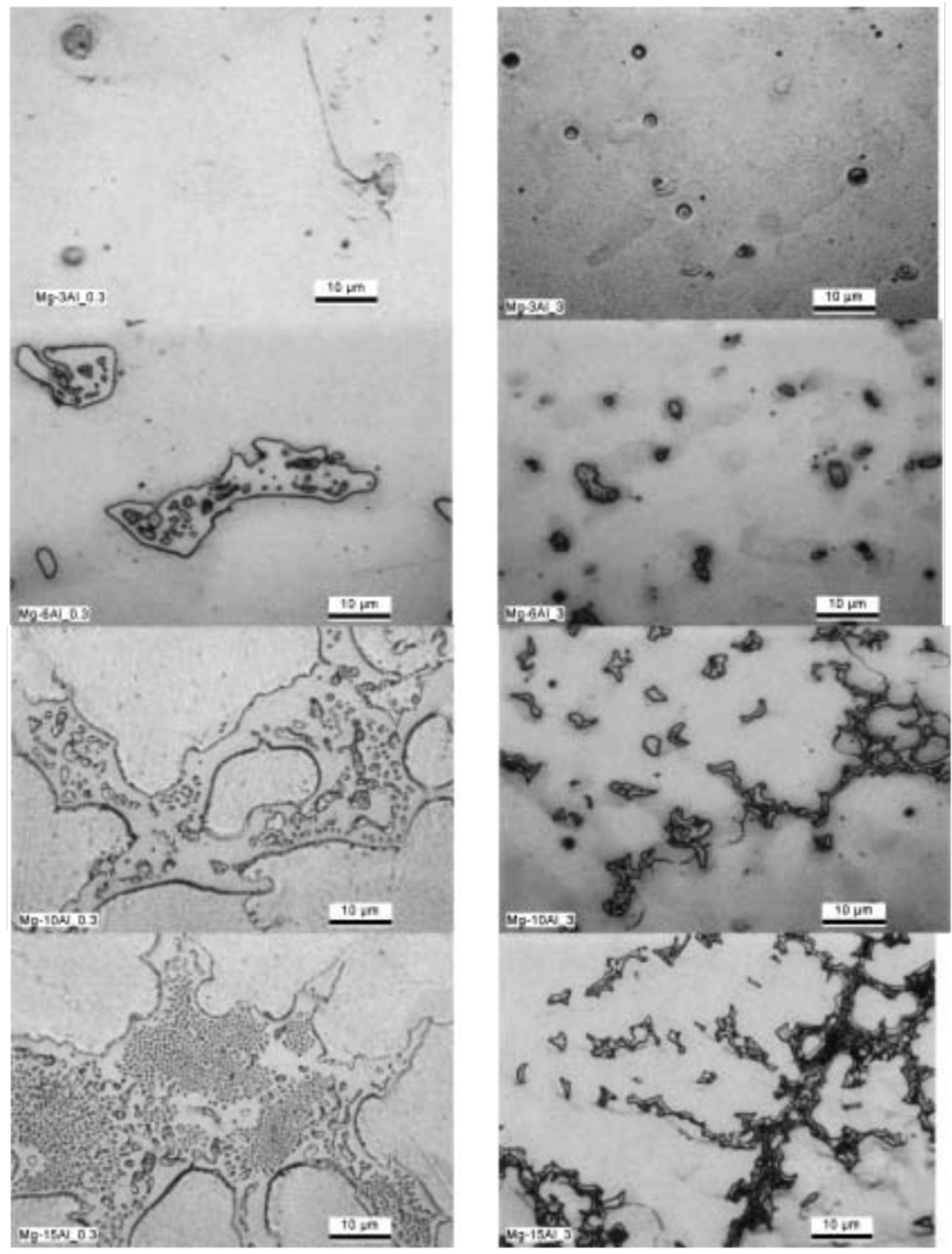

Figure 2.3: The influence of $\mathrm{Al}$ content and drawing rate (cooling rate) on the eutectic morphology. The left column shows $\mathrm{Mg}-\mathrm{Al}$ alloys at compositions of 3, 6, 10, and 15 weight percent $\mathrm{Al}$, drawn at $0.3 \mathrm{~mm} / \mathrm{s}$, and the right column shows $\mathrm{Mg}-\mathrm{Al}$ alloys with the same composition drawn at $3 \mathrm{~mm} / \mathrm{s}$. (Reproduced with permission from Springer Nature) [10] 
In $\mathrm{AZ}$ alloys with higher concentrations of aluminum, the $\gamma-\mathrm{Mg}_{17} \mathrm{Al}_{12}$ phase is only partially divorced, and becomes less divorced as the concentration of aluminum is increased. Once the aluminum content surpasses 10 percent by weight, the intermetallic phase also becomes more continuous and less evenly dispersed, forming an inter-dendritic network surrounding the $\alpha-\mathrm{Mg}$ phase [10]. Due to the brittle nature of this eutectic phase these alloys cannot withstand much plastic strain, therefore limiting their ultimate strength and ductility due to brittle fracture [10, 21]. The yield strength of AZ alloys has been shown to increase with both a refinement of the grain structure, and an increased volume fraction of the $\gamma-\mathrm{Mg}_{17} \mathrm{Al}_{12}$ phase [10, 21, 22]. These effects are shown in Figure 2.4 by Cao and Wessén, where the higher drawing rate (during direct-chill casting) corresponds to a more refined grain size. The aluminum content has an indirect effect on the strength of the alloy as well, as it has also been found that alloys with a higher aluminum content result in a finer SDAS or grain size [10, 23]. It is clear that increasing the aluminum content has a direct

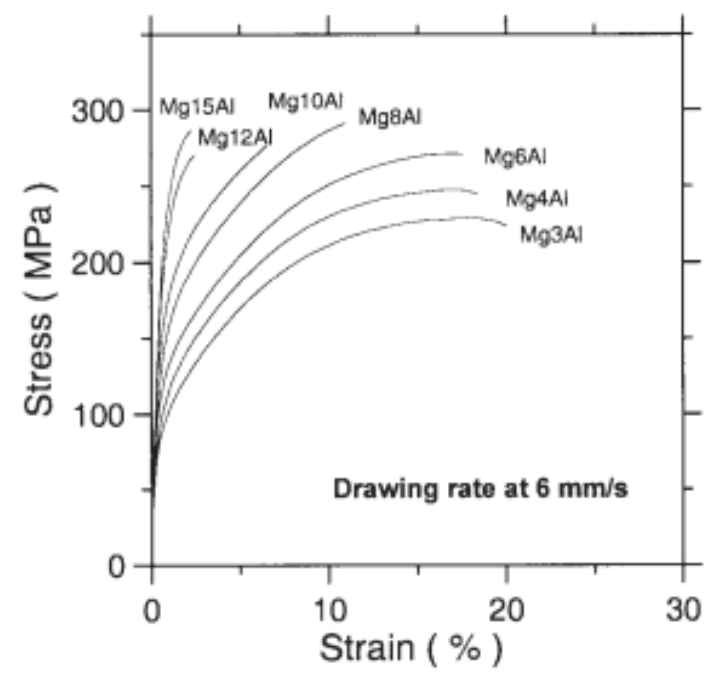

(a)

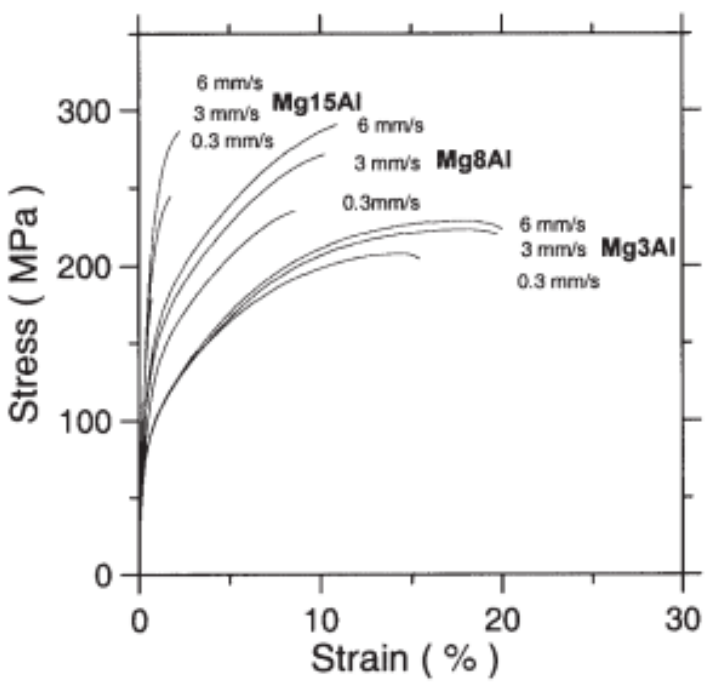

(b)

Figure 2.4: (a) and (b) Typical tensile stress-strain flow curves of $\mathrm{Mg}$ - $\mathrm{Al}$ alloys showing effects of alloy content and drawing rate. (Reproduced with permission from Springer Nature) [10]

correlation with the alloy strength, however at a certain point (past approximately $8 \%$ by weight), the alloy becomes too brittle, and the poor ductility causes a decrease in strength [10]. These findings are corroborated by the work of Dargusch et al. [24], who also saw a decrease in ductility with increasing aluminum content. They also saw an increase in yield 
and ultimate strength, however the ultimate strength was shown to peak at 14 percent aluminum by weight. This result might be explained by grain size effects, resulting from the difference in casting processes used in the studies.

\subsubsection{Effect of solidification rate on AZ alloy microstructure and properties}

Although the aluminum content can influence the grain size and SDAS as shown in section 2.1.2 the grain size and SDAS is much more significantly influenced by cooling rate [10], particularly for alloys in excess of $8 \%$ aluminum by weight, whereby a further increase in aluminum content does not contribute significantly to more refinement. The eutectic phase is also affected not only by aluminum content, but also by the cooling rate during solidification. The morphology of the eutectic phase was observed to be more divorced when solidified by higher cooling rates in the study by Cao and Wessén [10. This is shown in Figure 2.3, where the samples drawn at a higher drawing rate (and therefore a higher cooling rate) had a more divorced eutectic $\mathrm{Mg}_{17} \mathrm{Al}_{12}$, without any islands of $\alpha-\mathrm{Mg}$ within. However, the amount of aluminum in solid solution of primary or eutectic $\alpha-\mathrm{Mg}$ was not influenced by cooling rate. Increasing the cooling rate showed no effect on the morphology of the eutectic in a study by Yavari and Shabestari [23], forming a partially divorced structure in all cases, though this study did not quantify the degree to which the eutectic was divorced, as in the aforementioned study. In this work however, the amount of eutectic phase present in the microstructure was increased with an increase in cooling rate [23]. This is explained by an enrichment of the aluminum within the liquid ahead of the solid-liquid interface during higher cooling rates, causing this material to reach the eutectic composition. This work also studied the effect of cooling rate on the solidification characteristics of three $\mathrm{Mg}-\mathrm{Al}$ alloys, with varying aluminum contents of 3,6 , and 9 percent by weight. They proposed that the SDAS will decrease exponentially with an increase in cooling rate for all three alloys. Further, this decrease in grain size and SDAS results in an increase in yield strength, ultimate strength, and elongation to failure [10, 21, 23, 25]. Sharifi [25] showed that the hardness of AZ91 was found to decrease with an increase in average grain size, which is consistent in the work by Cao and Wessén [10]. Some studies have shown good correlation in accordance to the Hall-Petch relationship between SDAS and yield strength for AZ91 [26, 25], and AM60 and AE44 [25], which are also magnesiumaluminum alloys with approximately 6 and 4 percent aluminum by weight, respectively. 


\subsection{Deformation and forging of AZ alloys}

While die casting is commonly used for production of some structural magnesium parts, wrought forms of these same alloys can generally achieve much higher strength and ductility [27]. The increase in ductility is attributed to the reduction of internal casting defects, such as shrinkage pores and oxides, by means of plastic deformation during the wrought forming process. By imposing significant plastic deformation on the as cast structure, the alloy's grain structure is refined, resulting in higher strength. Moreover, it has been found that fatigue properties can also be greatly improved through forging. Gryguc et al. 77 have studied the fatigue properties of direct-chill cast AZ80 compared to forged AZ80 and found an increase in fatigue life by up to 5 times in the high-cycle region over that of the cast alloy in strain-controlled fatigue testing. Monotonic testing showed an increase of $33 \%$ in tensile ultimate stress, and an increase of $17 \%$ in compressive ultimate strength. A marked improvement in tensile ductility was also seen by an increase in fracture strain.

\subsubsection{Deformation modes}

The major limitation of using magnesium alloys for forging is their inherent poor formability. Due to their hexagonal close packed (HCP) crystalline structure, there are not enough available slip planes at room temperature to enable homogeneous deformation. It is known that for homogeneous deformation to occur, 5 independent slip systems must be active. The major slip systems in the HCP crystal of magnesium alloys are shown in Figure 2.5.
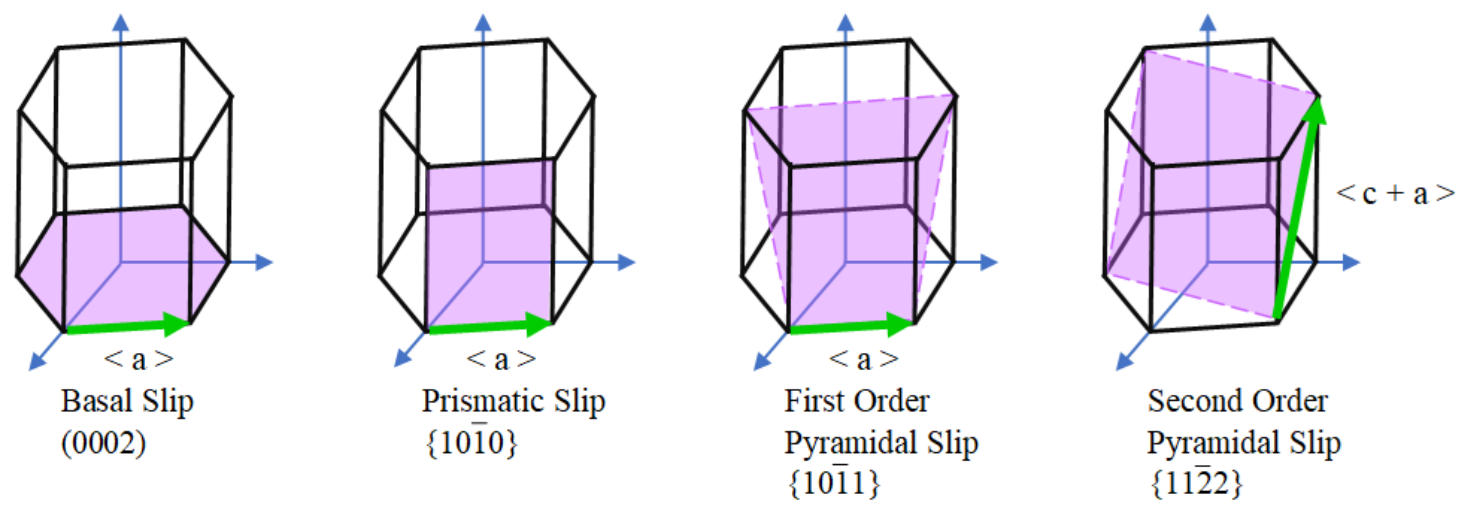

Figure 2.5: Major slip systems in magnesium alloys. 
For basal, prismatic, and first order pyramidal slip, the slip direction is along the $<11 \overline{2} 0>$ direction, noted as $\langle\mathrm{a}\rangle$ in Figure 2.5, however none of these slip systems permit any deformation in the $\langle\mathrm{c}>$ direction. Only the second order pyramidal system can accommodate deformation in the $\langle\mathrm{c}+\mathrm{a}\rangle$ direction. Deformation is not limited to conventional slip systems however, as these alloys are prone to activation of twinning in order to meet the required 5 slip systems to permit homogeneous deformation. In magnesium alloys, the twinning systems of $\{10 \overline{1} 2\},\{10 \overline{1} 1\}$, and $\{10 \overline{1} 3\}$ are common [28]. Each slip system has what is called a critical resolved shear stress (CRSS), which is the required shear stress along the slip direction during deformation to activate slip within that system. As shown in Figure 2.6, the CRSS required for deformation is decreased with increasing temperature in each of the $\{10 \overline{1} 3\}$ and $\{10 \overline{1} 1\}$ twinning systems, the prismatic slip system, and second order pyramidal slip system. Additionally, new stress-free grains can form via dynamic

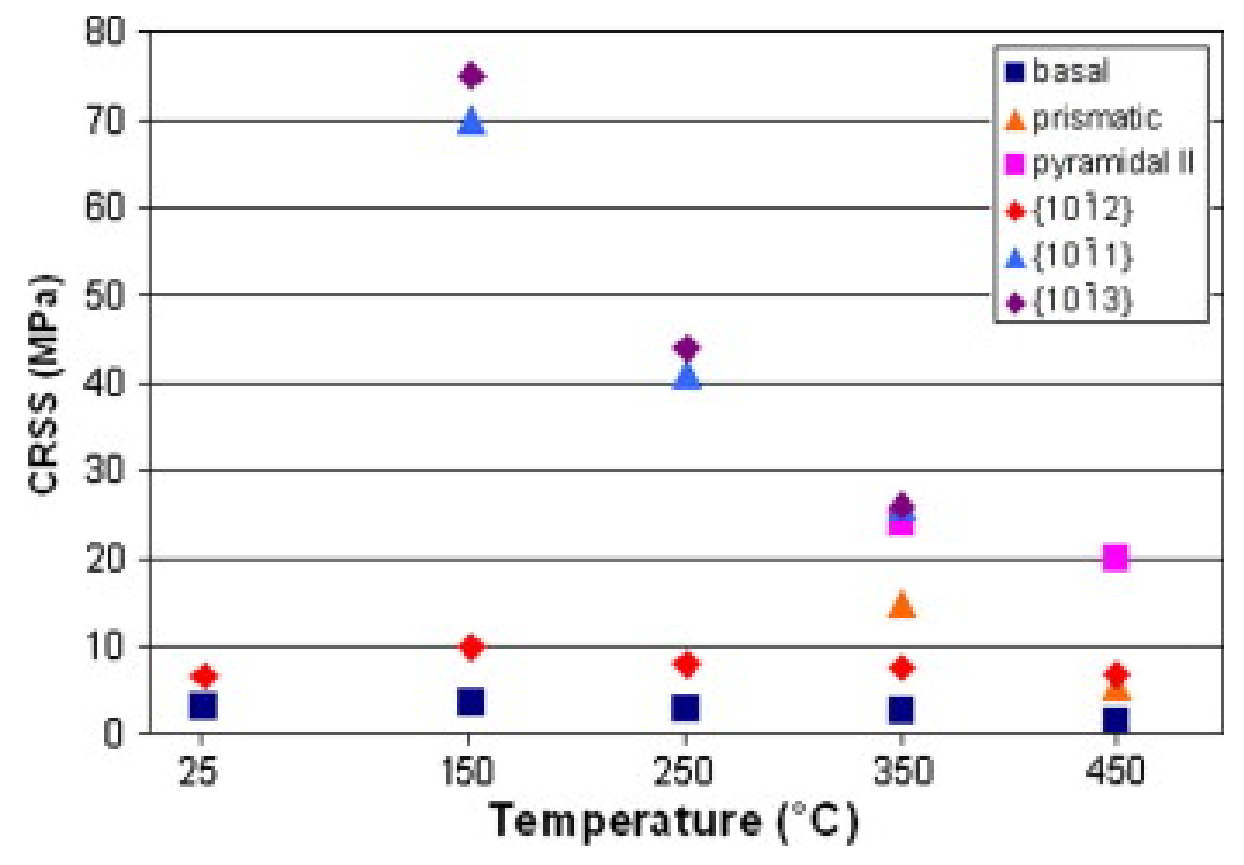

Figure 2.6: Estimated CRSS of slip and twinning systems in Mg at 1\% strain. (Reproduced with permission from Elsevier) [28]

recrystallization (DRX), which is a recrystallization mechanism that occurs during deformation. When compared to other AZ series alloys, AZ80 has exhibited excellent forgeability due to its ability to withstand cracking at high ram speeds and low temperatures [29]. This is thought to occur because of the reduction in activation energy required to initiate DRX as the aluminum content increases [30]. Additionally, the starting microstructure can influ- 
ence the morphology of the DRX grains. In a comparison of the compressive deformation of extruded and cast AZ80 at elevated temperatures, Prakash et al found that significant DRX occurred in both material states, however only the cast material showed occurrence of twinning [31. Further, the cast material saw DRX along deformation twins and grain boundaries, while the extruded material saw DRX grains only along the grain boundaries. Despite the differences between these two starting materials, it was found that the initial grain size of the starting microstructure has no effect on the DRX grain size after deformation. Upon significant deformation, both materials developed a basal texture, however this occurred much sooner in the cast material, which began with a random texture.

\subsubsection{Effect of initial state on deformation behaviour}

Research has shown that AZ80 castings with a finer grain size and a lower volume fraction of the $\gamma-\mathrm{Mg}_{17} \mathrm{Al}_{12}$ phase exhibit greater forgeability, shown by a decrease in the crack susceptibility during forging [8]. AZ80 forging stock was first produced by DC casting, however to improve the forgeability through a reduction in grain size, the castings were subject to a homogenization treatment followed by extrusion. Before forging, the extrusions were then heat treated again to reduce the volume fraction of the eutectic phase [8]. A study by Wang et al. [32] used a similar method to produce fatigue sensitive structural components from AZ80. Grain refinement was achieved by a pre-straining deformation process on homogenized as-cast material. Instead of extrusion however, the pre-straining was achieved by compressing to $50 \%$ strain at $300^{\circ} \mathrm{C}$. Samples with a finer initial grain size exhibited a peak flow stress approximately $20 \%$ lower than the homogenized as-cast material, across a range of strain rates and temperatures. The peak flow stress also occurred at a lower strain than in the as-cast material. These effects are seen in the true stress-true strain curves in Figure 2.7. This pre-straining and forging process was successfully extended to full scale hot forging of an AZ80 automotive wheel, where no cracks or signs of unstable deformation were seen.

In a study run by Liu et al. [33], the peak flow stress was in fact higher in extruded AZ31 when compared to the as-cast material. Among only the extruded samples, however, those formed with a higher extrusion ratio (and consequently a smaller grain size) exhibited a lower flow stress. In this study, they did not quantify the grain size of the as-cast material, and the effect of grain texture was not studied as only the extruded direction was tested. In a similar study by Beer and Barnett [34], wrought AZ31 samples with a fine grain structure saw an increase in peak flow stress over the as-cast samples at lower temperatures, however during compression at a higher temperature $\left(400^{\circ} \mathrm{C}\right)$, a reduction 

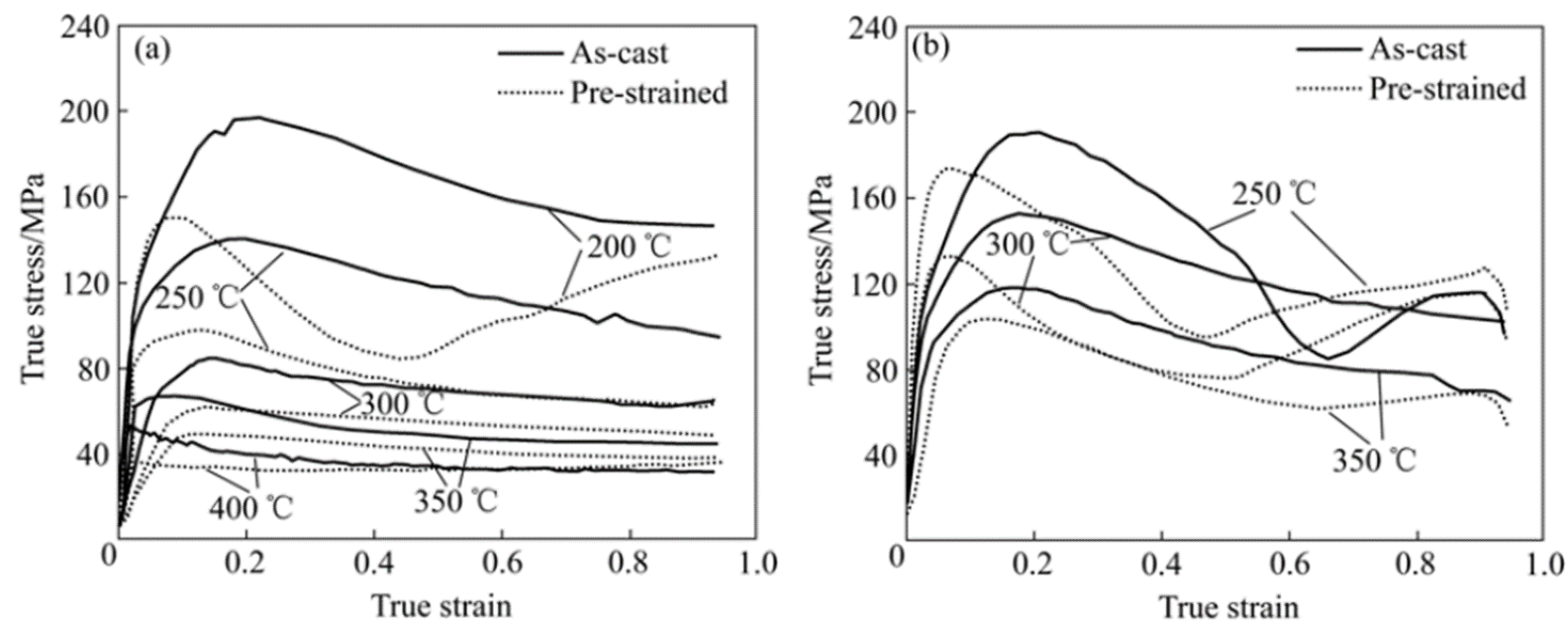

Figure 2.7: True stress-true strain curves of as-cast and pre-strained AZ80 alloy at strain rates of; (a) $0.01 / \mathrm{s}$ and (b) $0.1 / \mathrm{s}$. (Reproduced with permission from Elsevier) [32]

in the peak flow stress was seen compared to the as-cast material. The reason behind this behaviour in the wrought material is due to the enhanced activation of DRX with a refined grain size at high temperatures, and a grain boundary strengthening effect at low temperatures. Microstructures for both wrought and as-cast material, deformed to a strain of 0.2 at $350^{\circ} \mathrm{C}$ and a strain rate of $0.01 / \mathrm{s}$, are shown in Figure 2.8. The fine-grained wrought material experienced a high degree of DRX occurred along the grain boundaries, where the coarse grained cast material shows much fewer DRX grains. It is important to note that in this study while the "as-cast" material did have a much larger initial grain size, it too had experienced some amount of prior deformation, as it was taken from an extruded billet.

Prakash et al. 31] studied the microstructure and texture evolution during compression of DC-cast and extruded AZ80 (along the extruded direction), reporting similar peak flow stress values for both material conditions. Within the extruded material, the peak flow stress occurred at a lower strain than in the cast material, which indicates that DRX is initiated at a lower strain. The extruded material also showed a higher rate of work softening after the peak stress than the cast material. This was attributed to either faster DRX kinetics due to the fine-grained extruded material, or texture related effects, where the grain orientation relative to the compression direction were favorable for easy activation of other slip systems. In the cast material, DRX occurred both along the grain boundaries and within deformation twins, however the extruded material saw DRX only along the 
grain boundaries. Despite the differences in the early stages of deformation, at the final strain of 1.0, both the cast and extruded material were comparable by measured flow stress and by texture.

(a)

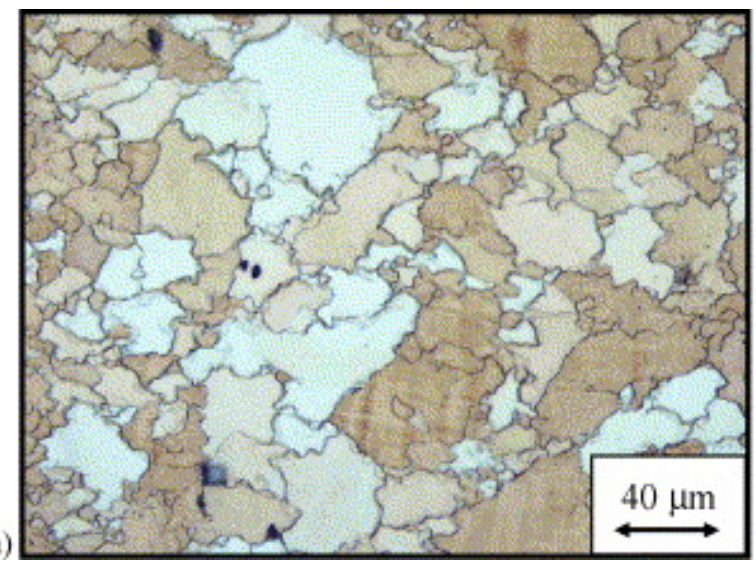

(b)

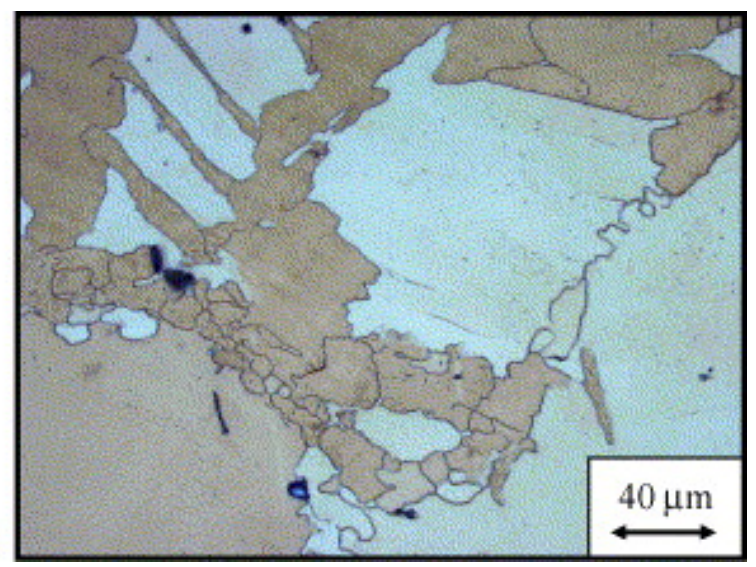

Figure 2.8: Microstructure after compression to a strain of 0.2 at $350^{\circ} \mathrm{C}$ and $0.01 / \mathrm{s}$ for (a) wrought AZ31 and (b) cast AZ31. (Reproduced with permission from Elsevier) [34]

Other studies on deformation of extruded AZ80 have shown that both a refined microstructure and material texture relative to the loading direction have a noticeable effect on compressive strength, [35, 36, 37], though after forging, the effect of texture on the ultimate compressive strength is lessened due to a more isotropic structure [36. In the study by Kobold et al. [35], the highest ultimate compressive strength was seen when the compression direction aligned with the extruded direction, followed by the radial and $45^{\circ}$ extrusion directions. This behaviour is a result of different deformation and crystal grain orientations influencing the onset of slip and twinning mechanisms. This change in peak stress with a change in sample texture orientation is of similar significance to what was reported by Liu et al. when comparing the effects of extruded grain size on compressive stress 33 . The reduction in ultimate compressive strength of the radial direction compared to the extruded direction was also seen in the work by Gryguc et al. [36], however the ultimate compressive strength in all directions was lowered once the extruded billets had been forged (and thus had a refined microstructure). In a study on the effects of grain size and texture on the mechanical properties of AZ80, Wang et al. [37] used multiple pass equal channel angular pressing to produce samples with increasingly refined grain size and sharpened texture. They showed that at room temperature the ultimate tensile strength increased with a reduction of grain size, while the ultimate compressive strength decreased. However, at elevated temperatures $\left(373\right.$ and $\left.423^{\circ} \mathrm{K}\right)$, both the tensile and compressive ultimate 
strengths were decreased in samples that had a more refined grain structure and sharpened texture. In tension, this behaviour is a result of increased grain boundary sliding, decreased dislocation strengthening, and texture weakening, with an increase in temperature, while at room temperature the strength increases according to the Hall-Petch relationship. In compression, the ultimate strength decreases with an increasingly sharp texture regardless of temperature, as the basal planes rotate closer to a more favorable direction for basal slip.

To make magnesium alloys more appealing to industry applications, it is desirable to produce high quality forgings with fewer intermediate processes. The deformation of AZ alloys in their as-cast form has not been as extensively studied compared to the extruded or forged conditions. It is well known that a higher cooling rate during casting can effectively refine the grain size, however higher cooling rates are difficult to obtain in larger volume castings, which is often the case for forging stock. In the study by Fujita et al. [20], grain refinement in permanent mould casting was achieved through addition of either $\mathrm{CaCN}_{2}$ or sulphur during casting of a magnesium-7\%wt-aluminum alloy. Both additives were effective in reducing the grain size, permitting the full-scale forging of an automotive wheel without pre-straining. This study also considered AZ80, and a magnesium-6\%wt-aluminum alloy, however the highest improvement in toughness upon forging was seen with $7 \%$ aluminum by weight. Strontium addition during casting has been used as a grain refinement method in AZ61, which enabled a higher volume fraction of DRX grains, attributed to the increased nucleation sites for DRX that accompany a fine grain size [38]. In a study on the effects of grain size on ductility, Lukáč and Trojanová [39] found that there was an increase in fracture strain with a decrease in as-cast grain size for pure magnesium and for magnesium with 2 percent by weight aluminum. This effect was more pronounced at elevated temperatures, above $200^{\circ} \mathrm{C}$. They suggest that this may be connected to the activation of non-basal slip and the effect of grain size on strain hardening rate. The effect of grain size on flow stress was studied by Weiler et al. [40] for a die cast AM60B alloy. By sampling material from different cross-sectional thicknesses of the casting, samples of different cooling rates and subsequent grain sizes were obtained. Through spherical indentation testing, it was found that the flow stress of this alloy increased with a decrease in average grain size (increase in cooling rate). For the material nearest to the mould wall, with the highest cooling rate, this relationship was well correlated to the Hall-Petch relationship. A similar study by Sharifi et al. 41] showed an increase in flow stress in samples with a refined cast grain structure in AM60 and AZ91 at low levels of plastic strain. The tensile properties affected by dendrite arm spacing have also been thoroughly studied for magnesium-aluminum alloys and follow the Hall-Petch relationship with respect to increasing yield strength with decreasing grain size [42]. When comparing the effects of solidification rate and ageing on mechanical properties of AZ91, Cáceres et al. [26] found no definitive correlation between solidification 
rate (and consequently the SDAS) and the room temperature yield strength or ductility of the material, though this is attributed to the dissolving of the $\gamma-\mathrm{Mg}_{17} \mathrm{Al}_{12}$ particles, effectively erasing the dendritic structure. The effect of grain size on the compressive strength of magnesium-aluminum alloys in their wrought form is fairly well established, and some studies have shown good correlation between grain size and compressive strength for cast alloys, however, the same conclusions have not been explicitly studied for the as-cast AZ80 alloy.

In addition to a change in grain size, heat treatments can have a significant effect on the strength of AZ alloys during hot compression. Homogenization is a common heat treatment before deformation, where much or all of the intermetallic phase is brought into solution with the primary phase, typically lowering the flow stress and making deformation easier. The effect of homogenization on the microstructure and mechanical properties of AZ80 has been studied by Yakubtsov et al. [11. Figure 2.9 shows the microstructure of the alloy after homogenizing for 20 hours at $420^{\circ} \mathrm{C}$, where almost none of the initially present $\gamma-\mathrm{Mg}_{17} \mathrm{Al}_{12}$ phase remains. What was found was that even by partial homogeniza-
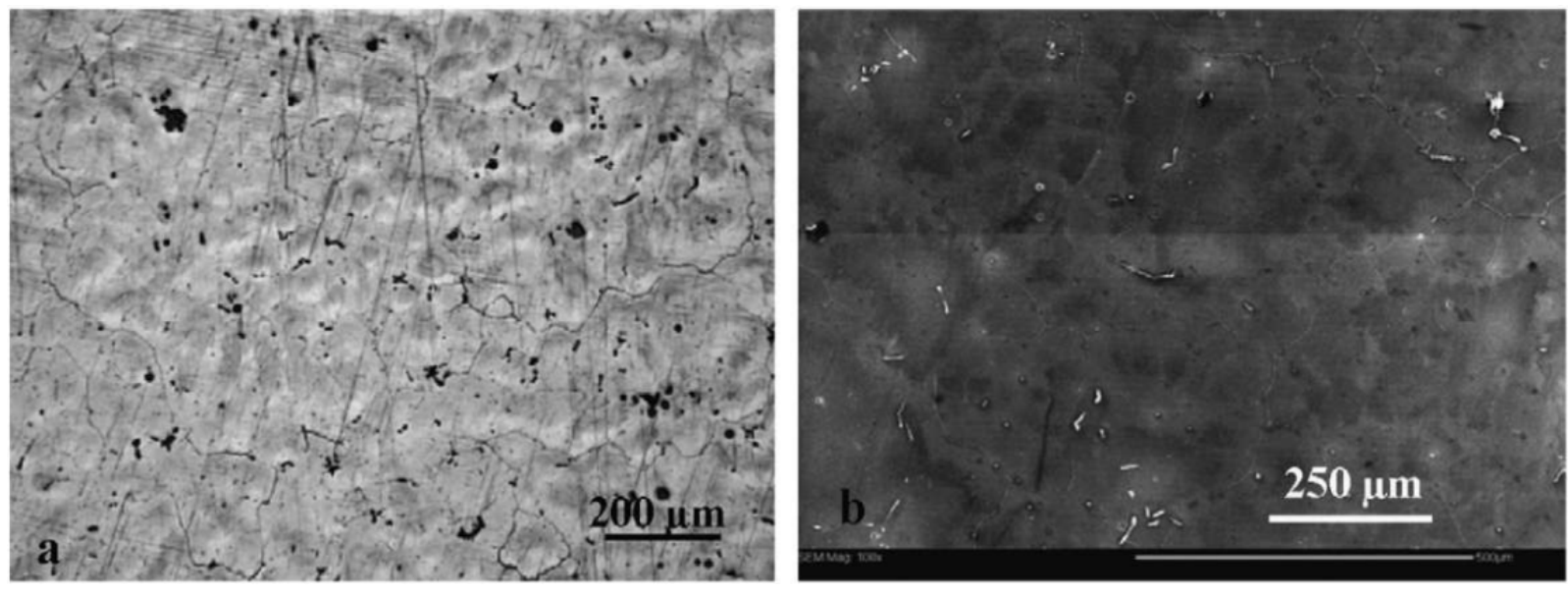

Figure 2.9: Microstructure after 20 hour homogenization treatment at $420^{\circ} \mathrm{C}$ for (a) cast AZ80 by optical microscopy and (b) grain refined cast AZ80 by scanning electron microscopy. (Reproduced with permission from Elsevier) [11]

tion, the ductility of the alloy is noticeably increased. Nearly complete homogenization increased the ductility much more significantly, an effect that was amplified even further by a refinement of the grain size. Additionally, the as cast alloys saw much more work hardening during the initial stages of deformation, resulting from dislocation interactions 
with the $\gamma-\mathrm{Mg}_{17} \mathrm{Al}_{12}$ phase. A similar result was reported by Guangjun et al. [22], where the tensile yield and ultimate strength and elongation increased after homogenization, for AZ61, AZ71, and AZ81. The influence of homogenization on the compressive stress has been well studied for alloys AZ31 [43, 44], and AZ61 [45]. In these studies, the flow stress was effectively lowered by fully dissolving the intermetallic phase through homogenization. Both studies on AZ31 reported an expansion of the domains in which the alloy is workable after homogenization, meaning instability and cracking is eliminated for a larger range of process parameters. The study by $\mathrm{Wu}$ et al on AZ61 showed not only a decrease in the flow stress, but a different dynamic softening behaviour. Due to the presence of the intermetallic phase, the occurrence and growth of DRX grains was restricted in the as-cast material. This resulted in a lower volume fraction of DRX grains, and a lower DRX grain size, leading to a higher flow stress and a slower declining slope in the softening region of the flow curve after the peak stress [45]. Similar results were reported for the AZ80 alloy by Meng et al. [46], where near complete homogenization occurred after holding the sample at $415^{\circ} \mathrm{C}$ for 16 hours. The homogenized samples had a higher volume fraction of DRX grains after deformation, and this more uniform distribution of fine grains yielded better mechanical properties than the deformed as-cast material. Different from the studies on AZ31 and AZ61, in a study on the effect of homogenization on hot deformation behaviour by Ziyu et al. [47], the AZ80 alloy showed an increase in peak compressive stress after homogenization, followed by a high rate of flow softening. This is explained to be an effect of solid solution strengthening by the $\mathrm{Mg}_{17} \mathrm{Al}_{12}$ phase that occurs after homogenization, where the dissolved solute atoms contribute to dislocation pinning, which may only show this significant of an effect at higher alloy contents as in the AZ80 alloy.

\subsubsection{Effect of process parameters on deformation behaviour}

Isothermal uniaxial compression tests were used by Cai et al. 48, to investigate the sensitivity of process parameters on the flow stress of AZ80. The flow stress showed sensitivity to temperature and strain rate, decreasing with either an increase in temperature or a decrease in the strain rate. Based on the sensitivity to temperature and strain rate, and microstructure images, they proposed that the optimal processing condition to ensure fine grains and excellent mechanical properties would be $300^{\circ} \mathrm{C}$ and a strain rate of $0.001 / \mathrm{s}$. In a similar study by $\mathrm{Su}$ et al. [49, the same effects of temperature and strain rate were seen, and a similar optimal processing condition was found. In this study however, they showed that the activation energy was dependent on the strain, decreasing from 153 to $96 \mathrm{~kJ} / \mathrm{mol}$ as the strain increased. 
In a study on the effect of temperature on the hot deformation behaviour of AZ80, Prakash [50] found that deformation temperature and its effects are highly related to the effects of the presence of the $\gamma-\mathrm{Mg}_{17} \mathrm{Al}_{12}$ phase. Deformation at $300^{\circ} \mathrm{C}$ saw much DRX occurring at the grain boundaries, which was due to particle stimulated nucleation at the lamellar $\mathrm{Mg}_{17} \mathrm{Al}_{12}$ precipitates. However, due to presence of lath precipitate $\mathrm{Mg}_{17} \mathrm{Al}_{12}$ phase also close to the grain boundaries, the growth of DRX grains was inhibited. Upon increasing the deformation temperature to $400^{\circ} \mathrm{C}$ however, the $\mathrm{Mg}_{17} \mathrm{Al}_{12}$ phase dissolves within the $\alpha-\mathrm{Mg}$ grains, and is therefore unable to pin the DRX grains. DRX occurred by grain boundary bulging, and since the lath precipitate $\mathrm{Mg}_{17} \mathrm{Al}_{12}$ phase, which can permit DRX grain growth, was brought into solution at $400^{\circ} \mathrm{C}$, both the size and volume fraction of DRX grains was increased. Microstructures of deformed samples at a strain of 0.15 are shown in Figure 2.10, It is seen that at $300^{\circ} \mathrm{C}$, the DRX grains are pinned at the grain

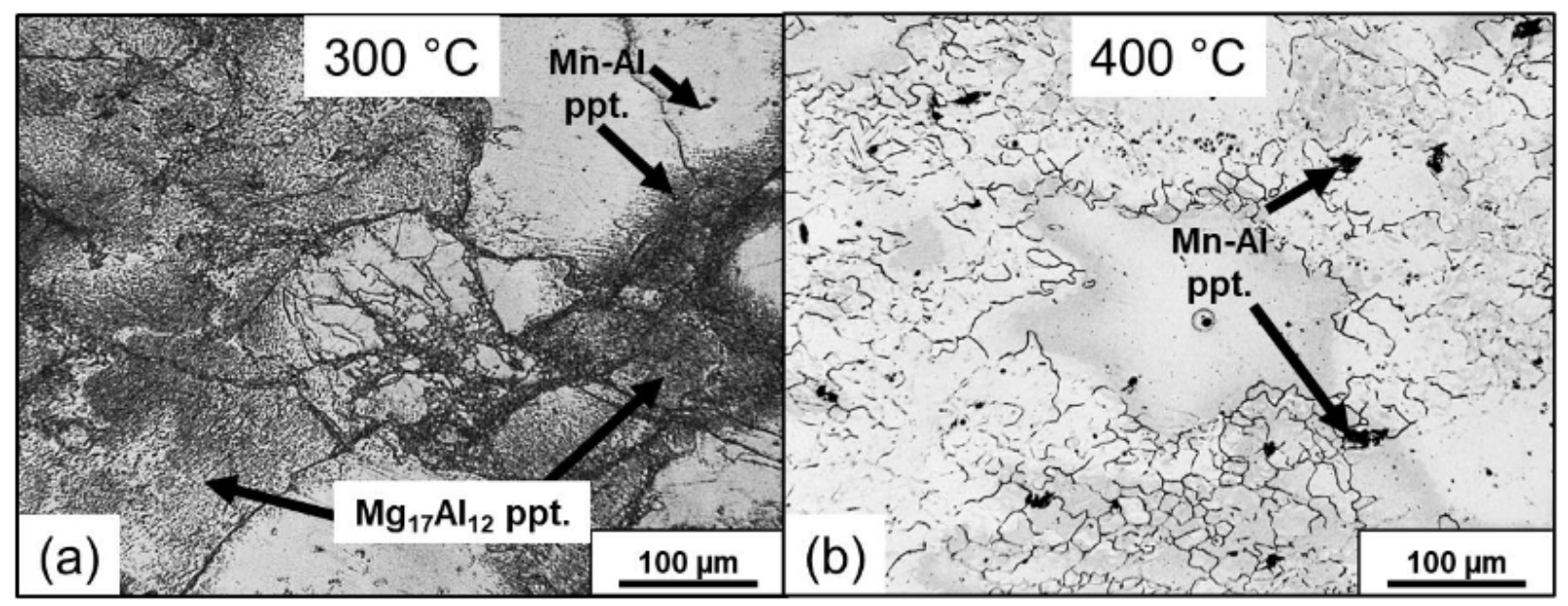

Figure 2.10: Microstructure of samples deformed at a strain rate of $0.001 / \mathrm{s}$ to a strain of 0.15 at temperatures of (a) $300^{\circ} \mathrm{C}$ and (b) $400^{\circ} \mathrm{C}$. (Reproduced with permission from Author and UWSpace) [50]

boundaries, whereas at $400^{\circ} \mathrm{C}$ the grains are bulging from the grain boundaries and are beginning to grow. The microstructure at $400^{\circ} \mathrm{C}$ shows no presence of the $\gamma-\mathrm{Mg}_{17} \mathrm{Al}_{12}$ phase. This result is very similar to what was seen after homogenization of AZ61 [45]. 


\subsection{Permanent mould design}

\subsubsection{Components of a casting mould}

Permanent mould casting requires a mould which will not be damaged during casting or part removal, and therefore can be re-used indefinitely. An example of a properly designed casting mould is shown in 2.11 including a pouring basin, a tapered sprue, a runner, and a gate [51]. A riser (feeder) is also included, which feeds the mould cavity during solidification shrinkage. A vent may be used to allow the air inside the mould to be easily displaced by molten metal, however in this example, the feeder acts as the vent. A well at the

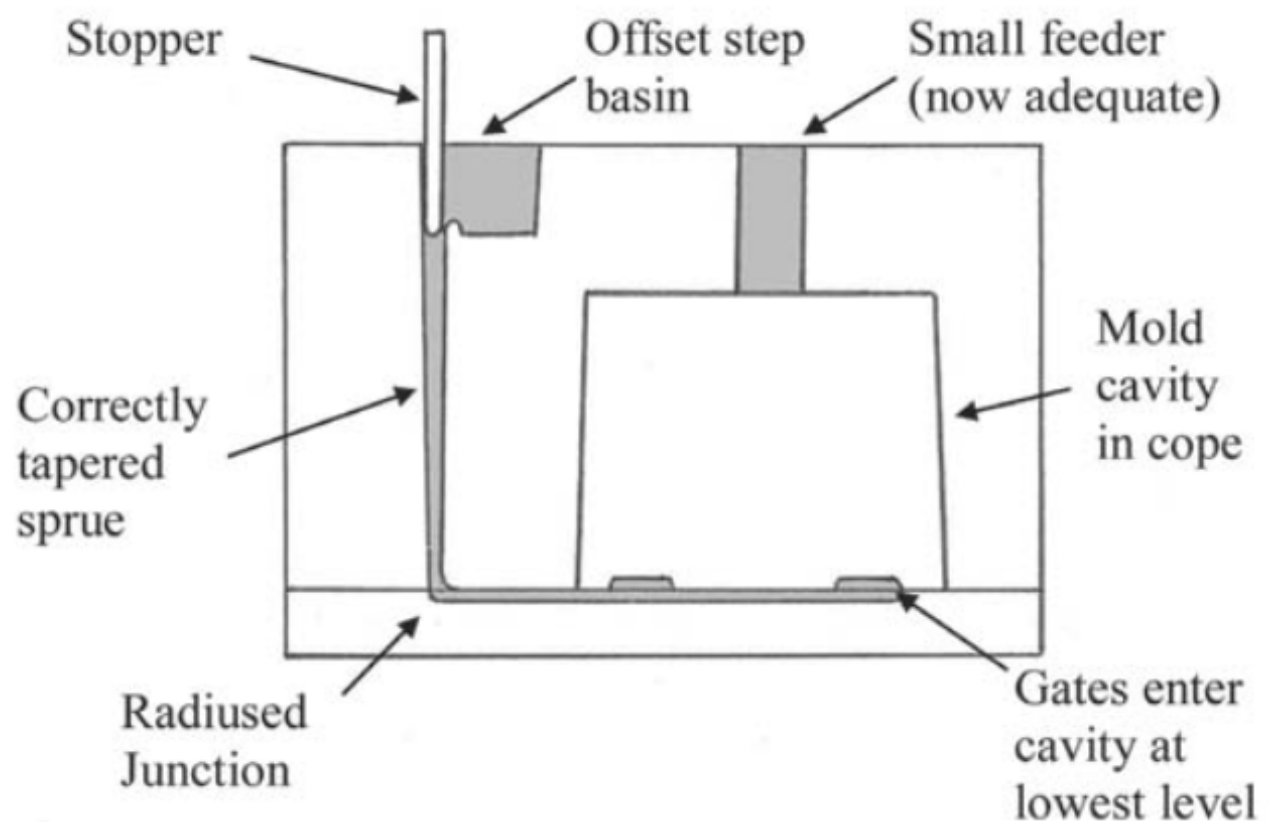

Figure 2.11: A schematic showing the components of a bottom-fed casting mould. (Reproduced with permission from Springer Nature) [51]

bottom of the sprue may also be included, instead of the radiused junction between the sprue and the runner in Figure 2.11, however is not always necessary. The sharp change of direction that the melt must endure with a sprue well can cause turbulence, which may cause entrainment defects [52]. The sprue well helps to reduce the velocity of the molten metal before it enters the runners, however, since the molten metal must change direction sharply once it has reached the bottom of the sprue [53]. 


\subsubsection{Designing a mould to minimize defects}

Often a result of poor mould design are entrainment defects which can weaken the mechanical properties of the casting. Entrainment occurs when there is folding or lapping of the liquid metal after it has formed a boundary skin layer, such that the skin layer is now fully submerged in liquid metal. This boundary skin layer is typically solidified material (often called cold shutting) or an oxide (called double oxide films), however entrainment can also include entrapped air. These defects can be detrimental to the mechanical properties of the casting and can also impede the fluidity of the melt into the remaining mould cavity. Entrainment occurs when there is high turbulence in the liquid, as shown in Figure 2.12, however it can also be caused by contraction of the liquid after the skin layer has been formed. These partially solid phases or oxides have now folded or lapped onto each other

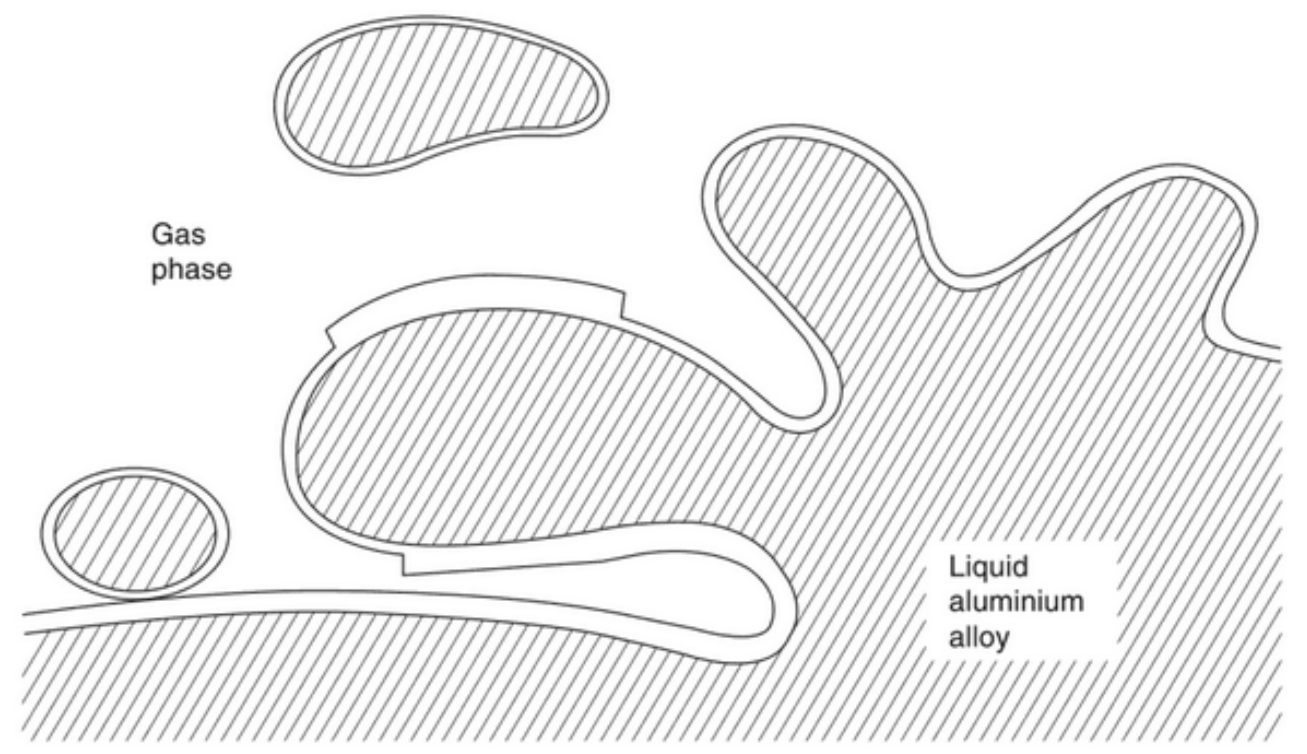

Figure 2.12: A sketch of a surface entrainment event in an aluminum alloy. (Reproduced with permission from Elsevier) [52]

creating an interface which has not bonded, effectively acting as a crack in the material [52]. Griffiths and Lai [54] studied the formation of double oxide films in cast magnesium, by casting plates of pure magnesium without any flux added to the melt. Samples for tensile testing were cast in two molds, one with a proper filling system and one that would induce turbulence and thus entrapment of surface oxide films. Higher tensile strength and elongation were found in samples cast with less turbulence, accompanied by a narrower 
distribution of properties. Inspection of fracture surfaces revealed the presence of oxides in all samples, though notably fewer in samples cast with lower turbulence, highlighting the importance of a proper runner and gating system in a mold design. In casting terminology, this accumulation of oxides and other impurities at the melt-air interface is called dross.

To prevent the dross from entering the mould cavity, traps may be placed at the end of the runners such that the liquid front carries the dross to the trap where it is solidified. Simple extension of the runners may not be sufficient, as it is important to consider the flow of liquid into these traps. Wedge shaped traps, or runner extensions that are of smaller cross-section than the runner itself, are used to ensure the dross does not flow back out of the trap. The dross-containing melt will solidify quickly in these extensions, owing to the high ratio of surface area to the volume in the runner extension, ensuring the dross is not recirculated [55]. These runner extension traps must be of sufficient length however, to ensure that dross-containing melt is not splashed and recirculated, and carried into the gate.

To reduce the turbulence of the molten metal as it enters the mould cavity, design of a proper gating system is required. Use of an in-gate with a lower flow velocity can help reduce the amount of turbulence, preventing two partially solid material fronts from meeting during filling, thus reducing the amount of entrainment defects [56]. Each material has a critical speed of which the melt should not exceed to prevent entrainment of oxide films as the liquid fills the mould cavity. This critical speed is determined by the surface tension, density, and critical radius, and is found to be between 0.55 and $0.6 \mathrm{~m} / \mathrm{s}$ for magnesium alloys [57]. If the melt exceeds the critical velocity, it may elevate above the fill level along the mould wall, and as it splashes back down it may entrap oxide defects. Turbulence can also be minimized by having the mould cavity filled from the bottom rather than the top (called bottom feeding). While this helps reduce the melt turbulence and velocity before entering the mould cavity, it is important to consider that the slower filling of the mould cavity can result in a lower cooling rate in the casting [55]. An even more effective method at controlling the flow is by side-feeding, through what is called a web gate. This design uses a vertical riser positioned beside the mould cavity and is connected to the entire height of the casting through a very thin in-gate. The thin in-gate section combined with the frictional forces at the mould walls slows the flow rate of metal significantly, reducing the turbulence and eliminating the need for a filter to create laminar flow [55]. One downside to this type of gating system however, is the possibility for the side of the casting closest to the gate to be much hotter than the opposing side, causing a gradient in cooling rate across the part and possibly shrinkage defects [55]. Further, this thinner section where the web gate is, may be prone to early solidification, causing cold shuts. 
The design of the sprue and pour basin is critical in reducing defects in the casting. While simple and capable of high pour rates, a conical basin that feeds directly to the sprue is a very poor method of filling the mould, as it acts as an air pump and will draw in air that will mix with the melt in the sprue [57]. A much more effective design is to have a larger, offset pour basin, where the melt is poured into a larger basin at a location offset from directly aligned with the sprue, as in the mould design presented in Figure 2.11. The basin is kept at a roughly continuous fill level throughout the pouring. This design does not allow air to mix with the melt, and also allows defects to float to the surface of the basin, avoiding the chance of being swept into the mould cavity [57]. The sprue must also be tapered correctly to ensure the melt will be pressurized against all of the walls of the sprue, and will not entrap any air. As the metal is falling from a height, as in gravity pouring through a sprue, the height of the fall dictates its velocity. If the volumetric flow rate of the system is known or can be estimated, then the cross-sectional area of any location along the sprue can be calculated. The sprue and runner may commonly be of rectangular or circular cross section, however it is important to match the sprue shape to the runner shape, as in Figure 2.11. This is once again to reduce turbulence [57].

\subsection{Casting process modelling}

In a review of commercially available casting simulation software, Khan and Sheikh 58] surveyed the capabilities of 6 commonly used software packages, including AutoCAST, CAPCAST, CastCAE, MAGMASoft, Nova-Solid/Flow, ProCAST, FLOW-3D Cast, and SOLIDCast. They found that while certain software could simulate more casting processes than others, the reliability of each model still relies on how thoroughly the simulation parameters are selected. These software solve using either the Finite Difference Method, Finite Element Method, or the Finite Volume Method, though it was found that the programs using the Finite Element method (ProCAST, CAPCAST, FLOW-3D Cast) were up to $10 \%$ faster than those using other methods. The most capable software, by measure of the number of casting processes that could be simulated, were ProCAST and FLOW-3D Cast. Another review by Vaskovà et al. [59] saw that software which solved by the Finite Difference Method requires significantly more calculation time than with the Finite Volume Method.

While the use of a commercially available software simplifies the modelling of casting processes significantly, boundary conditions such as the interface heat transfer coefficient between the casting and the mould wall is still a required input. Many attempts have been 
made to model this heat transfer coefficient, accounting for the metal-mould interface gap that forms upon solidification. The metal-mould interface gap is caused by contraction of the casting and expansion of the mould, and therefore is proportional to the temperature of the solidified casting. More difficulty lies in the fact that the casting is of non-uniform temperature. The contraction of the part will only depend on the outermost material in the casting which solidifies first and will continue to vary as more material solidifies. Further, mould materials, coatings, and surface roughness also effect the conductivity of the interface. In a fundamental study on understanding the decreasing interfacial heat transfer coefficient during casting, Ho and Pehlke [60] saw that a Copper-Aluminum alloy would initially have a heat transfer coefficient above $1000 \mathrm{~W} / \mathrm{m}^{2} \mathrm{~K}$ when first contacting the mould. Once this material began to solidify however, the contraction formed a gap between the metal and mould interface. Upon formation of the metal-mould interface gap, the conductive heat transfer through the surrounding gas becomes proportional to an increasing gap size. Once the gap size was increased substantially, the overall heat transfer coefficient decreased below $100 \mathrm{~W} / \mathrm{m}^{2} \mathrm{~K}$. The heat transfer by thermal radiation was not seen to be affected by the change in gap width, however with the large interface gap the radiation heat transfer accounted for approximately $60 \%$ of the overall heat transfer. In a later study, Nishida et al. [61] proposed that at least for the early stages of the gap formation (where the gap is small) that the heat transfer can be modelled as conduction through the surrounding gas, assuming that no convection would occur. They found that for much of the solidification the gap was very small, allowing this model to be used, however as was seen in [60], further contraction of the alloy nullifies this model.

More recent works have included finite element models, some of which have effectively predicted the cooling rates of the casting by having the heat transfer coefficient vary as a function of the casting surface temperature [62, 63]. In the model proposed by Hao et al. [62], the heat transfer coefficient was found through iteration, based on proposed values in literature and guided by experimental thermocouple measurements, meaning the model is specific to the set of conditions outlined in this experiment. Another heat transfer model, proposed by Sengupta et al. [63, used a combination of the contact heat transfer coefficient (estimated to be within 1000-2000 W/ $\mathrm{m}^{2} \mathrm{~K}$ ) and the air gap heat transfer coefficient (estimated to be between 50 and $200 \mathrm{~W} / \mathrm{m}^{2} \mathrm{~K}$ ), proportional to the fraction of solid and fraction of liquid respectively, to estimate the overall heat transfer coefficient during the primary cooling regime of DC casting where the material is in contact with the mould walls. The model predictions were in satisfactory agreement with experimental results, for both the primary and secondary cooling phases, however some iteration was required to improve the model accuracy further. Other studies, such as the one by Zhang et al. [64], have found an effective heat transfer coefficient by using experimental data and a 
commercially available software package. They began with estimated boundary conditions and iterated through simulation results using an optimization function on the heat transfer coefficient until the simulation temperatures adequately matched the measured temperatures. A similar study used the same software package for the simulation, but instead used a neural network architecture to adjust the heat transfer coefficient in order to match the experimental data [65]. While these methods are very effective, the heat transfer coefficient cannot be calculated by these methods without first having experimental data. 


\section{Research Scope}

This research aims to further develop the knowledge surrounding deformation and forging behaviour of the AZ80 alloy. While the impact of initial microstructure with regards to deformation and forging is not unfamiliar in literature, many existing works have failed to study the impact of the starting microstructure exclusive to as-cast material, particularly for AZ80. This work will investigate the impact of grain size and dendrite arm spacing on the flow stress during deformation. This is done by casting material at both high and low cooling rates, using the same casting process. Other techniques to modify the microstructure which may impact forgeability, such as homogenization treatment, using a different casting process, and addition of a de-gassing agent to the casting melt, are also explored.

While this study aims to complete some of the literature surrounding the forging of cast magnesium alloys, this work is also part of a larger project focused on the forging of an automotive control arm for a Ford Fusion car. In previous studies, these control arms were forged from extruded or cast AZ80 stock. In efforts to make this manufacturing process more effective and require fewer processes prior to forging, cast pre-forms will be used that are near-net shape to the final forging. This necessitates more knowledge surrounding the deformation of cast AZ80. As such, the experimental results of the flow curves, and any impact of the starting microstructure on the forged microstructure, will be a valued input toward developing the optimal pre-form shape for the desired forged properties. 


\section{Methodology}

This chapter describes the procedures and methodologies used to carry out this research. This includes the starting material, the techniques used for casting the starting material, the processing and testing of the material, and characterizing the properties of the material. Additionally, boundary condition calculation and simulation parameters used in the casting simulations are described. Finally, the design process for the permanent mould used in this project is described.

\subsection{Start Material}

The material used in this study is commercial grade AZ80 in the form of cast billets, obtained from Mag Specialties. The chemical composition of the starting material was found by SEM-EDX analysis. The as-received composition, measured prior to casting, is shown in Table 4.1, alongside the nominal ASM composition for AZ80, [66]. This analysis shows that the starting material is within the acceptable range for the AZ80 alloy. The recorded values represent the average of 4 measurements on the same sample.

Table 4.1: Composition of the as-received material, compared to the target range for the AZ80 alloy.

\begin{tabular}{|l|r|r|r|r|}
\hline Material & \multicolumn{1}{|c|}{ Al \% } & \multicolumn{1}{l|}{ Zn \% } & \multicolumn{1}{l|}{ Mn \% } & \multicolumn{1}{l|}{ Mg \% } \\
\hline As-received & 8.64 & 0.52 & 0.24 & Bal. \\
\hline Specified Range [65] & $7.8-9.2$ & $0.2-0.8$ & $0.12-0.5$ & Bal. \\
\hline
\end{tabular}

\subsubsection{Casting of Material}

Since the purpose of this study is to determine the influence of the as-cast material structure on the deformation behaviour and microstructure evolution during deformation, the material was cast to create different starting microstructures. To achieve this, the received billets described in Section 4.1 were melted at the CANMETMaterials facility in Hamilton, Ontario, in a $60 \mathrm{~kg}$ capacity crucible, controlled to $730^{\circ} \mathrm{C}$. The material was poured into a wedge mould using a ladle. The wedge mould was made from $25.4 \mathrm{~mm}(1$ ") thick copper plates, which contained $12.7 \mathrm{~mm}\left(0.5^{\prime \prime}\right)$ water cooling channels along the backside that were sealed by an aluminum backing plate, and the length of the wedge was controlled by copper wedge plates. The mould setup prior to pouring can be seen in Figure 4.1. More detailed 
images, as well as images of the cast wedges, are found in Appendix A. During solidification, the water flowed at a rate of 27.3 litres per minute through each side of the mould. The cooling water was at a temperature of $18^{\circ} \mathrm{C}$ at the cooling channel inlet, and saw an increase in temperature of $37^{\circ} \mathrm{C}$ upon pouring, before quickly stabilizing to approximately $20^{\circ} \mathrm{C}$. To eliminate the possibility of the cooling water retaining heat, which may occur in a closed-circuit cooling system, the cooling water was sourced directly from the municipal water tap and was not re-cycled through the cooling channels. Thermocouples were present

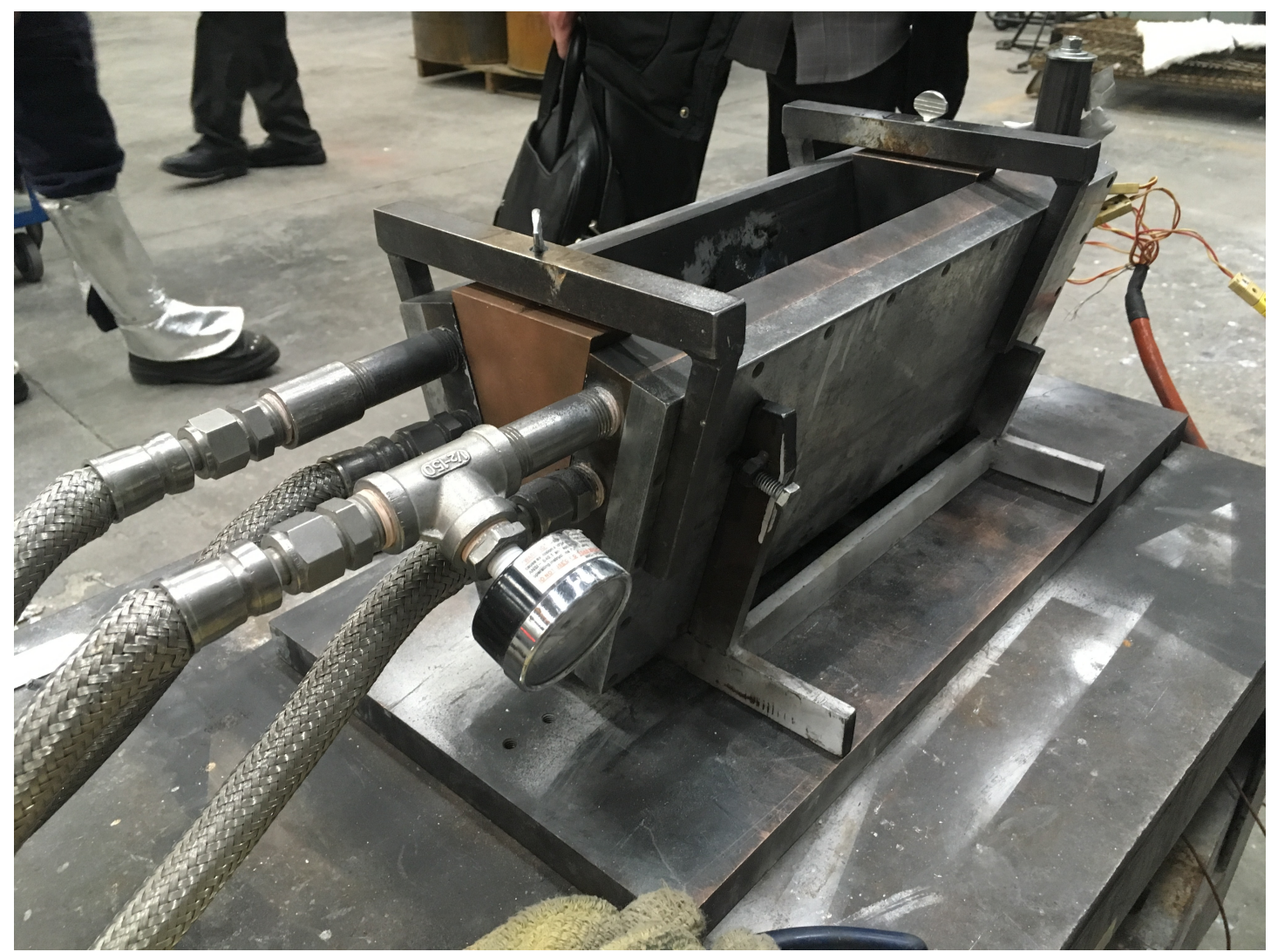

Figure 4.1: The wedge casting mould, with attached water lines.

in 7 locations along the centerline of the wedge mould, such that a correlation between cast material structure and cooling history can be made. The thermocouples are spaced and numbered according to Figure 4.2 , and inserted approximately $30 \mathrm{~mm}$ into the mould cavity from the end of the mould. This is to ensure representative temperature data with minimal effects of heat extraction through the ends of the mould, while still maintaining sufficient wedge material for sample extraction. Since the rate of cooling varies continu- 


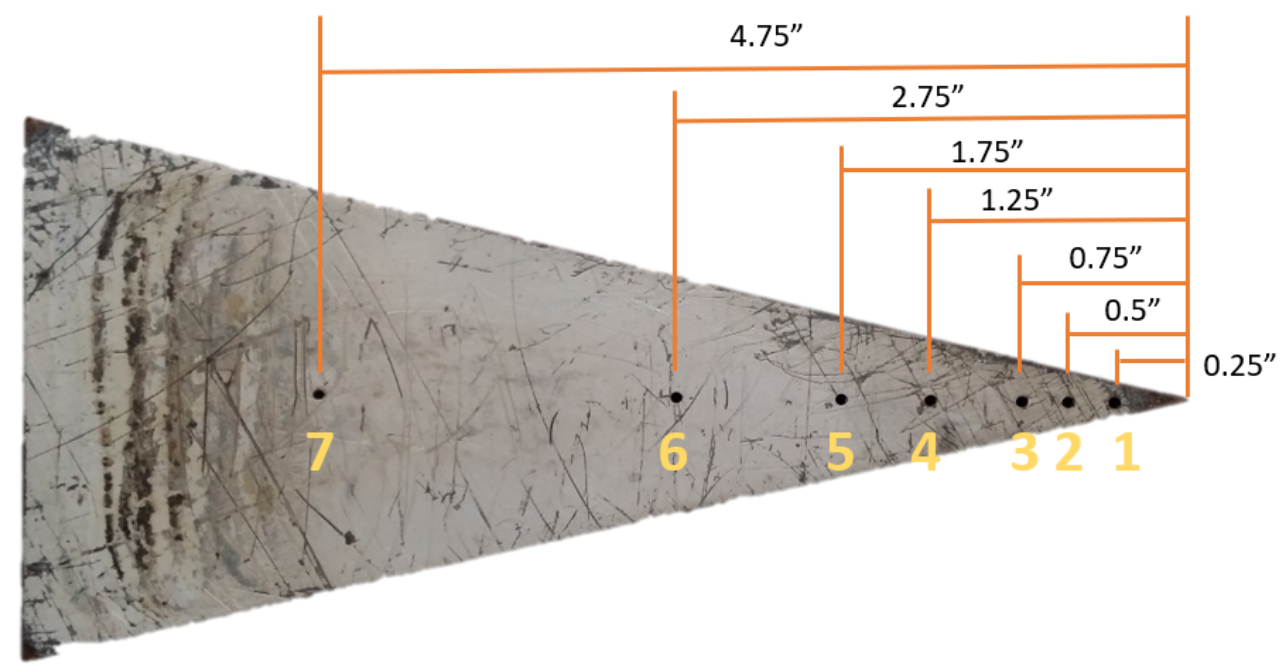

Figure 4.2: The locations of the thermocouples along the wedge.

ously during solidification, it is difficult to quantify a single value to represent the cooling rate. For consistency, the most linear section of the cooling curve from approximately $580^{\circ} \mathrm{C}$ to $480^{\circ} \mathrm{C}$ was used to determine the cooling rate. Two regions of interest were selected for samples; thermocouple 4 and thermocouple 7 , giving high and low cooling rate samples respectively (further referred to as HCR and LCR). These locations were selected for their significant difference in cooling rate while also having ample size within the wedge geometry for sample extraction. The recorded temperature during solidification for each thermocouple, and the slope showing the location where the cooling rate was measured, is shown in Figure 4.3. The liquidus and solidus temperatures that are shown were determined through use of a Universal Metallurgical Simulator and Analyzer, and is described in detail in Section 4.3.3. Using the same configuration, some wedges were cast with the addition of a de-gassing agent in the form of hexachloroethane tablets, added directly to the molten AZ80 in the crucible. The concentration of hexachloroethane was one $100 \mathrm{~g}$ tablet added for every $60 \mathrm{~kg}$ of material in the crucible. The purpose of this addition is to remove hydrogen gas from the melt, though some further grain refinement is anticipated. During this casting, the cooling water was at a temperature of $8^{\circ} \mathrm{C}$ at the cooling channel inlet, and saw an increase in temperature of $39^{\circ} \mathrm{C}$ upon pouring, before quickly stabilizing to approximately $14^{\circ} \mathrm{C}$. The difference in cooling water temperature between castings is a result of using the municipal water tap as a source, of which the temperature was not controlled. 


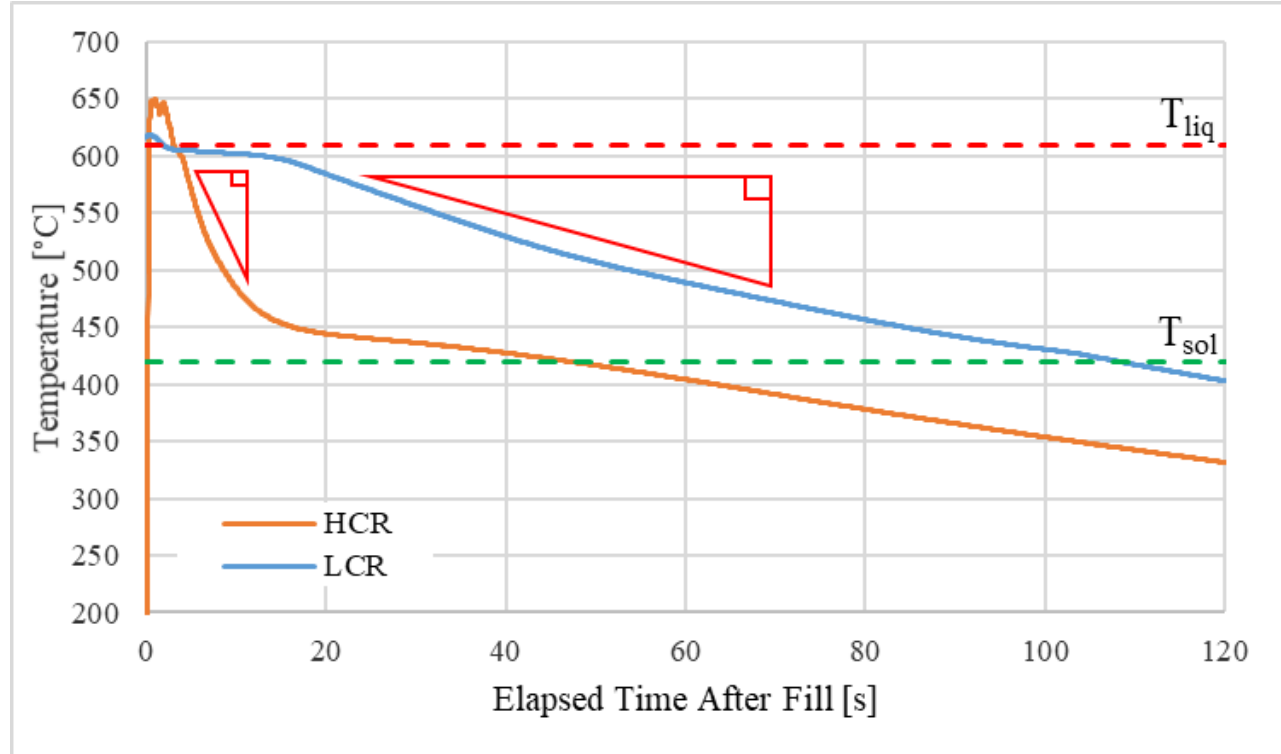

Figure 4.3: The temperature recorded by thermocouple 4 and thermocouple 7 after filling, showing the temperature range over which the cooling rate was calculated.

Cylinders of $63.5 \mathrm{~mm}$ diameter by $70 \mathrm{~mm}$ in height were also cast, for the purpose of smallscale forgings and more efficient sample extraction. Wedge castings incurred more waste and yielded fewer samples compared to the cylinder castings, therefore many of the samples used for mechanical property testing in this research were extracted from the cylinder casting. All cylinders that were cast using this mould were done so with the addition of the de-gassing agent, in the same melt concentration previously listed. The mould is made of H13 steel, with aluminum backplates that contained water cooling passages, shown in Figure 4.4. A more detailed image of the mould setup, mould cavity, and resultant castings, is found in Appendix A. The design of this mould will be described in detail, in section 4.5. In order to achieve a difference in cooling rates between cylinders, the castings were done in two configurations, water cooled and air cooled, through; a mould preheat of $50^{\circ} \mathrm{C}$ with aluminum cooling plates attached, and a mould preheat of $300^{\circ} \mathrm{C}$ without the cooling plates attached. As before the molten material was taken from the $60 \mathrm{~kg}$ crucible controlled to $730^{\circ} \mathrm{C}$ and poured from a ladle. As in the case of the wedge casting, the water flow rate was 27.3 litres per minute. The water inlet temperature for the water cooled cylinder casting was approximately $20^{\circ} \mathrm{C}$, and increased to a maximum temperature of $42^{\circ} \mathrm{C}$. Three thermocouples were present in this mould to record the cooling rate of the material as shown in Figure 4.5, placed approximately $13 \mathrm{~mm}$ from the cylinder wall. 


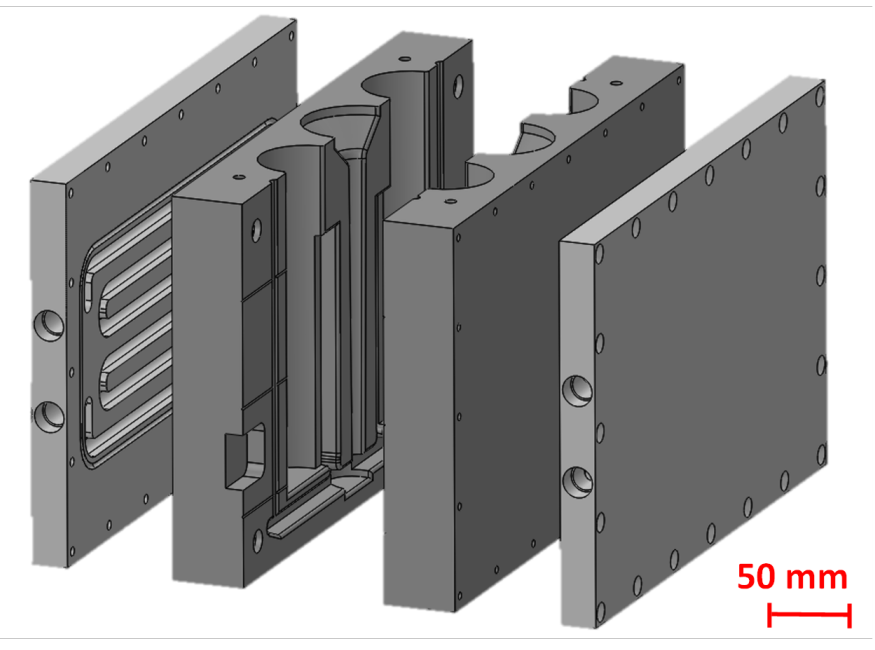

Figure 4.4: An exploded view of the cylinder casting mould.

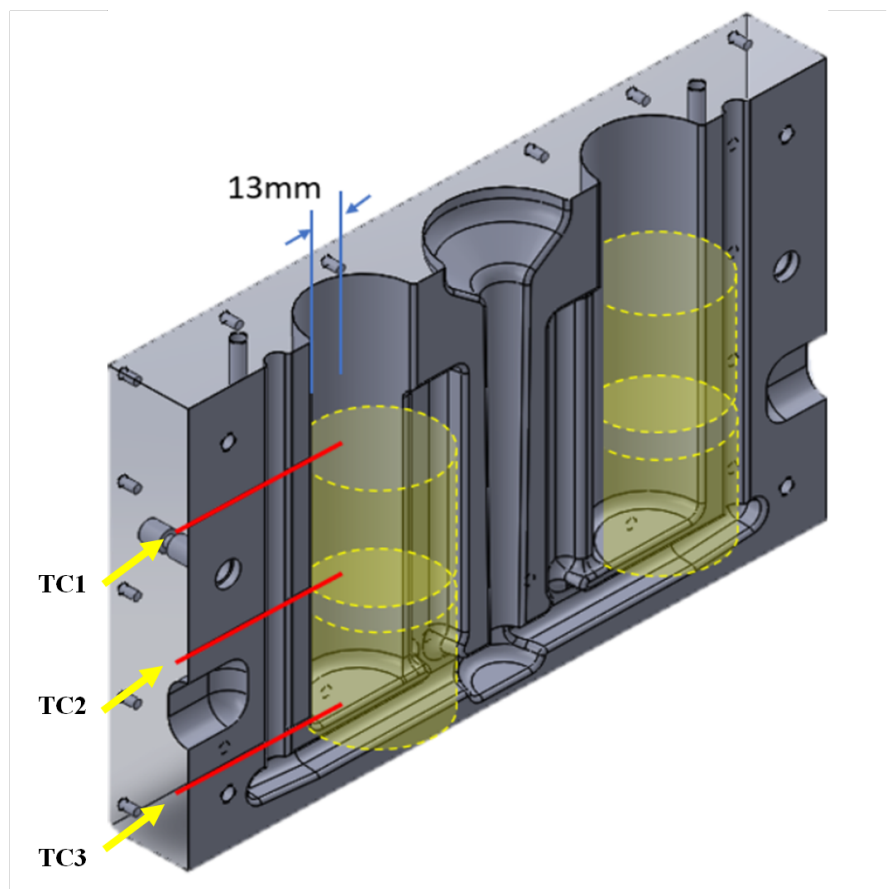

Figure 4.5: A view of one half of the cylinder mould, showing the thermocouple locations. 


\subsubsection{Homogenization Treatment}

Samples that were subject to homogenization treatment were placed in a wire-mesh cage, and inserted into a Techne FB-08C fluidized sand bath, both pictured in Figure 4.6, with alumina powder as a medium. The bath was controlled to $420^{\circ} \mathrm{C}$, with the fluidization air held at $15 \mathrm{l} / \mathrm{min}$. The time given for each sample to be held at this temperature was 24 hours. As the alumina powder bath cannot be run unsupervised, the homogenization treatments were divided evenly into 4, 6 hour sessions, with an immediate water quench each time the samples were removed from the bath.

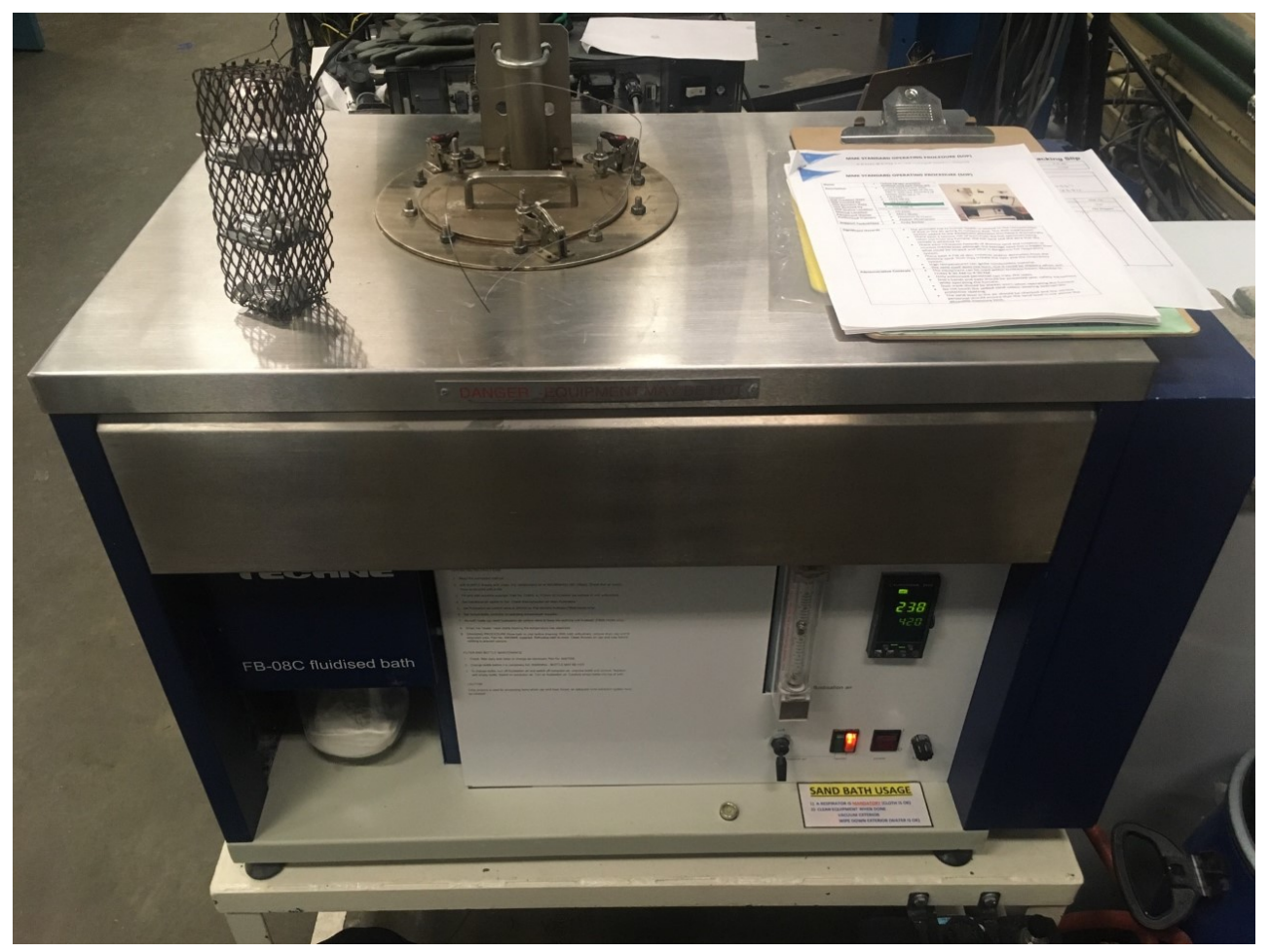

Figure 4.6: The fluidized alumina powder bath, and wire-mesh cage, used for homogenization treatment. 


\subsection{Uniaxial Compression Testing}

\subsubsection{Sample Geometry and Extraction from Starting Material}

From the wedge castings, samples of $15 \mathrm{~mm}$ height and $10 \mathrm{~mm}$ diameter were extracted from the vertical locations corresponding to thermocouples 4 and 7 , as seen in Figure $4.7 \mathrm{a}$. The surface finish was left as-machined, and the sample dimensions were controlled to $\pm 0.02 \mathrm{~mm}$. In the case of the cylinder castings, samples of the same dimensions and tolerances were extracted from locations at a radius of 0.75 " (approximately $19 \mathrm{~mm}$ ) shown in Figure 4.7b, corresponding to the approximate radial location of the thermocouples during casting.
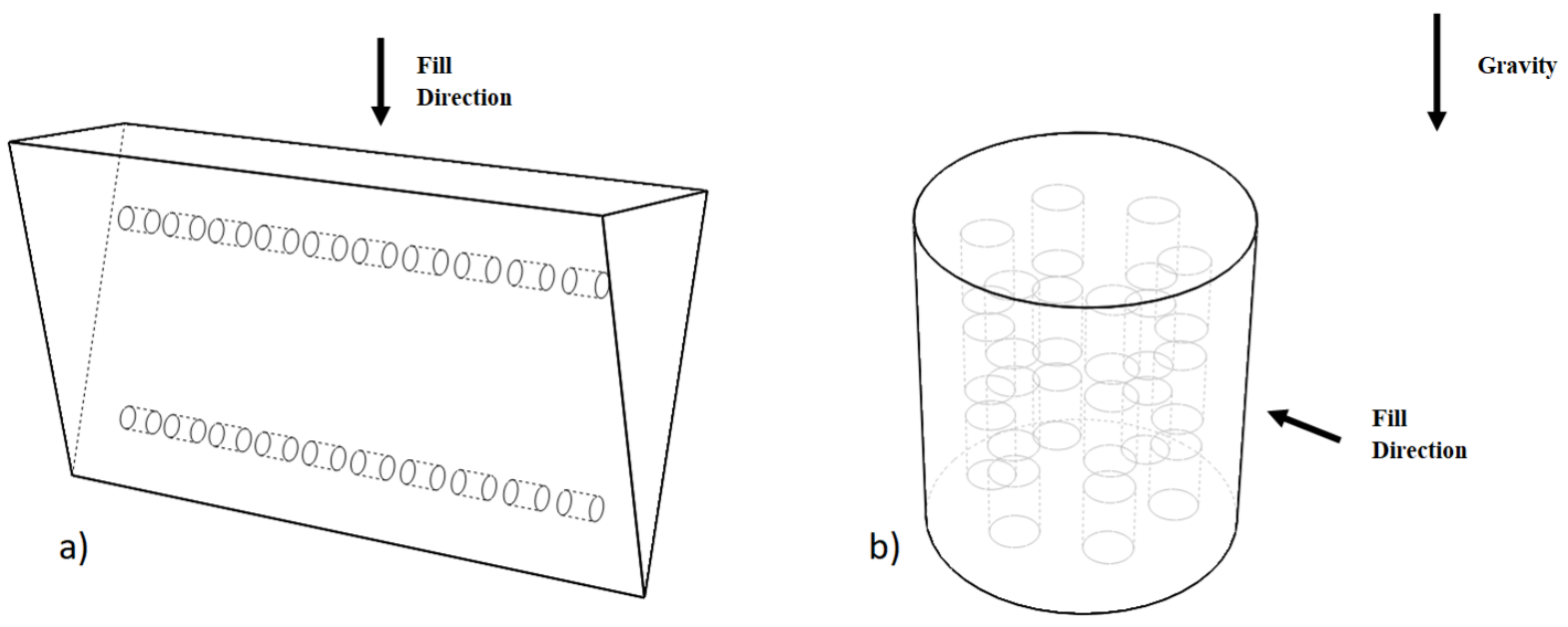

Figure 4.7: Compression sample extraction from the a) wedge casting and b) cylinder casting.

\subsubsection{Testing Procedure}

Compression tests were conducted on a Gleeble 3500 Thermal-Mechanical Process Simulator, available at the University of Waterloo. The Gleeble 3500 allows a maximum heating rate of $10,000^{\circ} \mathrm{C} / \mathrm{s}$, a maximum stroke rate of $1000-2000 \mathrm{~mm} / \mathrm{s}$, a maximum stroke of $100 \mathrm{~mm}$, and a maximum load of $100 \mathrm{kN}$. Sample temperature is controlled by a k-type thermocouple, which measures the potential difference between $\mathrm{Ni}-\mathrm{Cr}(+)$ and $\mathrm{Ni}-\mathrm{Al}(-)$ wires, 
for operating temperatures between 0 and $1250^{\circ} \mathrm{C}$. Both wires were spot-welded to the center of the sample, approximately $3 \mathrm{~mm}$ apart. Prior to testing, a sample was prepared with thermocouples at each end of the sample, as well as the center of the sample, to ensure the entire sample is of uniform temperature. At the maximum test temperature of $350^{\circ} \mathrm{C}$, the temperatures at each end and the sample center deviated no more than $\pm 3^{\circ} \mathrm{C}$. During testing, samples were heated at a rate of $5^{\circ} \mathrm{C} / \mathrm{s}$. Once the target temperature was reached, samples were held for 10 seconds prior to compression, to remove any thermal gradients. In all tests, strain, and thus the strain rate, was controlled by use of a linear potentiometer. The load was measured using a $100 \mathrm{kN}$ load cell which is internal to the Gleeble. Samples which were to be analyzed by optical microscopy following compression testing, were quenched to room temperature by spraying with water for 5 seconds immediately following the test, to preserve any microstructure features that may be lost during slow cooling.

Each test output a data file which reported the test time, force, linear position/displacement, program temperature, sample temperature, stress and strain. The stress and strain are not measured, but instead calculated based on the recorded force and position data with the standard formulae in equations 4.1 and 4.2 .

$$
\begin{gathered}
\sigma=\frac{F}{\frac{\frac{\pi\left(d_{0}\right)^{2}}{4} L_{0}}{L_{0}+\Delta L}} \\
\varepsilon=\ln \frac{L_{0}+\Delta L}{L_{0}}
\end{gathered}
$$

The strain that is output is the true strain, and the stress that is output is the true stress, which has been corrected for diametral expansion based on volume conservation, accounting for an idealized proportional increase in diameter with a reduction in height (uniform deformation). A plot of the measured load and stroke data is shown in Figure $4.8 \mathrm{a}$, alongside the calculated values for true stress and true strain in Figure 4.8b.

The lubricant that was used between the sample and the anvils was a nickel-based antiseize lubricant. The nickel-based anti-seize was found to be the most effective at reducing the interface friction when compared against the alternatively available lubricants; copperbased anti-seize, molybdenum di-sulphide grease, graphite, and no lubricant. This was 


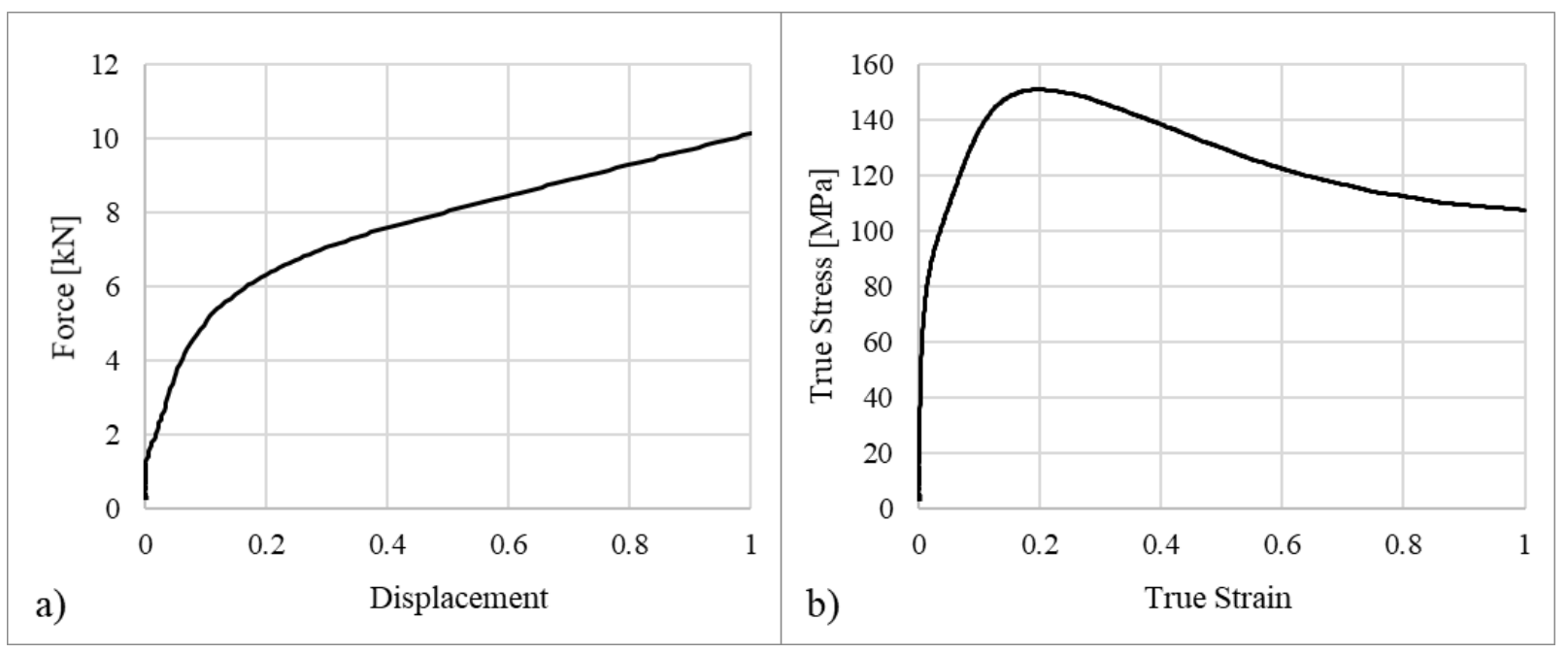

Figure 4.8: Plots showing the measured data for a) force and displacement, and calculated values for b) true stress and true strain.

based on a comparative analysis of the ideal diameter (i.e. by volume conservation) and the measured maximum sample diameter (in the center of the sample) during compression. Samples with a higher maximum diameter relative to the ideal diameter would have experienced more interface friction, causing more diametric expansion at the sample center than at the interface.

Accurate data from these tests is required as an input to a forging simulation software, DEFORM3D. As machine deceleration often causes an inconsistent strain rate when approaching the final strain, samples were compressed to a true strain of 1.05 such that accurate data could be obtained at the strain of 1.0.

\subsubsection{Correction Methods}

Despite the use of an effective lubricant, the friction at the sample-anvil interface cannot be fully eliminated. While the Gleeble software outputs the stress with a correction for the diametric expansion, it does not correct for the effects of interface friction on the nonuniformity of the sample's diametric expansion (referred to as barreling). The friction at the interface causes a resistance to expansion of material near the anvil, while the material in the sample center expands without this resistance, causing the sample to appear barrelshaped. Since the sample has expanded more in the center than at the ends, the "true 
stress" calculated by the Gleeble software will be calculated of an ideal (and smaller) cross-sectional area, resulting in a larger output stress reading than what is true of the test. Correction for this is done using Hill's friction correction method, where the final maximum barrel diameter and final height of the sample are used to determine a constant friction factor, which is applied to the true stress that is output from the Gleeble. This correction has been described in the literature [67, 68, 69]. While the sample temperature is accurately controlled during testing, higher strain rate test conditions often result in very rapid sample heating, where the machine is unable to correct in time. In this case, the data will require stress correction for this increase in temperature, since higher temperatures will require less load to deform the sample. The method used to correct for temperature was applied to the data which had been already corrected for friction. Shown in Figure 4.9 are data for the as-calculated (uncorrected) stress, stress that was corrected for friction only, and stress that was corrected for an increase in temperature following the friction correction. The

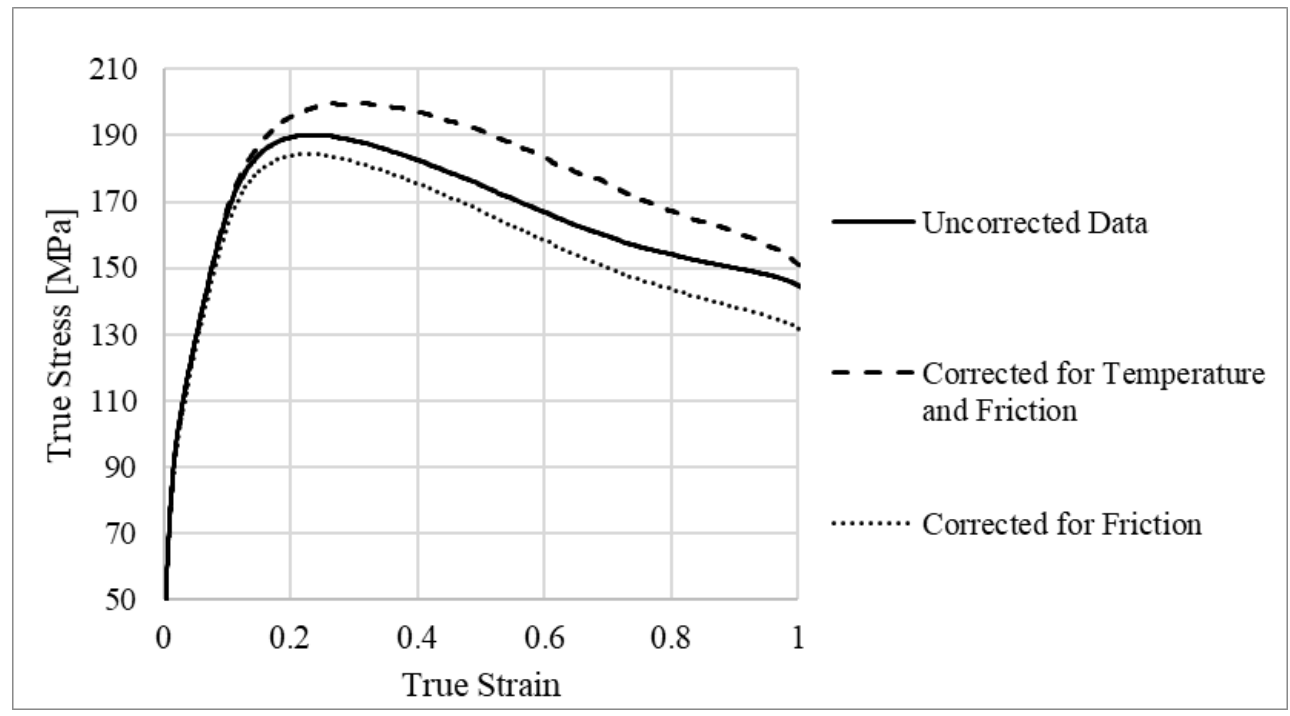

Figure 4.9: True stress-true strain curves of the uncorrected data, data with friction correction, and data with both friction and temperature correction.

temperature correction method uses a linear regression analysis to determine the rate of change of stress with increase in temperature, which is used in conjunction with the target temperature, actual temperature, and recorded stress, to determine what the representative stress will be. This method is described in detail by Luan et al.[70], and in this research was applied to any sample which had been compressed with a strain rate of 1.0. Samples tested at lower strain rates did not increase in temperature during deformation, and therefore did 
not require this correction to be applied. Corrections were only applied to wedge cast flow curves (as-cast and degas), where the data is used for the forging simulations necessary to develop the optimal pre-form shape. All other flow curves were not corrected in this work, as they were only used for comparison (cylinder cast material, and all homogenized material).

\subsection{Characterization}

\subsubsection{Optical Metallographic Sample Preparation}

Samples prepared for metallography were cold mounted in a 2-part fast curing Leco brand epoxy. Grinding to achieve a flat surface and remove excess epoxy was done using a belt sander, with a grit size of 240. Further coarse grinding was done by hand under flowing water on sandpaper with grit sizes of 400, 600, and 800, each time alternating the direction of sanding by $90^{\circ}$, and sanding until all of the visible scratches were unidirectional. Further grinding was done on a 1200 grit size sandpaper, using a Struers LaboPol-2 autopolisher with LaboForce-1 sample holder cross-head, with a force of $20 \mathrm{~N}$ and a rotational speed of 250RPM. A final fine grinding step was performed on the auto polisher, using a MD Largo grinding disc and a $9 \mathrm{um}$ diamond suspension, rotating at a speed of 250RPM, using $20 \mathrm{~N}$ of force on each sample, until the surface scratches were uniform. Following this were the polishing steps. The first polishing step used a $3 \mu \mathrm{m}$ diamond suspension on a MD Nap polishing pad, with additional DP-Lubricant Blue, a rotational speed of 250RPM, and 20N of force on each sample, for a time of 5 minutes. The second polishing step used a $1 \mu \mathrm{m}$ diamond suspension on a MD Nap polishing pad, with additional DP-Lubricant Blue, a rotational speed of $250 \mathrm{RPM}$, and $15 \mathrm{~N}$ of force on each sample, for a time of 5 minutes. Final polishing was done using a colloidal silica polishing medium, on a MD Chem polishing pad, a rotational speed of $250 \mathrm{RPM}$, using $5 \mathrm{~N}$ of force on each sample, for a time of 1 minute.

The etchant used to reveal the microstructure of this alloy for optical microscopy was a picric/acetic acid mixture, including $90 \mathrm{ml}$ Ethanol, $10 \mathrm{ml}$ acetic acid, and $5 \mathrm{~g}$ of picric acid. Etching times were approximately 5-10 seconds.

\subsubsection{Metallography Analysis and Quantification}

Since the microstructure of AZ80 is dendritic in structure and consists of approximately $11-12 \%$ by volume of the $\gamma-\mathrm{Mg}_{17} \mathrm{Al}_{12}$ phase [11], secondary dendrite arm spacing measure- 
ments are the preferred quantification method, as there can be no interference of the second phase, as often occurs when using the average grain size measurement techniques outlined in ASTM E112 [71]. The methods used for secondary dendrite arm spacing measurements were two variations of the linear intercept method, described in a comparative paper by Vandersluis and Ravindran [72] where both the average secondary dendrite arm spacing over " $n$ " consecutive arms, as well as individual arm spacing, was considered. This was done to increase the number of dendrites which could be measured, due to a shortage of consecutive and visible dendrite arms. Measurements were taken on the images using Image J analysis software, with the number of pixels in each $\mu \mathrm{m}$ was calibrated to the image scale bar. Despite the use of these two methods, obtaining a high number of secondary dendrite arm spacing measurements was difficult due to the coarse grains found within the low cooling rate castings. Further, cylinder cast material was more equiaxed, prohibiting dendrite spacing to be measured, therefore grain size measurements were also performed using the Heyn linear intercept method, described in [71]. A sufficiently long line was drawn across the image and the number of intersecting grains was counted, using optical images taken at a magnification of 50X. An example of these measurement techniques is shown in Figure 4.10, though the grain size example in Figure 4.10b is shown as a much smaller line on a higher magnification image for the sake of legibility.
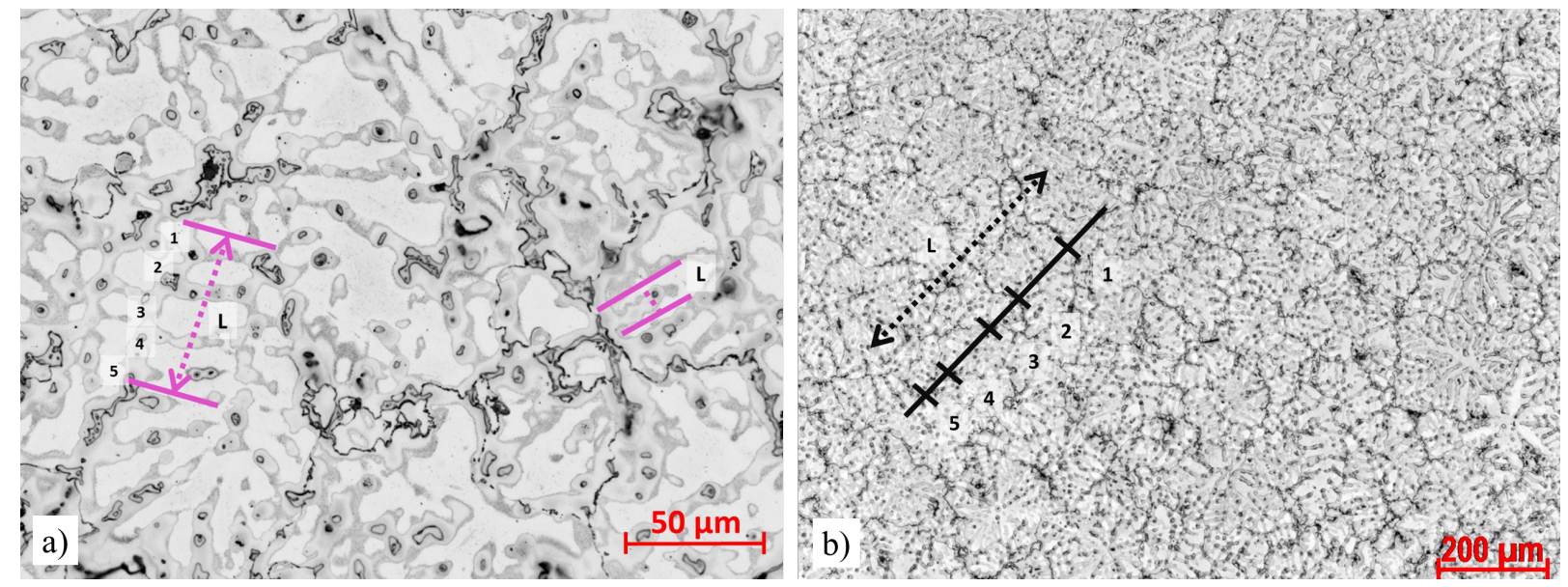

Figure 4.10: An example showing the methods used to measure a) SDAS and b) grain size.

To estimate the porosity volume fraction within the samples, a 2D area fraction of porosity was measured using ImageJ software. Samples were first prepared as described in Section 4.3.1, though were imaged prior to etching. The images were then measured for $2 \mathrm{D}$ area 
based on brightness; whereby very dark areas of the image represented voids in the material. An example of the selection of pore area by brightness is shown in Figure 4.11. A similar method was used to estimate the percentage of grains which had recrystallized

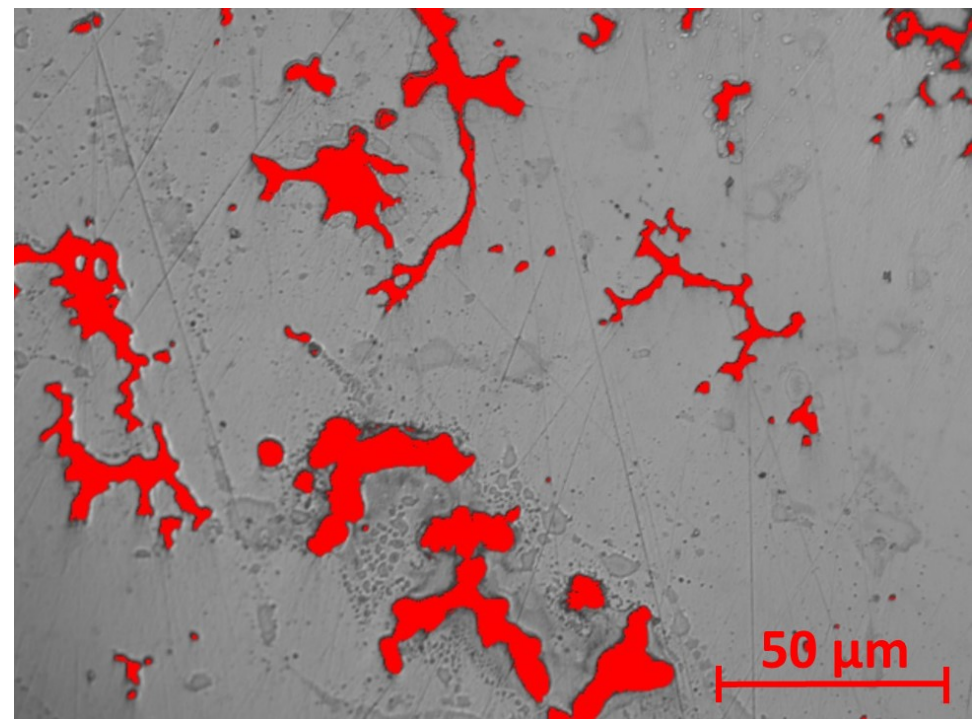

Figure 4.11: The voids within a polished sample selected for area fraction measurement.

in deformed samples. Because of the many grain boundaries that accompany the fine recrystallized grains, the recrystallized grains appeared darker than the un-deformed grains in low magnification optical microscopy images, and therefore could be filtered using the same technique. An example of how this analysis was performed is shown in Appendix C.

\subsubsection{Thermodynamic Property Measurements}

The liquidus and solidus temperatures of the alloy were measured through use of a Universal Metallurgical Simulator and Analyzer (UMSA) at CanmetMATERIALS. The measurement was performed on samples that were solid, hollow, and thin-walled hollow (for high cooling rates only). All samples were heated to $700^{\circ} \mathrm{C}$ and held for 300 s, before cooling by both natural cooling and quenching. The fraction solid at a given temperature could only accurately be determined on the tests with a slow cooling rate, namely the solid sample under natural cooling conditions. Similarly, the solidus and liquidus temperatures were determined for only samples that were solidified with natural cooling rates. For the hollow sample under natural cooling, the liquidus and solidus temperatures were found to be 
$609^{\circ} \mathrm{C}$ and $414^{\circ} \mathrm{C}$, respectively. For the solid sample under natural cooling, the liquidus and solidus temperatures were found to be $606^{\circ} \mathrm{C}$ and $419^{\circ} \mathrm{C}$, respectively.

The melting temperature of the $\gamma-\mathrm{Mg}_{17} \mathrm{Al}_{12}$ phase was determined using Differential scanning calorimetry (DSC). The measurement was performed on a Netzsch DSC 404 C. Prior to measurement, calibration was completed for pure metals of Iridium, Tin, Aluminum, Silver, and Zinc, with respective masses of $9.8 \mathrm{mg}, 8.6 \mathrm{mg}, 5.9 \mathrm{mg}, 9.8 \mathrm{mg}$ and $7.0 \mathrm{mg}$, using an aluminum oxide crucible for both the sample and the reference crucibles. Before each test is run, the machine is cycled with Argon gas three times. The samples were heated to $100^{\circ} \mathrm{C}$ above their melting temperature, at a rate of $10^{\circ} \mathrm{C}$ each minute, prior to cooling to a temperature $100^{\circ} \mathrm{C}$ below their melting temperature, at a rate of $20^{\circ} \mathrm{C}$ each minute. To prevent inconsistent surface contact effects between the sample and the crucible, the heating cycle was repeated 3 times, using the average recorded enthalpy of only the second and third repetition for calibration. The sample crucible had a mass of $329.5 \mathrm{mg}$, and the reference crucible, which was empty for calibration tests, had a mass of $335 \mathrm{mg}$. Tests were completed in a medium of ultra-high purity, grade 5.0, argon gas, flowing through the chamber at a rate of approximately $150 \mathrm{Nml} / \mathrm{min}$. Prior to testing, the calibration was checked against a $16.9 \mathrm{mg}$ Aluminum sample which was run in a $326.7 \mathrm{mg}$ sample crucible. The average onset melting temperature over 2 measurements was within $0.5^{\circ}(<0.1 \%)$, with each individual measurement within $1 \%$ of the target. The average enthalpy over 2 measurements was within $4 \mathrm{~J} / \mathrm{g}(<1 \%)$, with each individual measurement within $2 \%$ of the target. Test samples were prepared for DSC as small cylinders of $5 \mathrm{~mm}$ diameter and $3 \mathrm{~mm}$ in height, machined to a tolerance of $\pm 0.02 \mathrm{~mm}$. Sample mass was recorded prior to each measurement, and aluminum oxide crucibles were used for the sample and reference crucibles. Analysis for melting temperature measurement was only conducted on the heating cycles, since a cooling cycle will have had a change in microstructure once the phases have melted and solidified again. A maximum temperature of $500^{\circ} \mathrm{C}$ was used, to prevent damage to the crucible through sample ignition or melting.

\subsubsection{Electrical Conductivity}

Measurements of electrical conductivity were used to verify that the $\gamma-\mathrm{Mg}_{17} \mathrm{Al}_{12}$ phase was solutionized during homogenization treatment. Conductivity was measured using a Foerster Sigmatest 2.069. The instrument was calibrated using two standard samples: $100.9 \%$ IACS $(58.5 \mathrm{MS} / \mathrm{m})$, followed by $7.610 \%$ IACS $(4.414 \mathrm{MS} / \mathrm{m})$. Each sample was measured twice, once on each side of the sample, and an average value was taken to be it's conductivity. 


\subsection{Casting Experiment Simulation}

Of the available casting simulation software, the ProCAST software was selected, due to its capability to simulate a variety of casting processes.

\subsubsection{Simulation Setup and Procedure}

To ensure validity of the wedge casting experiment results, a thermofluidic simulation software, ProCAST, was used to model the experiment. The wedge casting model was built to closely replicate the water-cooled mold used during casting, where possible. 3-D models of the mould were imported into the software, using a mesh size of 3mm. Figure 4.12 shows an exploded view of the wedge mould components.

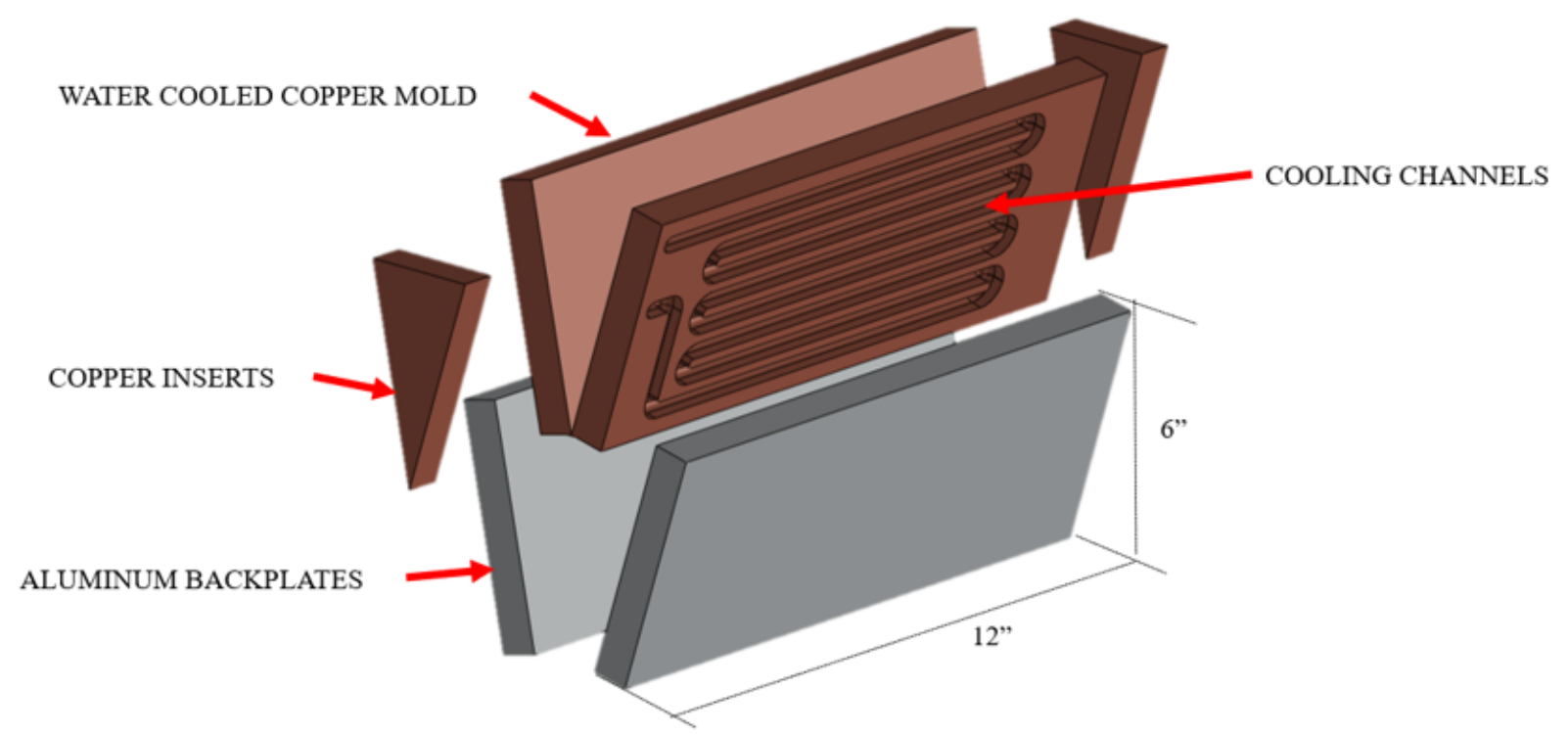

Figure 4.12: An exploded view of the wedge mould components used in the ProCAST model.

The average pour-rate was estimated based on the volume of the casting and the observed pour time, and was found to be $300 \mathrm{~g} / \mathrm{s}$. Similarly, the inlet liquid diameter was estimated as $20 \mathrm{~mm}$ diameter, based visually on what was seen during casting. A boron-nitride mould coating was used on the sides of the copper mould, which was modelled to be $100 \mu \mathrm{m}$ in 
thickness in the simulation. The heat transfer through the water cooling channels was a software pre-set, with a heat transfer coefficient of $5000 \mathrm{~W} / \mathrm{m}^{2} \mathrm{~K}$ and a temperature of $20^{\circ} \mathrm{C}$. The temperature dependent properties used for each of the mould components were included in the software's material database, including H13, 6061 aluminum, and water. The software did not however have AZ80, but through using the built-in Computherm thermodynamic database, the thermal properties could be obtained. Computherm requires the chemical composition, and selection of a solid diffusion model from the Scheil, lever, back diffusion, or multiple solidification models. The liquidus and solidus temperatures of AZ80 were calculated to be $607^{\circ} \mathrm{C}$ and $423^{\circ} \mathrm{C}, 607^{\circ} \mathrm{C}$ and $496^{\circ} \mathrm{C}$, and $607^{\circ} \mathrm{C}$ and $412^{\circ} \mathrm{C}$, using the Scheil, Lever, and Back Diffusion methods respectively. The UMSA test reported $606^{\circ} \mathrm{C}$ and $419^{\circ} \mathrm{C}$ for natural cooling of a solid sample, which most closely matches the Back Diffusion model. For the fraction solid as a function of temperature, however, the Scheil method most closely matched what was seen in the UMSA results. Therefore, the thermodynamic properties used in the casting simulation model were initially calculated by the Scheil method, though the fraction solid (and thus the liquidus and solidus temperatures) were replaced with data from the solid natural cooling UMSA test, described in Section 4.3.3. The remaining temperature dependent properties of conductivity, density, specific heat, and viscosity, were therefore calculated by the Scheil method, based on the measured compositions reported in Section 4.1 .

\subsubsection{Boundary Conditions}

Both software pre-set and calculated heat transfer coefficients were used at material interfaces within the model. The software included many mould combination heat transfer coefficients, coefficients for air and water cooling, and die coating coefficients, which were used in the model. Much like the material properties for AZ80, there was no heat transfer coefficient between AZ80 and the H13 mould. Further, any of the combination heat transfer coefficients did not account for the air gap formation caused by the thermal contraction that occurs during solidification, as described in Section 2.4. Therefore, the interface heat transfer coefficient had to be calculated between the cast part and the mould. Since the air gap formation at the part-mould interface is dependent on thermal contraction, it will vary with part thickness and part temperature. Because of this, and the non-constant thickness of the wedge, the wedge mould model required differing heat transfer coefficients along its height. This was accomplished by partitioning the mould surface where it will contact the wedge and giving each partition its own heat transfer coefficient. The heat transfer coefficient that was used was a combination of two heat transfer models for the air gap formation in casting, proposed by Nishida et al. [61] and Sengupta et al. [63]. The work 
by Nishida et al. proposed that the heat transfer coefficient can be modelled as conduction through the air in the gap, where the gap width was proportional to the part temperature and the part thickness, through contraction. The model proposed by Sengupta et al. combined the heat transfer through the air gap with heat transfer by conduction, by a proportion based on the fraction solid, which was assumed to vary linearly from liquidus to solidus temperature. When the material is fully liquid, the heat transfer is based on contact only (proposed to be between $1000-2000 \mathrm{~W} / \mathrm{m}^{2} \mathrm{~K}$ ), and when it has solidified it is based only on the air gap conduction (proposed to be between $50-200 \mathrm{~W} / \mathrm{m}^{2} \mathrm{~K}$ ). In this work, the Sengupta et al. model was used, but the air gap conduction model by Nishida et al. was used as the air gap heat transfer, instead of the proposed estimate. The heat transfer coefficient for the contact heat transfer was selected to be $1500 \mathrm{~W} / \mathrm{m}^{2} \mathrm{~K}$. The model was divided into 14 vertical partitions, each with its own air gap heat transfer coefficient. The thermal contraction was calculated using the distance from the center of the partition to the center of the wedge, and the temperature at the surface of the part in contact with the center of the partition. The updated model with the partitions can be seen in Figure 4.13

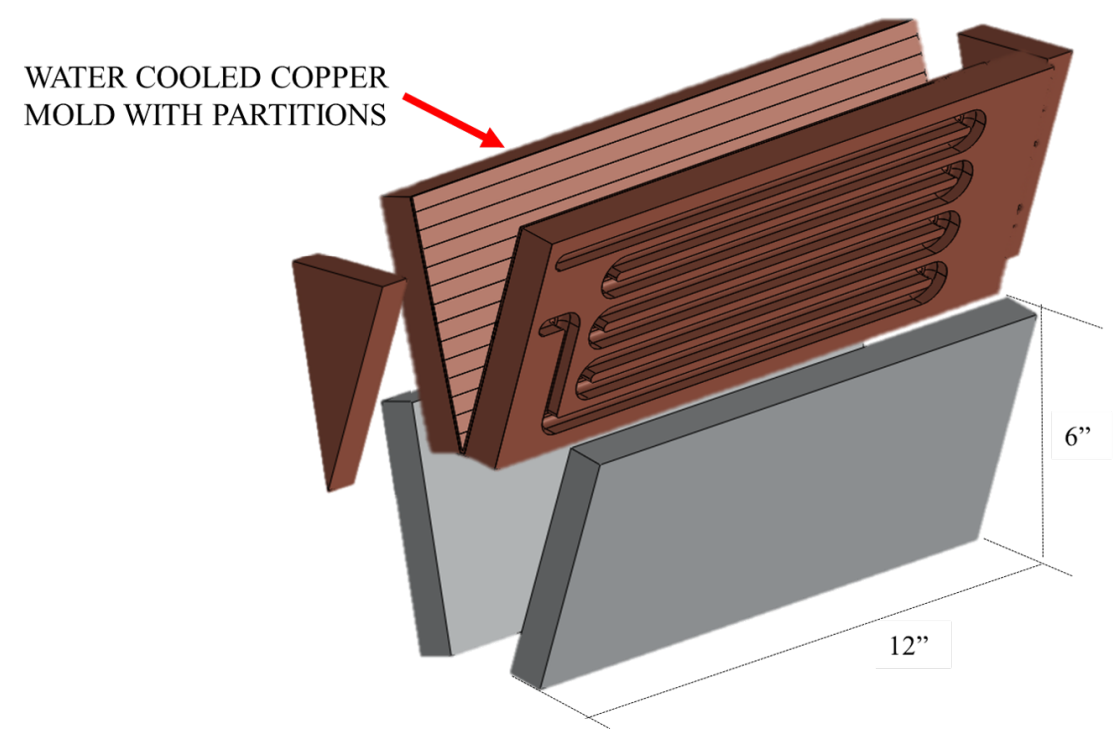

Figure 4.13: An exploded view of the wedge mould components used in the ProCAST model, including the partitions for variable heat transfer coefficient calculation.

An example of a calculated heat transfer coefficient from the center-most vertical partition, plotted as a function of interface temperature, is shown in Figure 4.14. Heat transfer 
coefficients of other partitions were similar in nature, though would vary depending on the width of the wedge perpendicular to the partition.

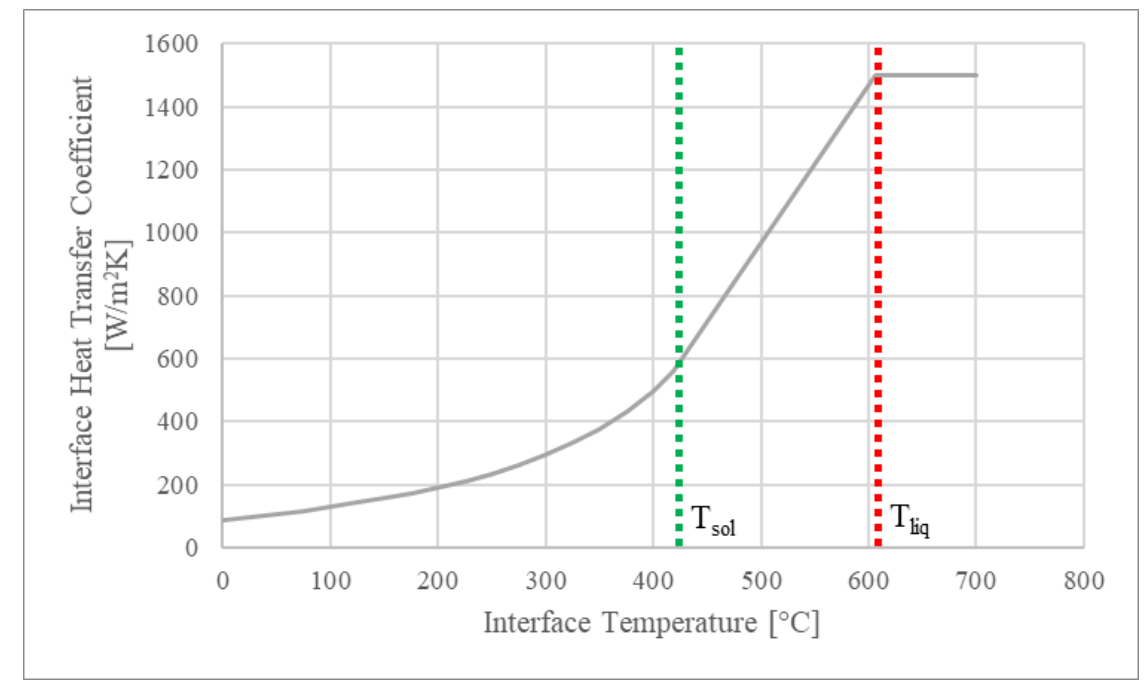

Figure 4.14: The interface heat transfer coefficient, as a function of interface temperature, for the center partition of the wedge mould simulation, with liquidus and solidus temperatures labelled.

\subsection{Permanent Mould Development}

To study the forging behaviour on a larger scale, I-beams were forged from cast cylinders. The cylinders needed to be sized to fit the forging die, requiring a diameter of $63.5 \mathrm{~mm}$ and a height of $70 \mathrm{~mm}$. As in the wedge casting, different cooling rates were required to study the effect of cooling rate on forging behaviour and final microstructure. Therefore, a cylinder casting mould was required that could produce the required geometry with high and low cooling rates, which was achieved through water cooling and air cooling, respectively.

The cylinder casting mould was developed iteratively using ProCAST simulations, until a desirable result was shown. Since ProCAST had modeled the wedge casting process reasonably well, it was used as a tool for developing the new mould, so long as similar initial and boundary conditions were used. Since the wedge casting process had been gravity poured using a hand ladle, it was decided to use a similar pouring process for the cylinders. 
The mould was designed as two symmetric halves, with the parting line directly along the length of the cylinder, allowing easy separation after casting. Like the wedge casting, to achieve a higher cooling rate, cooling channel backplates were designed. The backplates were made of $25.4 \mathrm{~mm}$ (1") thick alumunum, with $12.7 \mathrm{~mm}\left(0.5^{\prime \prime}\right)$ deep water channels cut into them. To reduce the amount of waste, it was desirable to have 4 cylinders out of each casting, meaning the mould itself must be rather large. The large mould also meant that distortion was a risk during repeated heating and cooling, therefore the mould was designed with $18 \mathrm{~mm}$ of material between the edge of the mould cavity and the edge of the mould. Since a relatively high pour rate was desired, much turbulence was expected. To remedy this, a web gate was used, to restrict the flow of highly turbulent liquid into the cylinder cavity, allowing only laminar part filling. The ProCAST model was compiled using similar parameters to those that were found reasonably valid through modelling of the wedge casting process. This includes the heat transfer coefficient between the cylinder and the mould, which was re-calculated to match the cylinder geometry. Most of the modifications in each iteration focused on achieving the desired cooling rate based on mould thickness (i.e. proximity of part center to the cooling channels), while maintaining a thick enough mould for rigidity. A similar pour rate to what was estimated after the wedge casting process was predicted, allowing proper sizing of the sprue and runner/gate system of the mould. Several iterations were required to prevent cold-shuts and improve flow into the cylinders to reduce turbulence: particularly in the gate region. Cold shuts were commonly seen in early revisions of the mould with the water cooled condition, since the mould was at a low enough temperature to promote rapid material solidification. The final mould design and resulting cast part is shown in Figure $4.15 \mathrm{a}$ and b, with all features labelled.
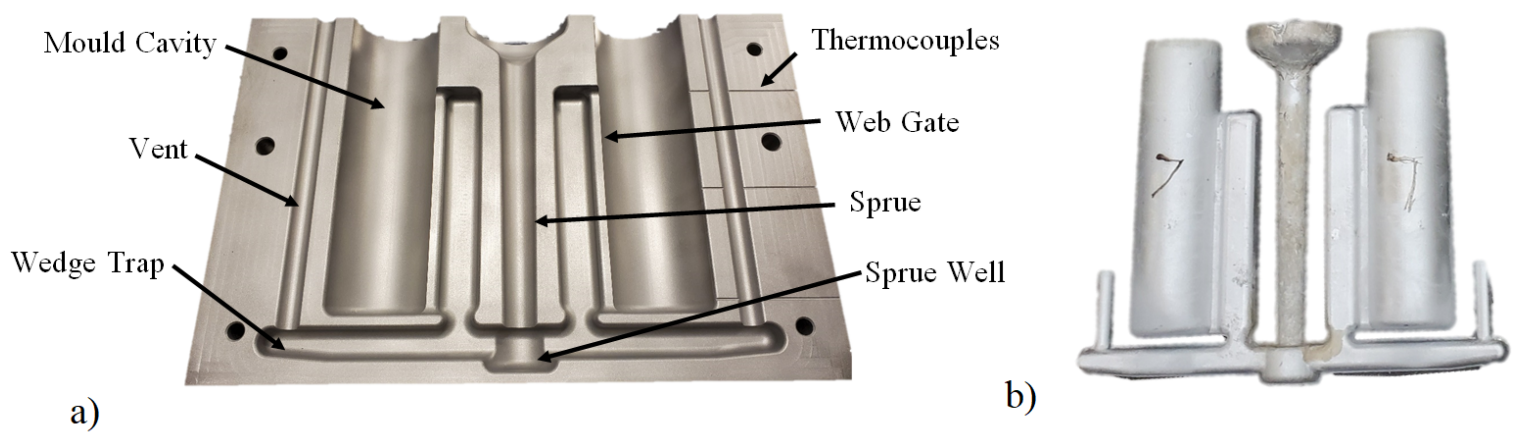

Figure 4.15: Details of the final mould design including a) the mould itself with important features labelled and b) the resulting cast part from the mould. Images courtesy of Peter Newcombe at CANMETMaterials. 


\section{Results and Discussion}

\subsection{Cast Microstructure}

\subsubsection{Effect of Cooling Rate}

The microstructure effects of cooling rate during casting solidification were studied using material from the wedge casting process, at thermocouple locations 4 and 7 , as described in Section 4.1.1. As shown in Figure 5.1, both locations have a microstructure which is dendritic, though the structure becomes more equiaxed with a lower cooling rate.
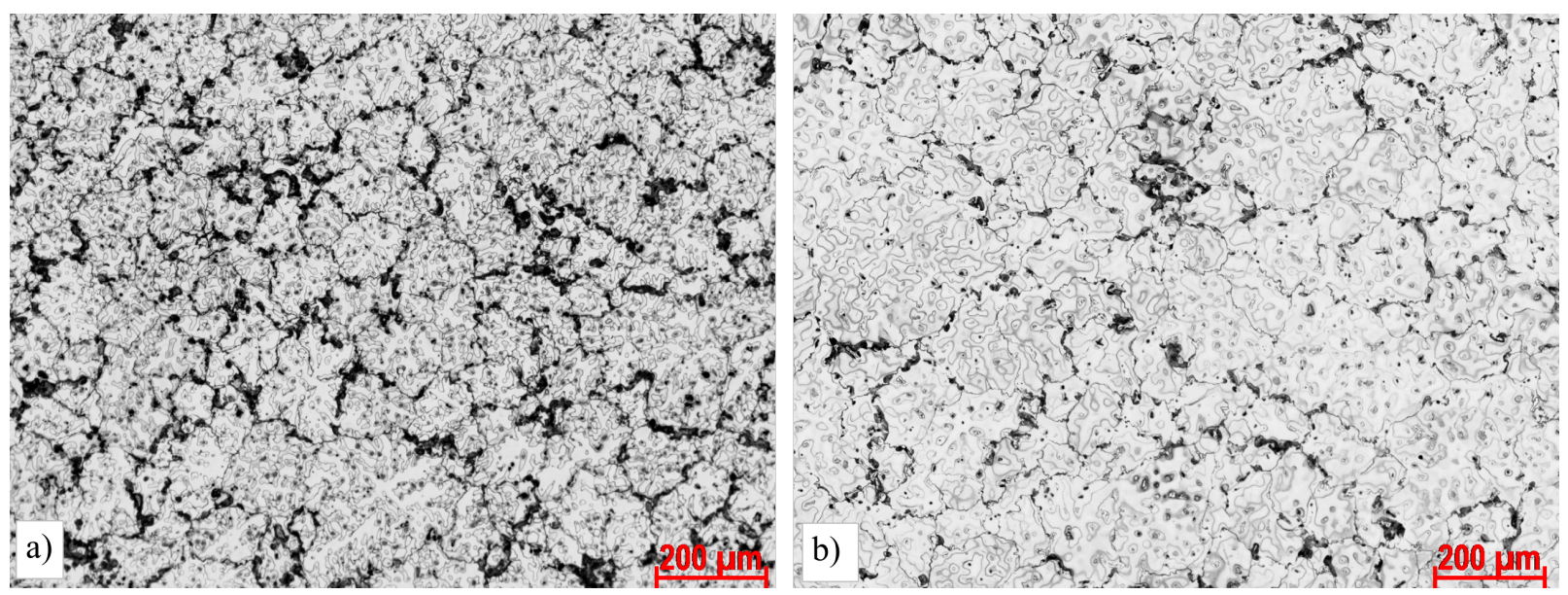

Figure 5.1: Optical microstructure of wedge cast AZ80: a) High cooling rate (HCR), and b) Low Cooling Rate (LCR).

At higher magnifications, as shown in Figure 5.2 , the eutectic morphology is clearer and can be characterized. The as-cast HCR microstructure in Figure $5.2 \mathrm{a}$ shows a partially divorced eutectic morphology, where the $\gamma-\mathrm{Mg}_{17} \mathrm{Al}_{12}$ phase is not fully separated from the $\alpha$-Mg phase. The structure contains a high amount of discontinuous and continuous, or lath, $\gamma-\mathrm{Mg}_{17} \mathrm{Al}_{12}$ precipitates, along the grain boundaries. The as-cast LCR microstructure also is of a partially divorced eutectic morphology, which also contains both discontinuous and continuous precipitates. The LCR material appears to have more visible eutectic $\gamma$ $\mathrm{Mg}_{17} \mathrm{Al}_{12}$ than the HCR material, however, there does appear to be more $\mathrm{Mg}_{17} \mathrm{Al}_{12}$ phase in the HCR material, which is consistent with the literature [41]. There is quite extensive 
porosity present in the as-cast LCR material, which will be quantified in a later section. Some of this porosity may be visible as round, dark areas in Figure 5.2, though it is unclear by these images if this is in fact porosity or another particle.
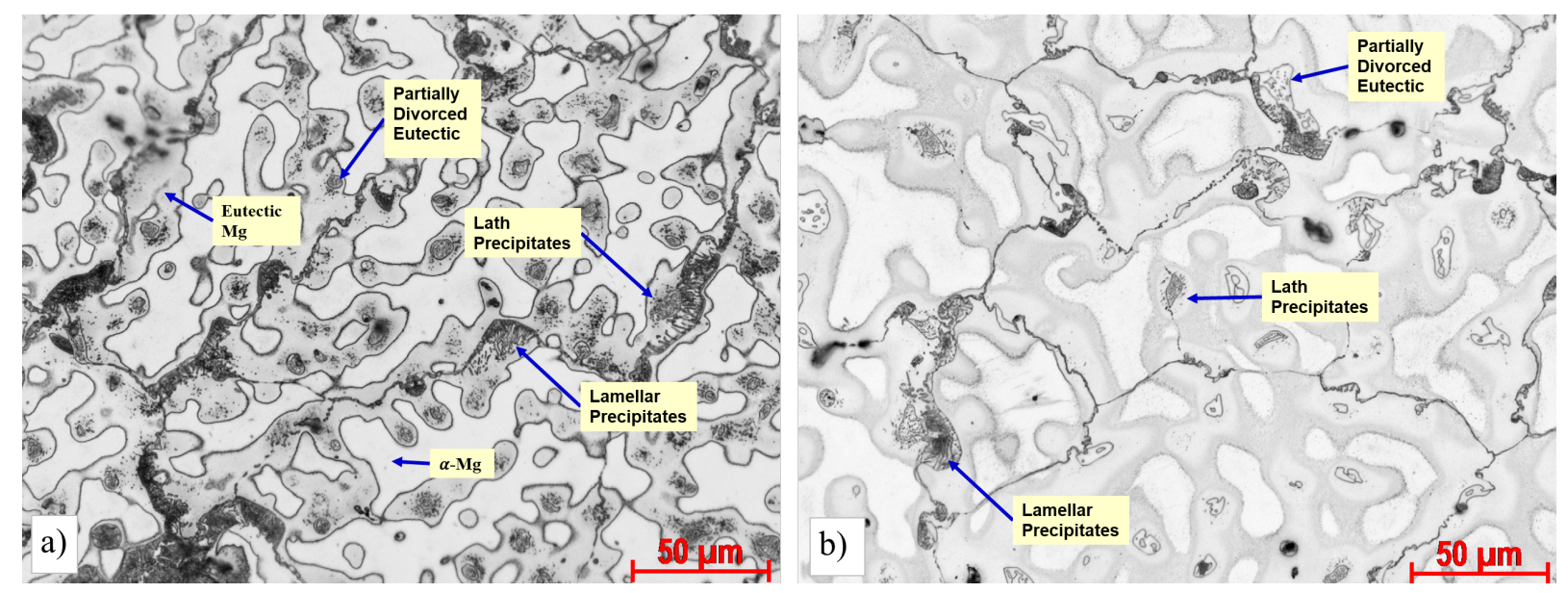

Figure 5.2: Optical microstructure of wedge cast AZ80: a) HCR, b) LCR, at higher magnification.

The effect of cooling rate on the microstructure of cast AZ80 is apparent. Material cast with a higher cooling rate will have a smaller secondary dendrite arm spacing (SDAS) and smaller grain size on average than material cast with a lower cooling rate. The measured SDAS and standard deviation for HCR and LCR wedge castings was found to be $17 \mu \mathrm{m}$ $\pm 4 \mu \mathrm{m}$ and $27 \mu \mathrm{m} \pm 4 \mu \mathrm{m}$ respectively, while the measured grain size and standard deviation was measured to be $119 \mu \mathrm{m} \pm 8 \mu \mathrm{m}$ and $201 \mu \mathrm{m} \pm 25 \mu \mathrm{m}$ respectively. While it has been shown in literature that material cast with a higher cooling rate will have a more divorced microstructure [10], this was not necessarily seen for these cooling rates. Since this material was cast with a wedge casting process however, this is likely explained by the material closer to the bottom of the wedge (i.e. the high cooling rate material) becoming re-heated as more liquid metal that is being poured on top, after it has been mostly solidified. This causes a slowing of the cooling rate in the HCR material below approximately $450^{\circ} \mathrm{C}$, shown in Figure 5.3 , likely providing the mechanism for diffusion and precipitation of the $\gamma-\mathrm{Mg}_{17} \mathrm{Al}_{12}$ phase. 


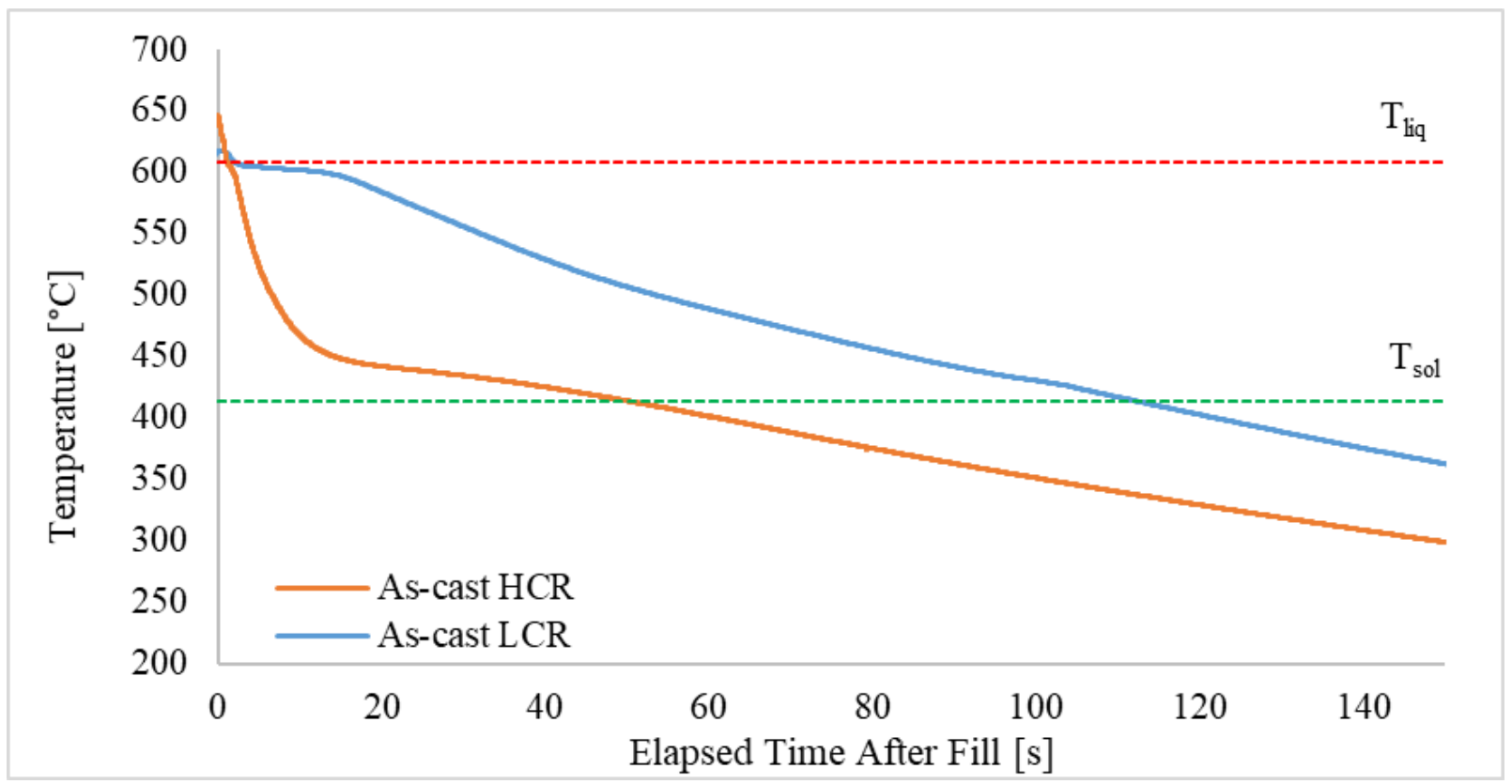

Figure 5.3: Temperatures recorded by thermocouple 4 (HCR) and thermocouple 7 (LCR) during solidification of the as-cast wedge casting, with measured liquidus $\left(\mathrm{T}_{\text {liq }}\right)$ and solidus $\left(\mathrm{T}_{\mathrm{sol}}\right)$ temperatures shown.

\subsubsection{Effect of De-gas Addition}

A similar microstructure comparison was done for the de-gassed material, with samples taken from thermocouple locations 4 and 7, corresponding to the HCR and LCR conditions. As in the as-cast material, the microstructure is dendritic, consisting of primary $\alpha-\mathrm{Mg}$ dendrites, surrounded by a eutectic consisting of secondary $\mathrm{Mg}$ and $\gamma-\mathrm{Mg}_{17} \mathrm{Al}_{12}$. A comparison of the as-cast and de-gas microstructures at 100x magnification is shown in Figure 5.4. The microstructures of the de-gas HCR and LCR samples have a measured SDAS of $16 \mu \mathrm{m} \pm 4 \mu \mathrm{m}$ and $27 \mu \mathrm{m} \pm 5 \mu$ respectively, and have a grain size of $127 \mu \mathrm{m} \pm 25 \mu \mathrm{m}$ and $193 \mu \mathrm{m} \pm 18 \mu \mathrm{m}$ respectively. This is understandably similar to the as-cast material, as they were both cast with a comparable cooling rate.

It appears in this figure that the de-gas microstructure has less of the $\gamma-\mathrm{Mg}_{17} \mathrm{Al}_{12}$ phase, shown by darker areas on the image. However, when viewing at a higher magnification of $500 \mathrm{x}$ as in Figure 5.5, there appears to be a similar volume fraction of the $\mathrm{Mg}_{17} \mathrm{Al}_{12}$ phase, only the morphology is different. While still only partially divorced, the de-gas HCR ma- 

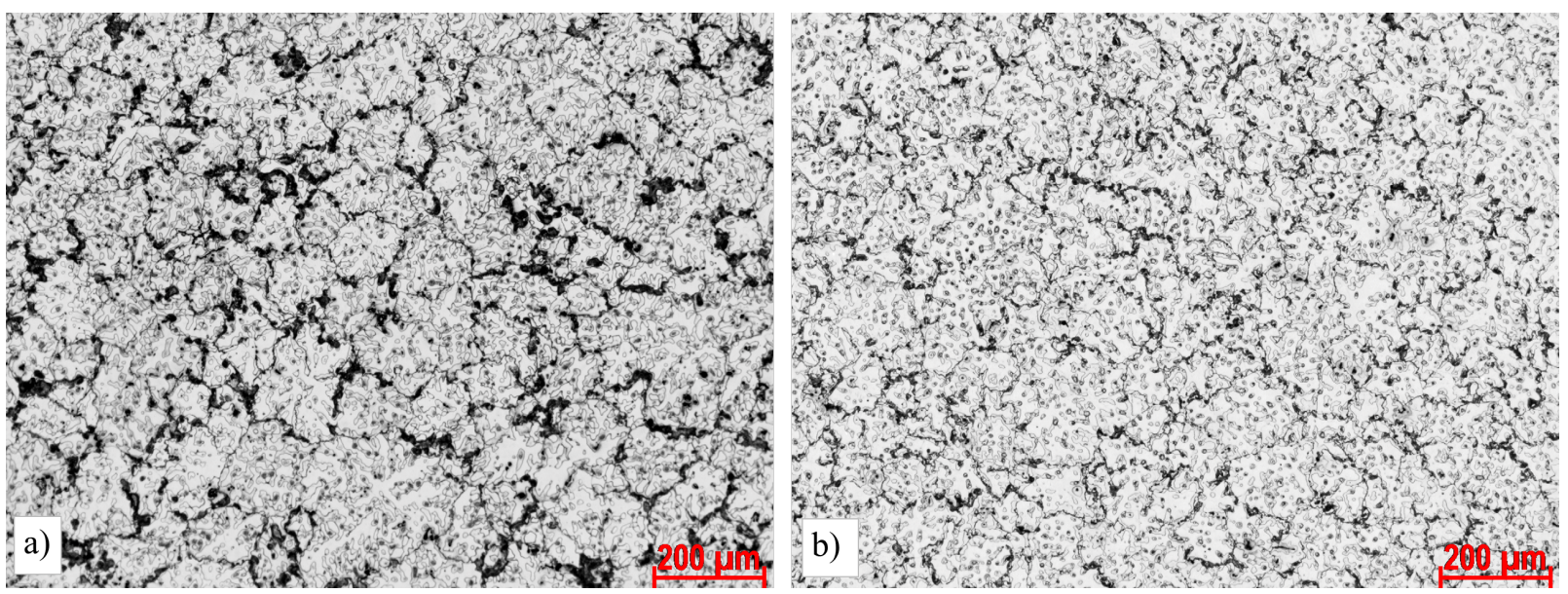

Figure 5.4: Optical microstructure of wedge cast AZ80 at high cooling rate: a) without addition of de-gas agent, b) with de-gas agent.

terial has a more highly divorced eutectic than the as-cast HCR material. This is shown by larger regions of isolated eutectic $\gamma-\mathrm{Mg}_{17} \mathrm{Al}_{12}$ phase in Figure 5.5b, where there are also fewer precipitates. The as-cast microstructure in Figure $5.5 \mathrm{a}$ shows very little isolated eutectic $\gamma-\mathrm{Mg}_{17} \mathrm{Al}_{12}$ phase, however a much higher fraction of precipitated $\gamma-\mathrm{Mg}_{17} \mathrm{Al}_{12}$.
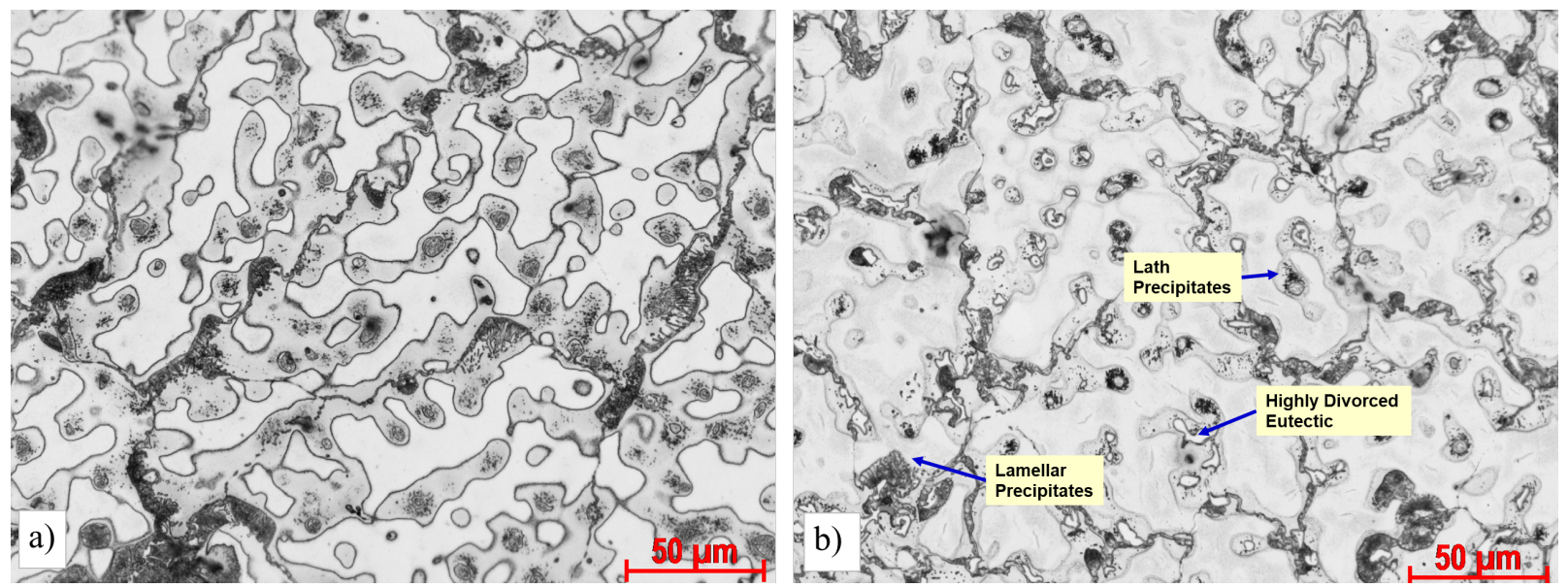

Figure 5.5: Optical microstructure of wedge cast AZ80 at high cooling rate: a) without addition of de-gas agent, b) with de-gas agent, at higher magnification. 
The reason behind this microstructure difference is not resulting from the addition of the de-gas agent. Instead, there appears to be a difference in how quickly each material was cooled during the later stages of solidification. While the cooling rates of the HCR samples are similar between as-cast and de-gas material for the initial stages of solidification, where the cooling rate was measured, the later stages of solidification show a much slower cooling rate in the as-cast material. This is shown in the cooling curves recorded by the thermocouples during solidification, in Figure 5.6. As described in the previous

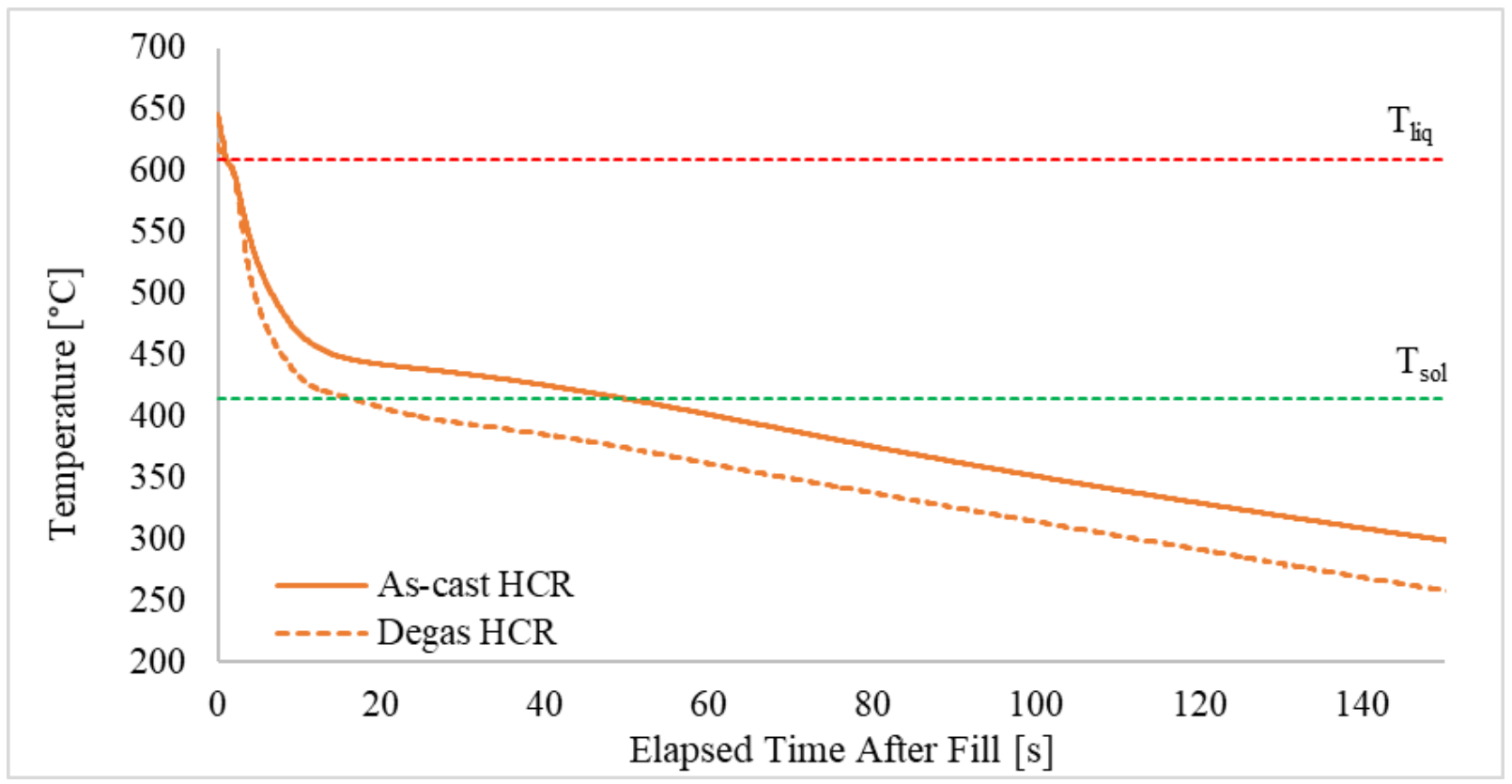

Figure 5.6: Temperatures recorded by thermocouple 4 during solidification for the wedge casting of as-cast and de-gas material.

section, this change of cooling rate is likely related to the re-heating of material during the wedge casting process. The difference between as-cast and de-gas wedges however may be explained by an inconsistent melt pour rate, since the pour rate was controlled manually by tilting of a pouring ladle. The de-gas material is thought to have been cast with a faster pouring rate, therefore the entire wedge will begin solidification more simultaneously, instead of some areas having time to solidify quickly before being re-heated by additional melt. Therefore, while the grain size is similar between both as-cast and de-gas HCR material, the difference in eutectic morphology that may be seen is due to this difference in late-solidification cooling rate. 
The intent of the de-gas addition was to reduce the gas porosity within the melt. The volume fraction of porosity was estimated using a 2-D area fraction. The results of the 2-D area fraction are shown in Figure 5.7. While the as-cast material only showed a fraction of

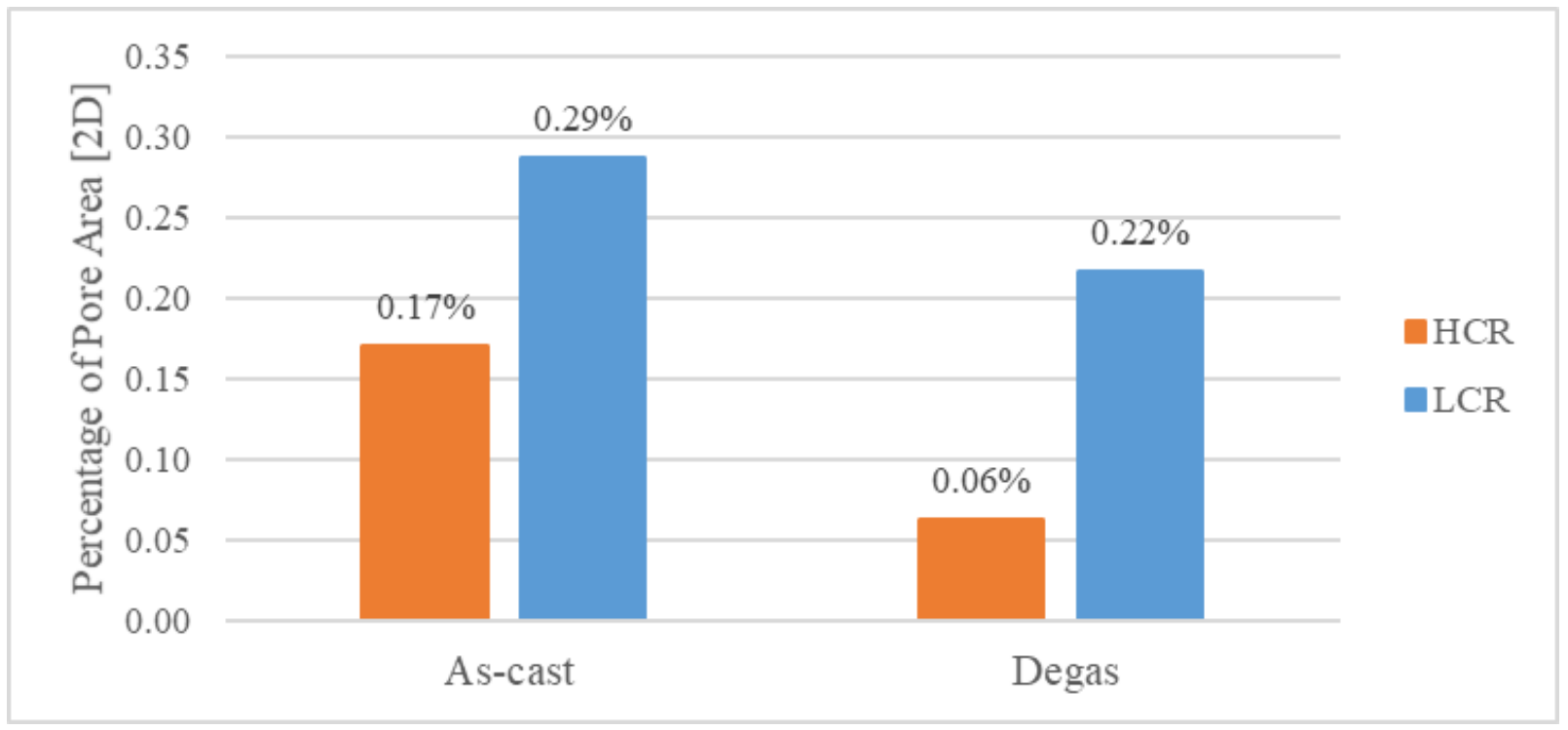

Figure 5.7: The percentage of pores on a 2D surface of HCR and LCR samples from both wedge casting trials, including the de-gas samples.

a percent of its 2-D area to be porosity, there was still a noticeable reduction in porosity after casting with the de-gas additive for both the HCR and LCR samples. The de-gas material still contains some porosity; however this is thought to be a result of shrinkage porosity. In both castings, the LCR sample has a higher amount of porosity than the HCR material. This is explained by a higher amount of shrinkage porosity in the LCR samples, since they are at the top of the wedge. The wedge mould was an open-top mould with no riser or other molten metal supply to account for material shrinkage. Therefore, if shrinkage were to occur during solidification of the material at the LCR location, there will be no molten metal supply above to supplement for the shrinkage [52].

\subsubsection{Casting Mould Design}

Two different casting moulds were used to prepare materials for this work: the wedge casting mould and the cylinder casting mould. The wedge casting mould was mainly used for cooling rate comparisons, but was inefficient for mass sample preparation and unable to 
produce samples for small-scale forgings, therefore requiring the cylinder casting mould. The wedge casting mould had material poured directly into the mould, without a gate or runner system, and was open at the top, without a riser. The cylinder mould had a runner system that fed a riser, which supplied the mould cavity through a web-gate. The intention of the web gate was to reduce turbulence during filling, and therefore prevent oxide film defects. To achieve different cooling rates with the cylinder casting, some castings were poured with the mould held at $300^{\circ} \mathrm{C}$ and air cooled, giving a low cooling rate, while some were poured with the mould held at $50^{\circ} \mathrm{C}$ and water cooled, giving a high cooling rate. These conditions are referred to as air and water cooled cylinder castings, respectively. Unlike the wedge casting, all cylinder castings were poured with the addition of the de-gas agent. Because of the difference in these mould designs, it is important to compare the microstructure of material cast from each process. The temperature recorded at each of the three thermocouples in the cylinder casting for both air and water cooled conditions are shown in Figure 5.8. A gradient in cooling rate was seen from the bottom to the top of the cylinder, however there is still a difference in cooling rate between each condition.

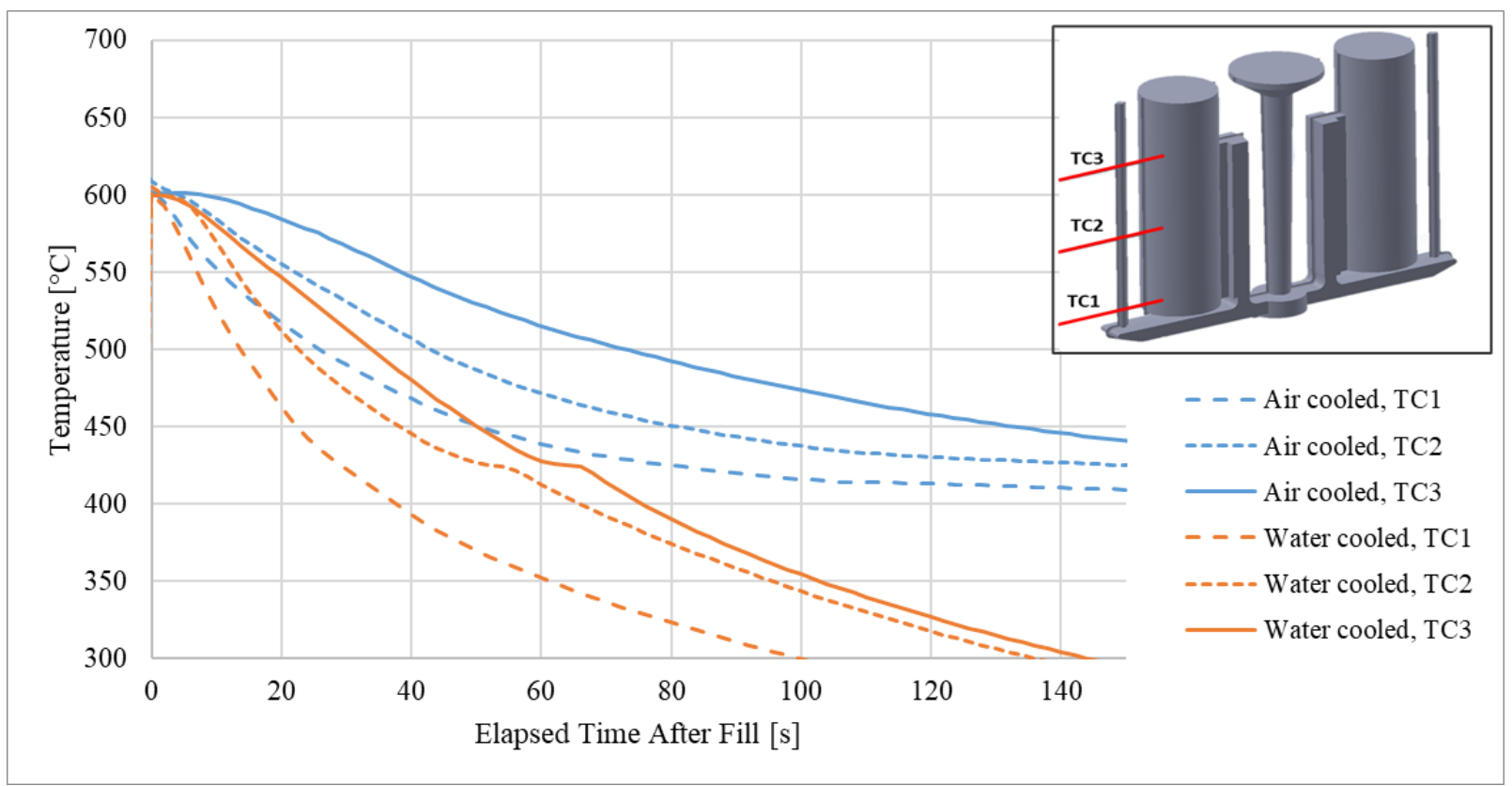

Figure 5.8: The temperature recorded at each thermocouple in the cylinder casting mould for air and water cooled castings.

While the cooling rate of the water cooled cylinder is indeed higher than the air cooled 
cylinders, this must be compared to the HCR and LCR material of the wedge casting. In Figure 5.9, cooling curves from the wedge cast thermocouple 4 and 7 (HCR and LCR) are compared to the middle thermocouple (labelled TC2 in Figure 5.8) in the air and water cooled cylinder castings. The water cooled cylinder casting solidifies at a much lower rate

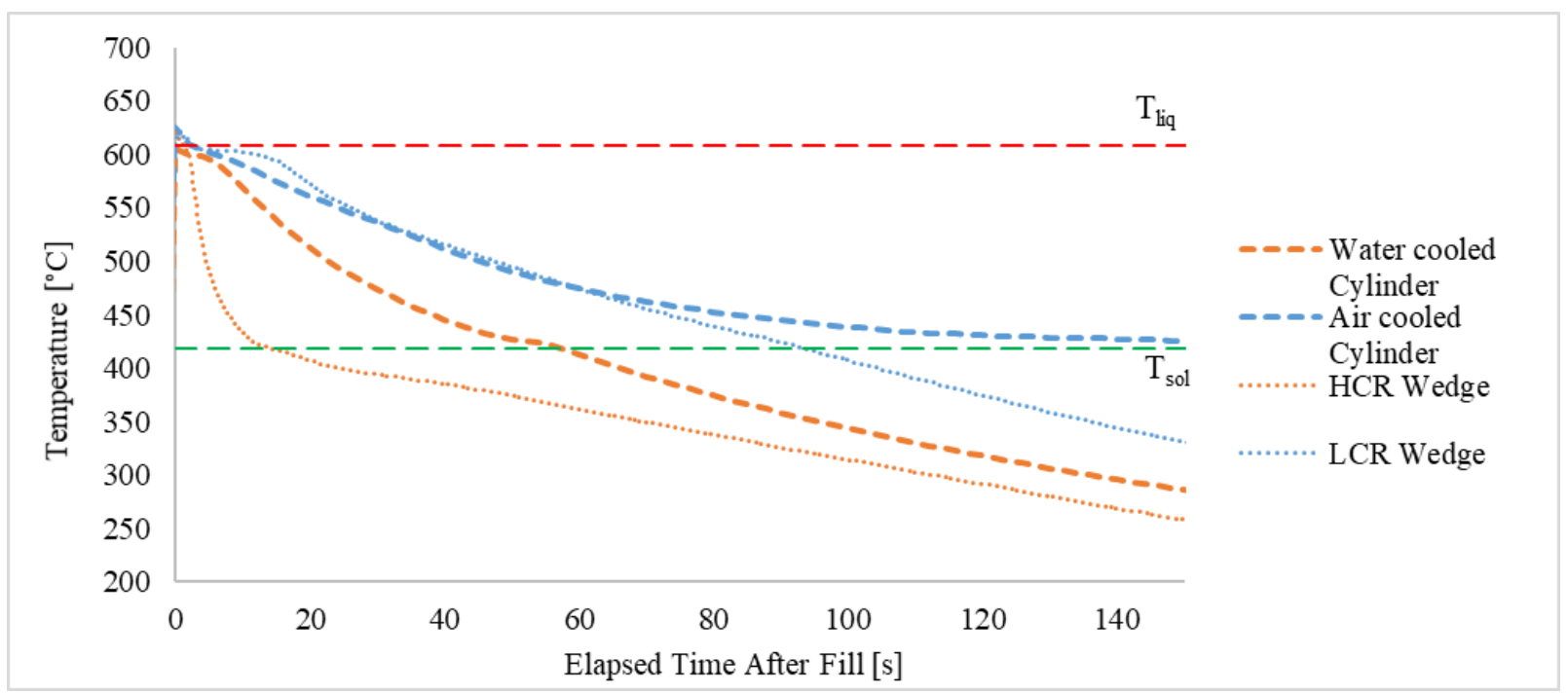

Figure 5.9: Comparison of the cooling rate between the wedge casting and the permanent mould casting processes.

than the HCR wedge casting, and therefore is expected to have a different microstructure. The cooling rate of the air cooled cylinder is comparable to the LCR wedge casting for much of the solidification process, however in the later stages of solidification, the cylinder casting is solidified with a much lower cooling rate than the wedge. This effect is evident in the microstructure. Microstructures of the cylinder and wedge cast material, cast with a low cooling rate and with the de-gas additive present are shown in Figure 5.10. The cylinder cast material shows an equiaxed grain structure, different than the coarse dendritic structure seen in the wedge cast material. Since the cooling rates are similar, this difference in grain morphology is likely more explained by the mould shape. In the wedge casting process, the material will solidify from the sides of the wedge toward the center, causing directional solidification. The very high cooling rate at the mould-part interface will initiate the columnar dendritic solidification, which will progress toward the center. In the cylinder mould however, the mould wall is much thicker than in the wedge casting. This means there will not be the very high cooling rate at the mould-part interface, as the interface is much further from the cooling channels. Further, since the mould fully 

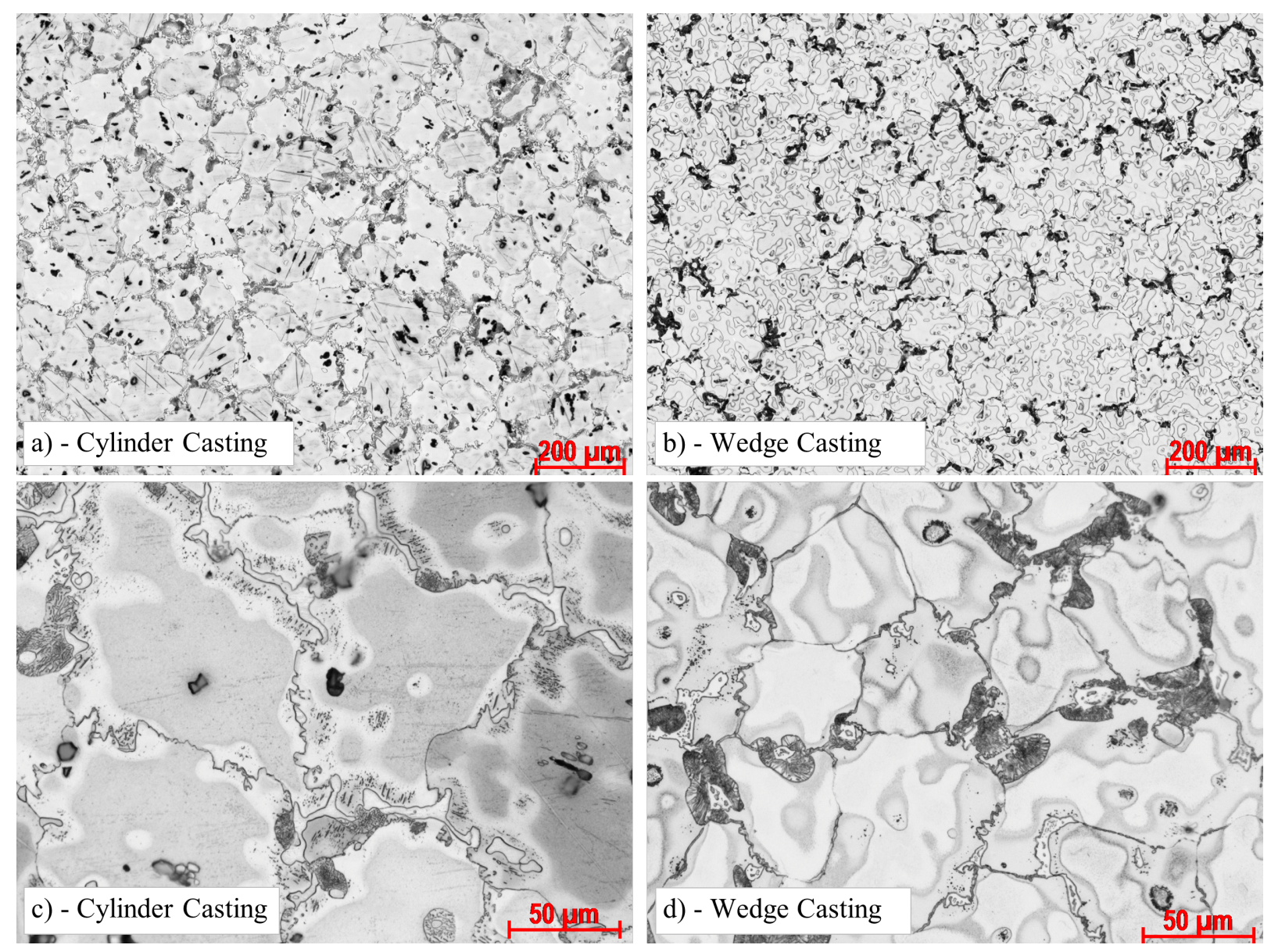

Figure 5.10: Optical microstructure of cast AZ80 from the a) air cooled cylinder casting, b) LCR wedge casting, and at 500x magnification from the c) air cooled cylinder casting, and d) LCR wedge casting.

surrounds the cylinder, there is no preferential direction for solidification as heat will be extracted in all directions, promoting a more equiaxed structure. Both structures show a partially divorced eutectic, though the cylinder cast material has much more concentrated areas of the $\gamma-\mathrm{Mg}_{17} \mathrm{Al}_{12}$ phase. This difference is explained by the difference in grain morphology, and not by the subtle difference in cooling rate. The eutectic material which solidifies at the inter-dendritic regions in the wedge cast material will only appear to be in small concentrations in some areas, depending on how the sample was sectioned relative to the dendrite orientation. Both materials also show precipitated $\gamma-\mathrm{Mg}_{17} \mathrm{Al}_{12}$ phase along the grain boundaries, though this is present in higher amounts in the cylinder cast material. 
Despite the similar cooling rate, the grain size of each casting process is largely different, measuring $94 \mu \mathrm{m} \pm 7 \mu \mathrm{m}$ in the air cooled cylinder casting, and $192 \mu \mathrm{m} \pm 18 \mu \mathrm{m}$ in the LCR wedge casting. This difference in measured grain size may also come from the difference in grain morphology, where columnar dendritic grains may appear larger than equiaxed grains for the same cooling rate. The grain size of the water cooled cylinder casting was not measured for this comparison, since the cooling rate was different from what was measured during wedge casting. For the remainder of this work where cylinder cast material is used, it is only the air cooled cylinder which is used.

\subsubsection{Effect of Homogenization}

Samples from the cylinder casting were used to compare the effect of homogenization on the microstructure of AZ80. For this comparison, only air cooled cylinder material was used. As described in Section 4.1.2, samples were held at $420^{\circ} \mathrm{C}$ for a total of 24 hours, then quenched in water. It is clear that the homogenization treatment was effective in dissolving the $\gamma-\mathrm{Mg}_{17} \mathrm{Al}_{12}$ phase within the $\alpha$ - $\mathrm{Mg}$ matrix, as no eutectic or precipitate phase is visible in Figure 5.11b. When comparing the higher magnification images in Figures 5.11k and $d$ however, some amount of very fine particles may remain within the grains and near the grain boundaries in the homogenized sample. Therefore, it is unclear without further analysis if this sample was truly fully homogenized, however the heat treatment has not been ineffective at bringing the $\gamma-\mathrm{Mg}_{17} \mathrm{Al}_{12}$ phase into solution. It was found by Kulkarni et al. [73] that during homogenization, it is the discontinuous or lamellar precipitates that are solutionized first, followed by divorced eutectic and then partially divorced eutectic. Since the eutectic morphology of these samples are partially divorced, the samples may not have been completely homogenized. In a summary by Sager et al. [8], it is stated that 5 hours may be sufficient to dissolve most of the $\gamma-\mathrm{Mg}_{17} \mathrm{Al}_{12}$ phase, however between 10 and 15 additional hours is required for full solutionizing to occur, also allowing the microstructure to become more uniform through diffusion. Further to the volume fraction of the eutectic phase, the samples experienced some very slight grain growth throughout the heat treatment. The as-cast sample measured a grain size of $94 \mu \mathrm{m} \pm 8 \mu \mathrm{m}$, while the homogenized sample measured $118 \mu \mathrm{m} \pm 10 \mu \mathrm{m}$. This slight growth of grain size is very small in comparison to the difference between HCR and LCR wedge cast samples, and is therefore not expected to have any significant influence on the compressive stress. Both samples in Figure 5.11 show signs of deformation by twinning, though it is important to note that this is only a result of the metallographic preparation, and is not relevant to this analysis. 

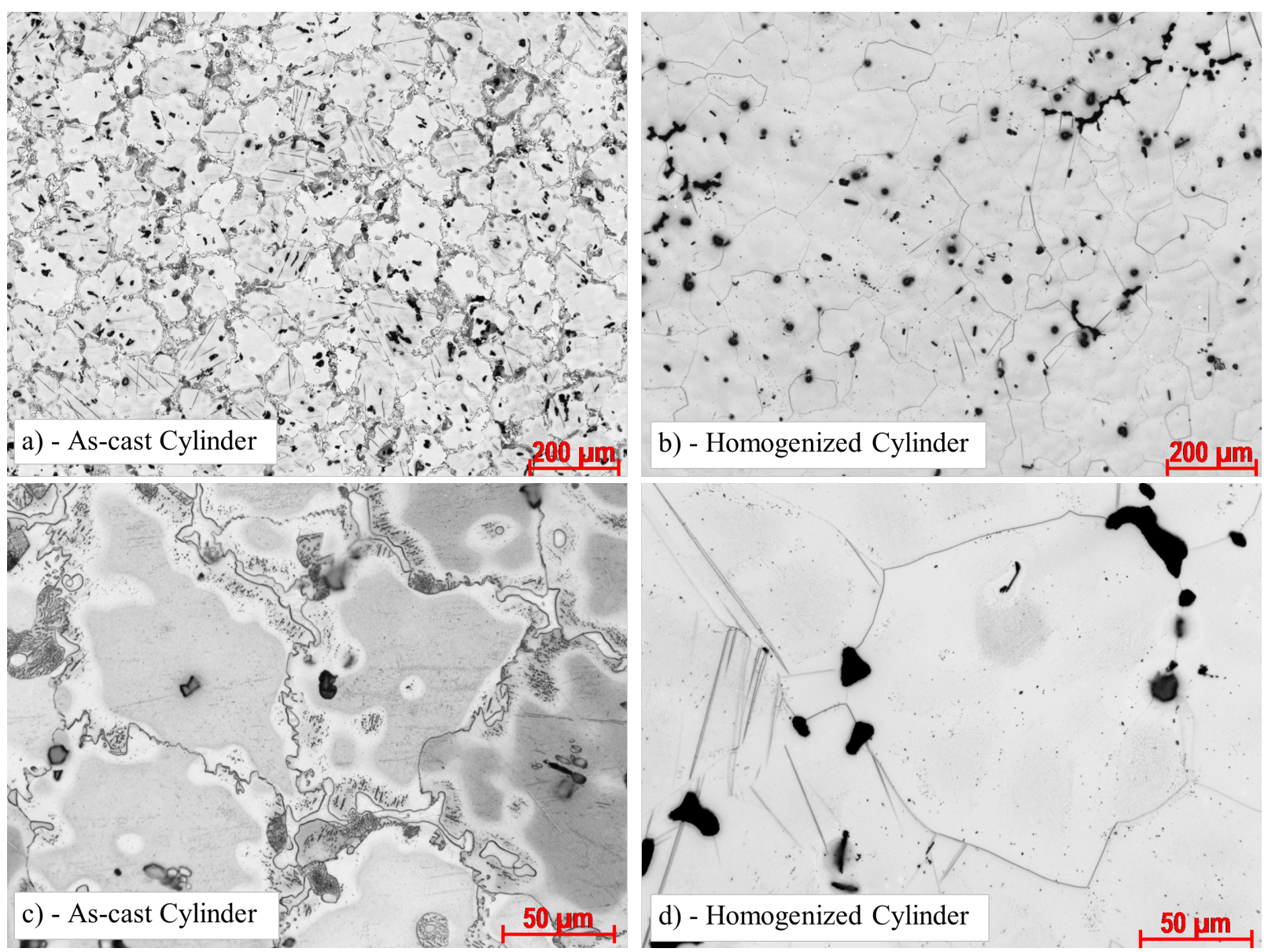

Figure 5.11: Optical microstructure of air cooled cylinder cast AZ80 at 100x magnification: a) as-cast, prior to homogenization, b) after homogenization, and at 500x magnification: c) as-cast, prior to homogenization, and d) after homogenization.

The $\gamma-\mathrm{Mg}_{17} \mathrm{Al}_{12}$ phase was confirmed to be dissolved by differential scanning calorimetry (DSC) analysis. The as-cast samples observed an endothermic peak upon heating, indicative of the melting of the $\gamma-\mathrm{Mg}_{17} \mathrm{Al}_{12}$ phase. The homogenized samples did not show any peak, and therefore it was confirmed that the $\gamma-\mathrm{Mg}_{17} \mathrm{Al}_{12}$ phase had been solutionized and sufficiently dispersed within the $\alpha-\mathrm{Mg}$ matrix. These results are presented in Figure 5.12 . The as-cast sample shows an endothermic peak upon heating, where the homogenized sample does not. This endothermic peak occurred at $437^{\circ} \mathrm{C}$, based on an average of 3 measurements, which is very close to what is reported in literature as the melting temperature of $\mathrm{Mg}_{17} \mathrm{Al}_{12}$ [73]. The onset of melting of $\mathrm{Mg}_{17} \mathrm{Al}_{12}$ occurs at $428^{\circ} \mathrm{C}$, determined 
by the temperature at which $0.5 \%$ of the endothermic reaction had occurred, based on the cumulative enthalpy at that point. An average enthalpy from 3 as-cast samples was found to be $11.2 \mathrm{~J} / \mathrm{g}$, as calculated by the DSC software. All measurements were taken from the heating cycle, to ensure no effects from microstructure changes after melting of the $\mathrm{Mg}_{17} \mathrm{Al}_{12}$ phase.

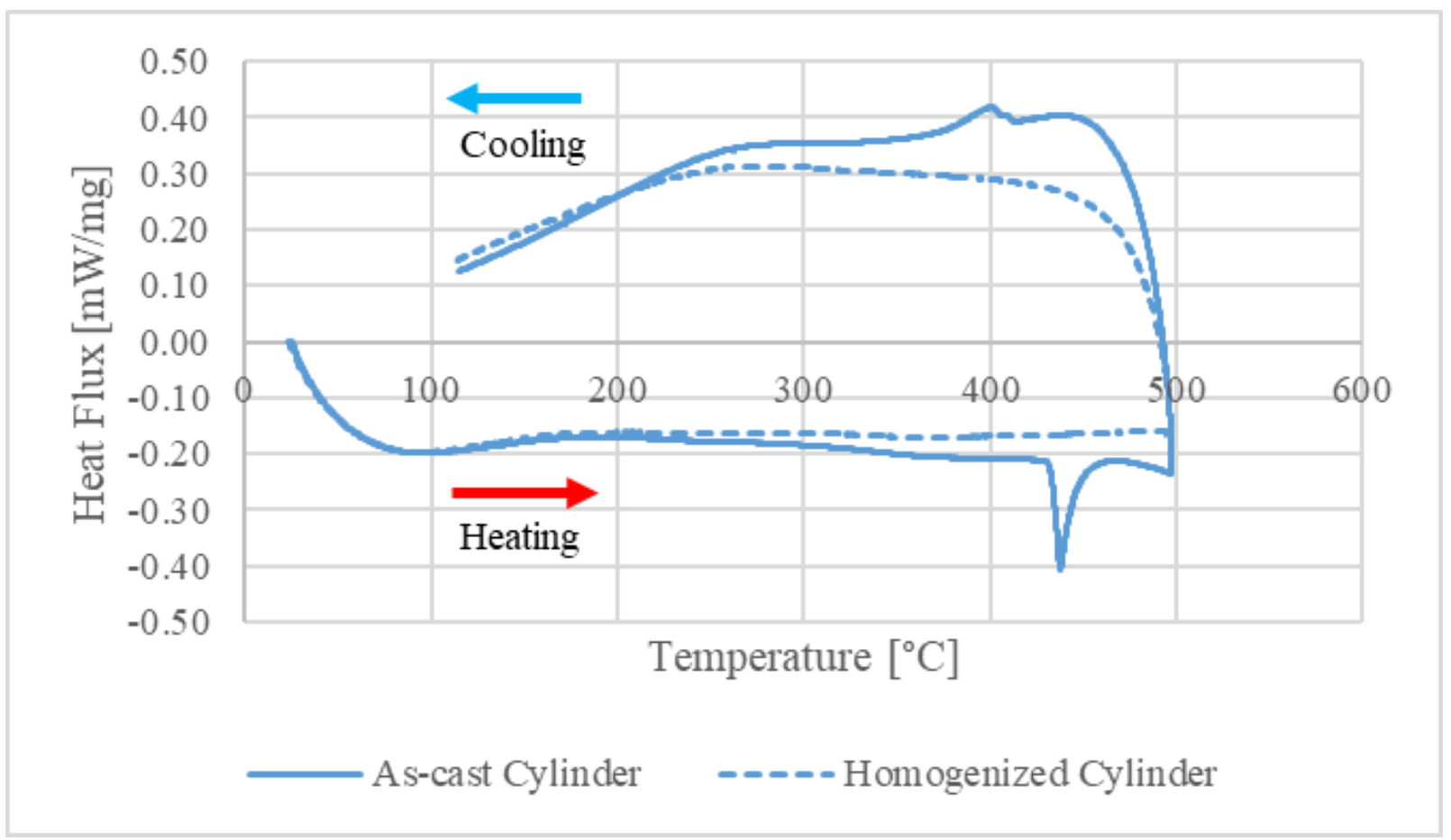

Figure 5.12: The DSC heat flux plotted with respect to temperature, during the heating and cooling stages, for the air cooled de-gas cylinder in both the as-cast and homogenized state.

To study the effect of cooling rate after homogenization, the same homogenization heat treatment was applied to some HCR and LCR wedge samples. The heat treatment was interrupted in 6 hour time increments, however, so that the electrical conductivity could be measured. Figure 5.13 shows the results of these measurements. Each measurement represents the average conductivity of 4 samples, each measured twice, with error bars showing the maximum and minimum conductivity of all measurements. The intent of this measurement was to develop a correlation between precipitate volume fraction (or inversely, solutionized fraction), and the electrical conductivity. Before homogenization, 
both the HCR and LCR samples measure a similar conductivity. After 6 hours at $420^{\circ} \mathrm{C}$, the conductivity decreases. After further homogenization time, the conductivity does not seem to decrease further. The conductivity measurements could be an effective method for determining how much intermetallic has gone into solution, as the conductivity decreases noticeably after 6 hours, and it is suggested that 6 hours is sufficient duration to solutionize this alloy [8]. However during further heat treatment, as the solute becomes more evenly dispersed in the matrix, the electrical conductivity does not change, and therefore it is not an effective measure of homogenization during later stages of the heat treatment.

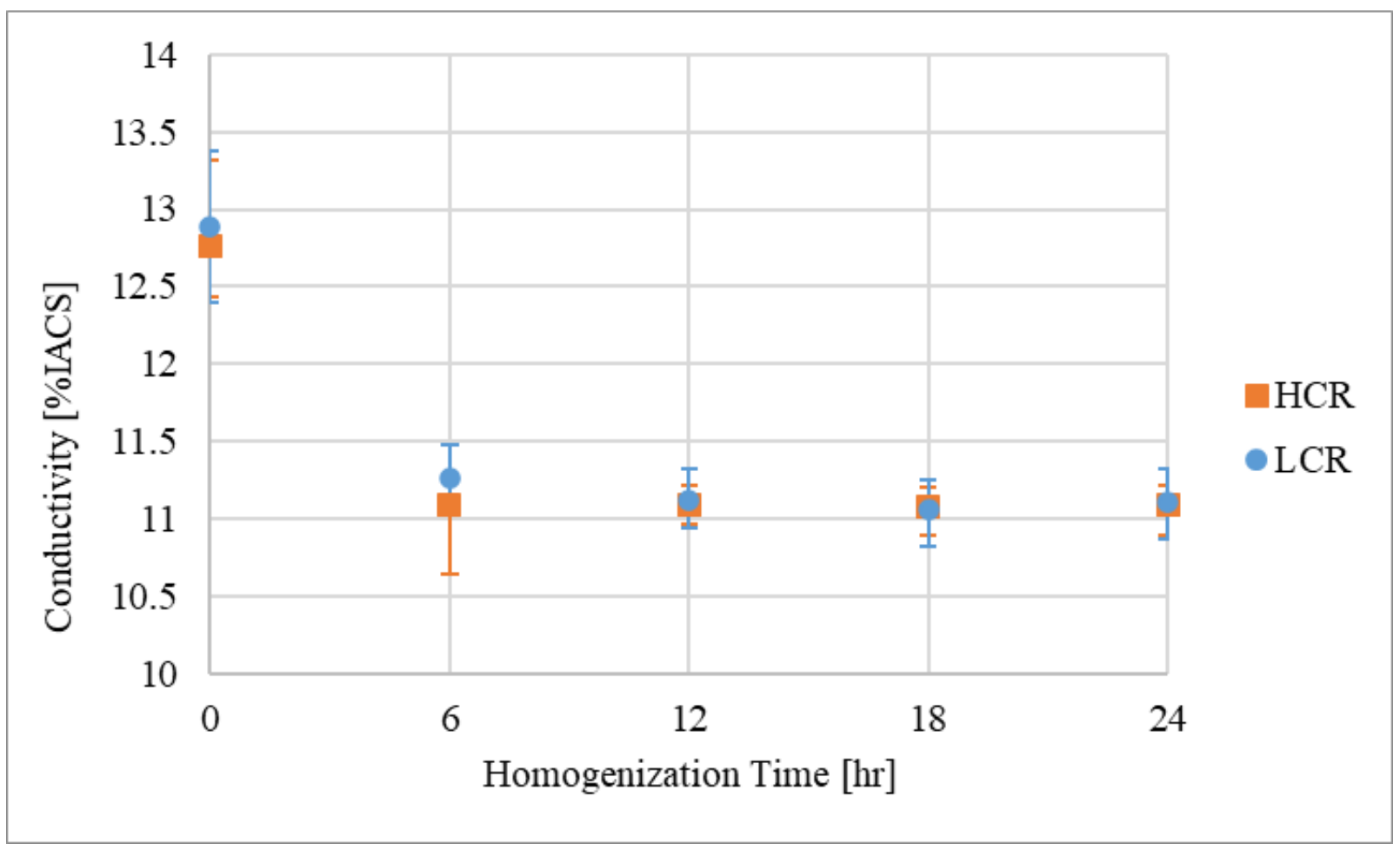

Figure 5.13: The evolution of average electrical conductivity of AZ80 samples measured in \%IACS (percentage of international annealed copper standard), during homogenization treatment. 


\subsection{Hot Compression Behaviour}

\subsubsection{Typical Stress-Strain Curve}

This section will analyze the effects of starting material structure, and deformation parameters, on the deformation and stress in compression, therefore it is important to define the terminology used to describe the compressive true stress-true strain curve. Each compression test records load and stroke data, which is translated into a compressive true stress-true strain curve. An example of one of these curves is shown in Figure 5.14, plotted alongside the calculated rate of change of compressive stress (work hardening rate). The

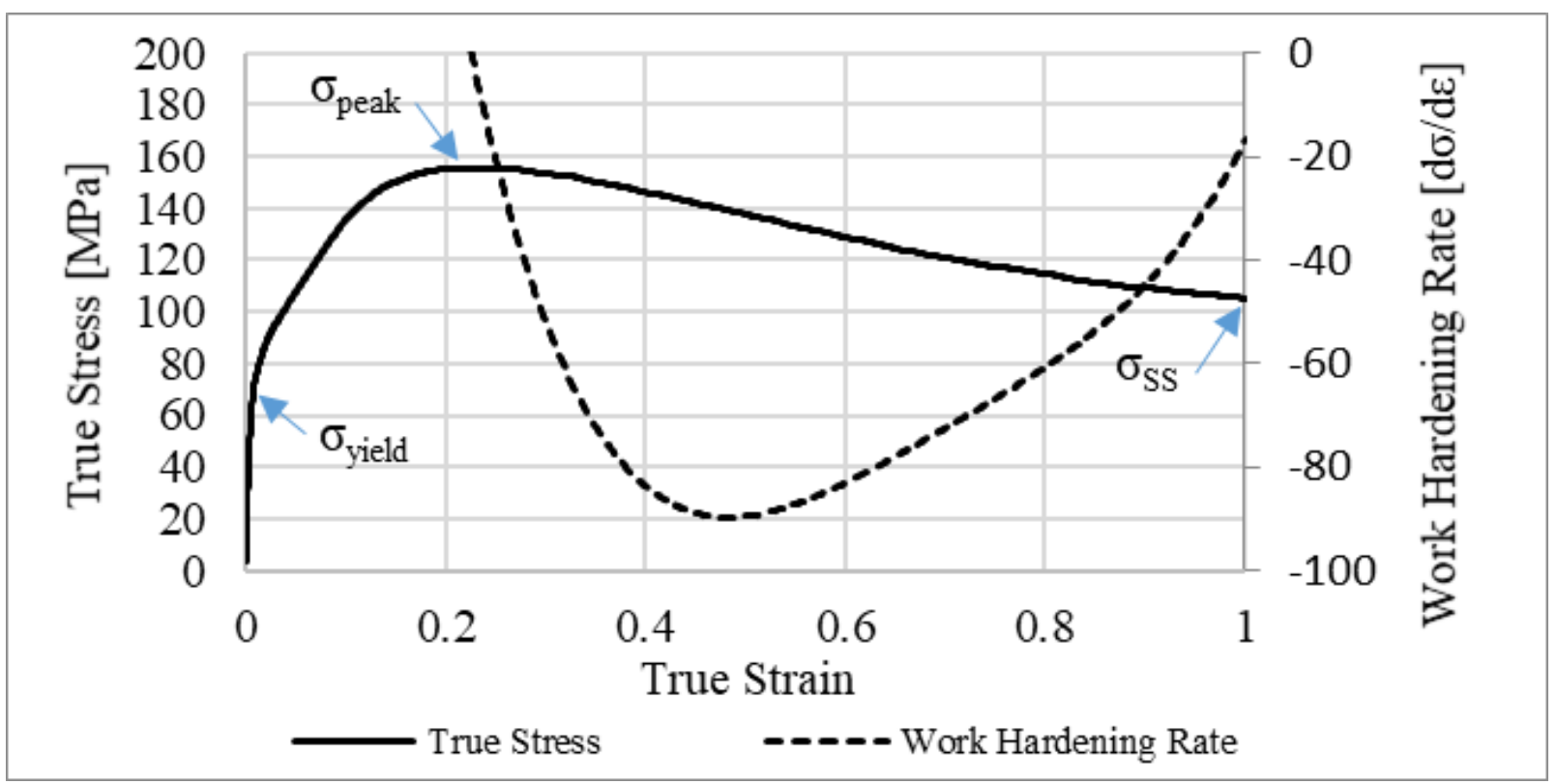

Figure 5.14: A typical measured compressive stress curve showing the calculated rate of work hardening. The sample in this example was a de-gas LCR wedge cast sample, compressed at $300^{\circ} \mathrm{C}$ and a strain rate of $1 \mathrm{~s}^{-1}$.

compressive true stress-true strain curve (often referred to as a flow curve, or flow stress curve) for this alloy shows an initial work hardening stage following the yield stress, and before reaching the peak stress. During this research, the yield stress is defined as the level of stress at which the true stress-true strain curve becomes non-linear. The peak stress occurs when the work hardening rate is equal to zero, which is also the maximum stress. The peak stress is followed by a rapid softening stage, shown by a decrease in the 
compressive stress and a higher magnitude of work hardening rate. This stage is referred to as dynamic softening, or flow softening. Finally, the stress begins to stabilize as the work hardening rate approaches zero again, until eventually reaching a point of steady state stress. The maximum strain that was tested in this work was 1.0, and although at this strain the stress has not fully stabilized (i.e. the work hardening rate has not returned to zero), further deformation would result in a loss of data accuracy, due to high amounts of sample cracking. Therefore, in this work, the steady state stress is taken to be the stress level at a strain of 1.0. The factors which influence the compressive stress-strain curve are discussed in the following sections, however not every measured curve is presented. To view all of the compressive stress-strain curves for the wedge cast material, the reader is referred to Appendix B.

\subsubsection{Effect of Temperature}

Deformation temperatures of $250^{\circ} \mathrm{C}, 300^{\circ} \mathrm{C}$, and $350^{\circ} \mathrm{C}$ were studied in this research. These temperatures are suitable for deformation, based on the number of available slip systems discussed in Figure 2.6. Compressive true stress-true strain curves at a strain rate of $0.1 \mathrm{~s}^{-1}$ at each temperature are shown in Figure 5.15.

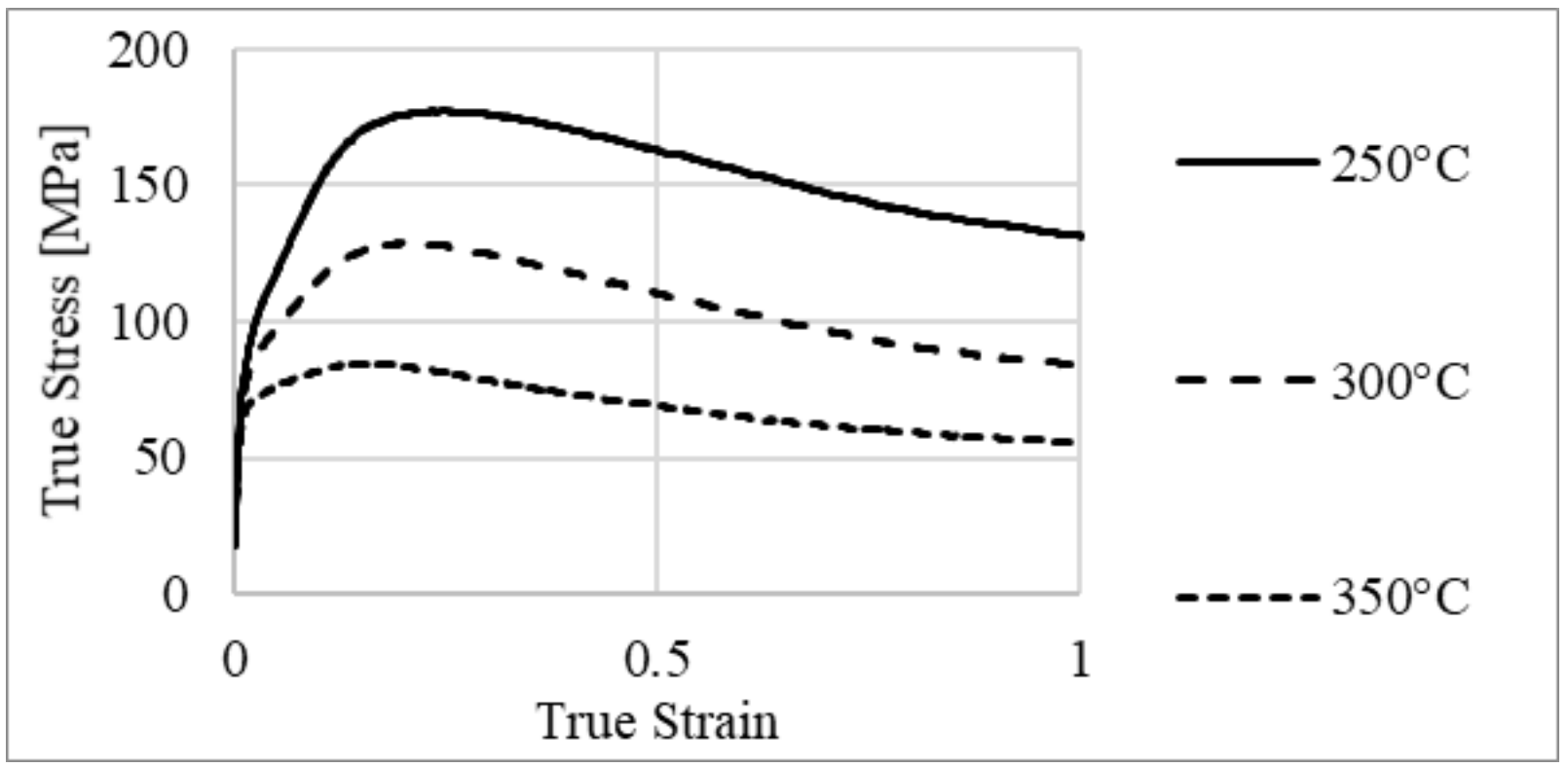

Figure 5.15: Effect of deformation temperature on the compressive strength of de-gas LCR wedge cast AZ80 at a strain rate of $0.1 \mathrm{~s}^{-1}$. 
As the deformation temperature is increased, the compressive stress is reduced at all levels of plastic strain. The strain required to achieve the peak compressive stress is also reduced. This result is very consistent with the literature [74, 75], and was expected. The yield stress is very similar, and does not appear to vary with temperature. The work hardening rate between the yield and peak stress is increased with a decrease in temperature (shown by a steeper curve between yield and peak stress), though after the peak stress the samples appear to soften at a similar rate, independent of temperature. Since deformation heating was observed in the higher strain rate tests, tests were not conducted at $400^{\circ} \mathrm{C}$, as the sample may increase in temperature near to the onset of melting of the $\mathrm{Mg}_{17} \mathrm{Al}_{12}$ phase, possibly exceeding this temperature in localized regions. This phase was found to begin melting at only $428^{\circ} \mathrm{C}$ by DSC analysis, presented in Section 5.1.4. Further, it has been previously shown that testing at $400^{\circ} \mathrm{C}$ will quickly solutionize the material, resulting in behaviour similar to as if it were homogenized [74]. This work studies the differences between cast and homogenized material during deformation, presented in future sections of this thesis, and therefore studying the phenomena of compression at $400^{\circ} \mathrm{C}$ or above was not necessary. Previous works have shown that lower deformation temperatures are preferable for higher mechanical properties in forgings [75] however this will require much more load than deformation at higher temperatures. Additionally, the propensity for cracking is much higher at lower deformation temperatures for higher strain rates, as presented in Section 5.1, and therefore forging at lower temperatures may constrain the strain rate, or more practically, the forging speed.

\subsubsection{Effect of Strain Rate}

Strain rates of $0.01 \mathrm{~s}^{-1}, 0.1 \mathrm{~s}^{-1}$, and $1 \mathrm{~s}^{-1}$ were selected for this work. These strain rates encompass the range that would be expected to be seen in the material when forged at a practical strain rate in an industrial application, based on simulations conducted in the $\mathrm{APC}$ project. Compressive true stress-true strain curves at a temperature of $300^{\circ} \mathrm{C}$ at each strain rate are shown in Figure 5.16 . 


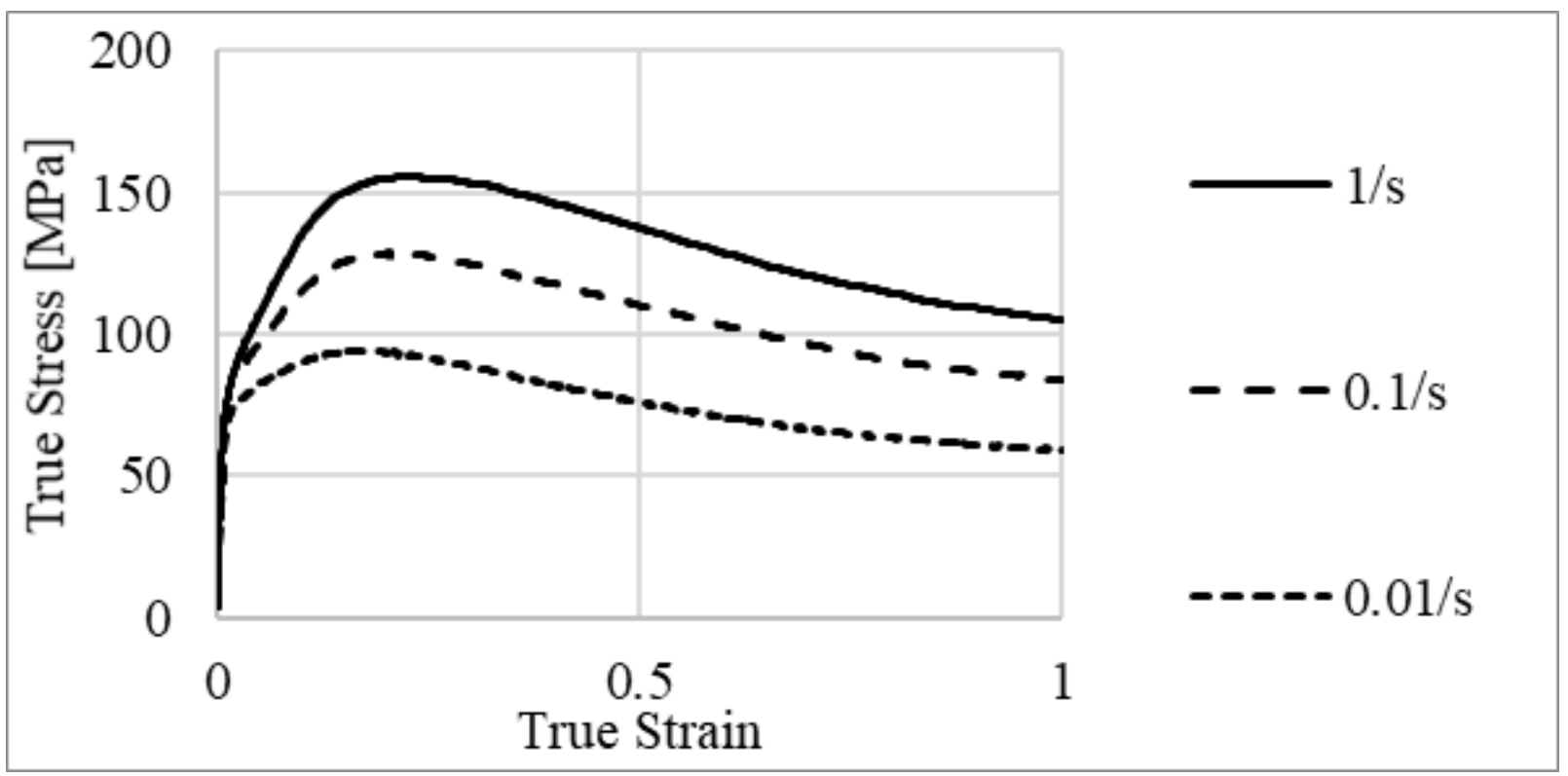

Figure 5.16: Effect of strain rate on the compressive strength of de-gas LCR wedge cast AZ80 at a temperature of $300^{\circ} \mathrm{C}$.

As the strain rate is increased, the compressive stress increases for all levels of plastic strain. Additionally, similar to the effect shown with an increase in temperature, decreasing the strain rate also decreases the strain necessary to reach the peak stress. The yield stress is comparable to what was seen in the previous section, and does not appear to be influenced by strain rate. The work hardening rate between the yield and peak stress is increased with an increase in strain rate (shown by a steeper curve between yield and peak stress), though following the peak stress the work hardening rate appears to be independent of strain rate. In comparing the microstructure evolution of cast and homogenized cylinder castings, some samples were tested at a higher strain rate of $0.1 \mathrm{~s}^{-1}$. A comparison of the microstructures seen when deformed at strain rates of $0.01 \mathrm{~s}^{-1}$ and $0.1 \mathrm{~s}^{-1}$ to strains of 0.15 , 0.4, and 1.0, is shown in Figure 5.17. Both strain rates show very little DRX grains at the strain of 0.15 . At strains of 0.4 and 1.0 however, the DRX grains are more abundant. The area percentage of the microstructure which is made up of DRX grains has been measured using the technique described in Section 4.3.2, and is presented in Figure 5.18. More detail on how these measurements were taken is given in Appendix C. 

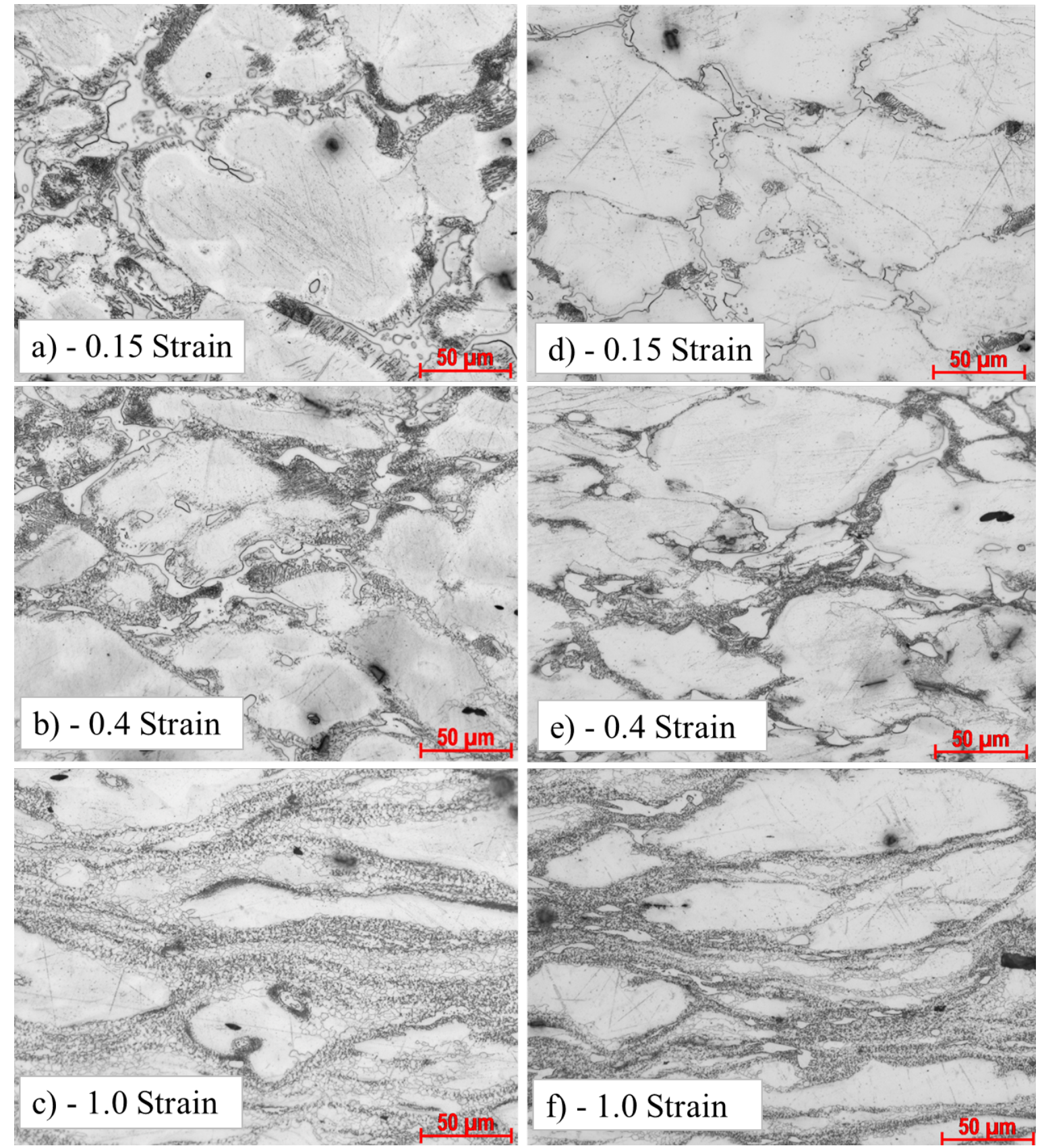

Figure 5.17: Optical microstructure of cylinder cast samples deformed at a temperature of $300^{\circ} \mathrm{C}$ at $500 \mathrm{x}$ magnification: a) 0.15 strain $0.01 \mathrm{~s}^{-1}$ strain rate, b) 0.4 strain $0.01 \mathrm{~s}^{-1}$ strain rate, c) 1.0 strain $0.01 \mathrm{~s}^{-1}$ strain rate, d) 0.15 strain $0.1 \mathrm{~s}^{-1}$ strain rate, e) 0.4 strain $0.1 \mathrm{~s}^{-1}$, and f) 1.0 strain $0.1 \mathrm{~s}^{-1}$. 


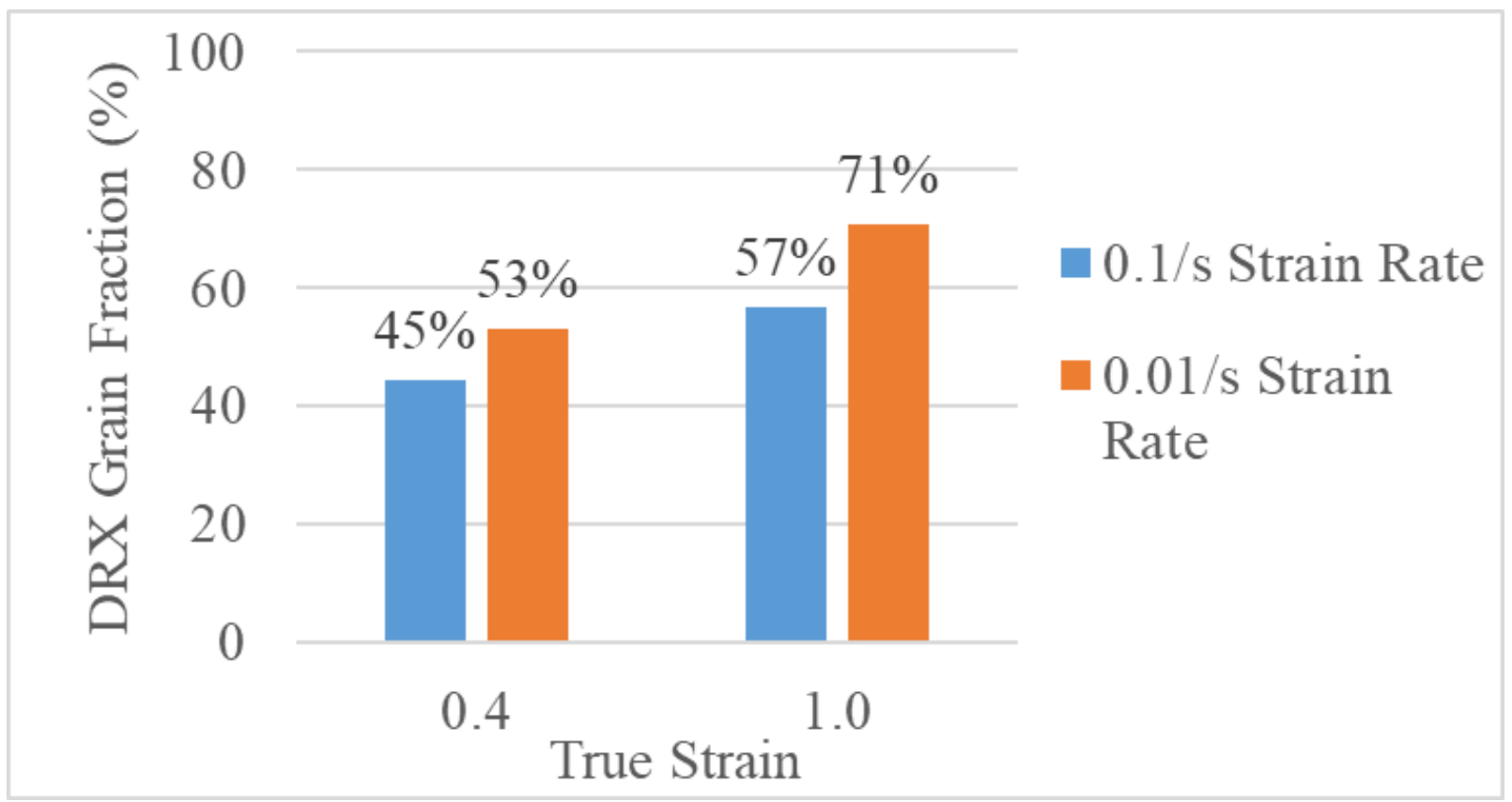

Figure 5.18: Effect of strain on the percentage of area of DRX grains for strain rates of $0.1 \mathrm{~s}^{-1}$ and $0.01 \mathrm{~s}^{-1}$, at a deformation temperature of $300^{\circ} \mathrm{C}$.

At lower strain rates for both strains, there is a much higher fraction of DRX grains than at higher strain rates. This effect is heightened at a strain of 1.0, where a significantly higher amount of DRX has occurred in the low strain rate sample. Referring to Figure 5.17 , the samples tested at the higher strain rates appear to show a finer DRX grain size than those at the lower strain rates. This is understandable, as the samples with the higher strain rate have less time for grain growth to occur. This added time for grain growth explains the higher area fraction of DRX grains in the low strain rate samples. This is mostly seen in the 0.4 and 1.0 strain samples, as there is not much visible DRX in the 0.15 strain samples. This is in good agreement with what is reported in the literature for AZ91, where higher strain rates show a smaller DRX grain size, but only a small decrease in the fraction of DRX grains [76]. This finer grain size is predicted to be beneficial for final mechanical properties after forging, however some research has suggested that the mechanical properties of magnesium forgings are not as sensitive to a change in strain rate as they are to a change in temperature [75, 76]. An interesting observation in these samples is the lower number of precipitates present in the microstructure of the higher strain rate test, despite being extracted from the same location within the cast cylinder. It has been reported for the AZ91 alloy that precipitation of $\mathrm{Mg}_{17} \mathrm{Al}_{12}$ can occur in the aluminum rich 
eutectic $\alpha-\mathrm{Mg}$ regions, near the grain boundaries, at deformation temperatures as low as $300^{\circ} \mathrm{C}$ [76]. It is possible that during heating and deformation, some of the intermetallic has precipitated along the grain boundaries in these areas. Since the low strain rate test will require the sample to be held at an elevated temperature for a longer period, more precipitates will come out of solution. Without further analysis, it is unknown the influence these precipitates may have had on the microstructure evolution comparison of these two strain rates. It is possible that the precipitation of the $\mathrm{Mg}_{17} \mathrm{Al}_{12}$ phase may be responsible for the increase in DRX percentage in the low strain rate sample, since DRX can be promoted in areas with discontinuous lamellar precipitates.

\subsubsection{Effect of Cast Cooling Rate}

The effects in deformation of initial cooling rate during casting solidification was studied using material from the wedge casting process, at thermocouple locations 4 and 7 (HCR and LCR respectively), described in Section 4.1.1. Samples were compared by compressive stress during deformation, and by observation of crack formation during deformation. The typical compressive stress-strain behaviour of as-cast HCR and LCR cast material is shown in Figure 5.19. The material cast with a high cooling rate (and lower average grain size) showed a higher peak compressive stress than the lower cooling rate material.

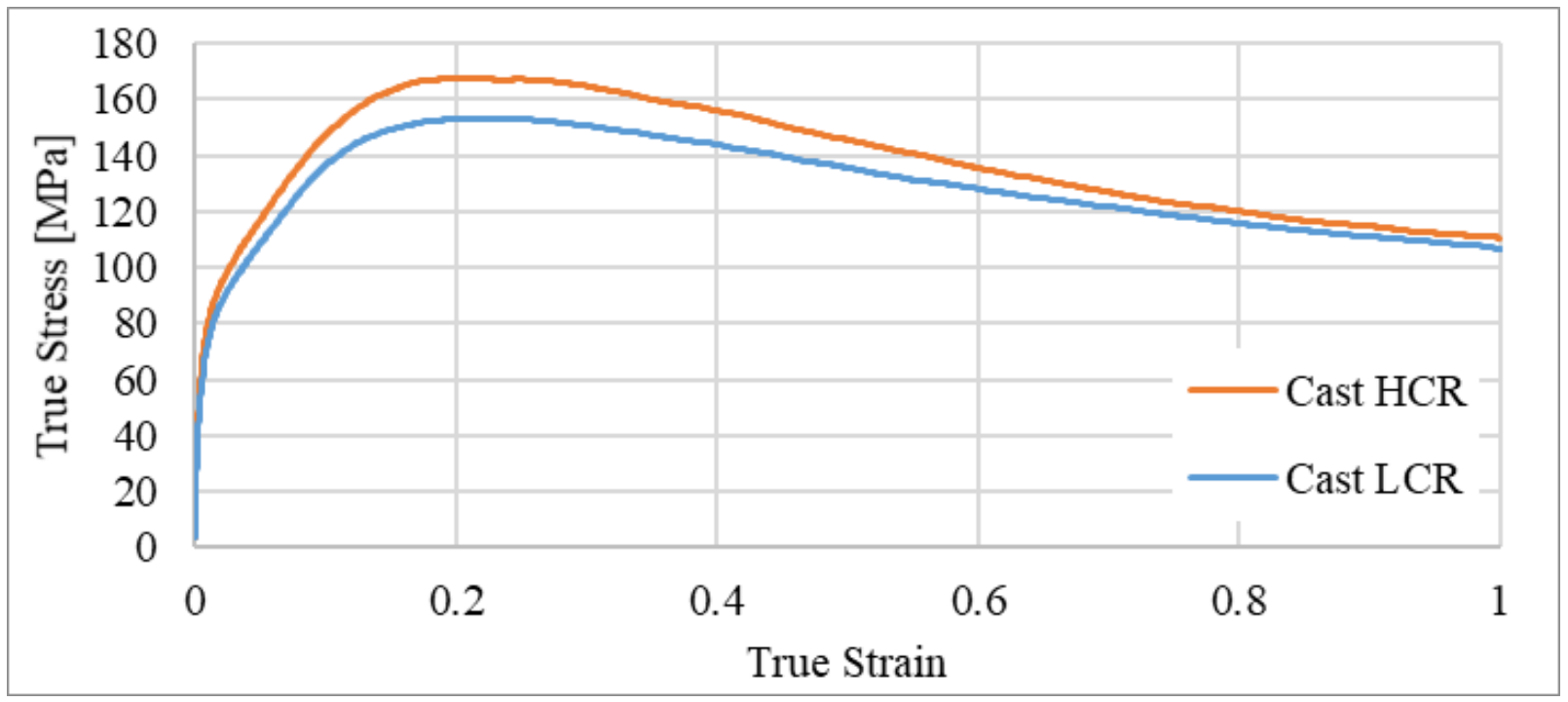

Figure 5.19: Measured compressive stress-strain curves for as-cast LCR and HCR wedge cast samples, tested at $300^{\circ} \mathrm{C}$ and a strain rate of $1 / \mathrm{s}$. 
During the initial stages of compression after the yield point, HCR samples had a higher rate of work hardening than the LCR samples, as the stress increased at a higher rate after the yield stress. HCR samples also saw a higher rate of softening following the peak stress. Following the flow softening, the steady-state stress was comparable between HCR and LCR material. It is believed that at high levels of strain, significant enough deformation has occured within the grain structure that any effects of the starting microstructure are insignificant. Material which was cast with the addition of the de-gassing agent saw no significant difference in compressive stress when compared to the as-cast material, for either cooling rate. A comparison of these two cast materials is shown in Figure 5.20. This behaviour was typical for both as-cast and de-gas wedge castings for all deformation

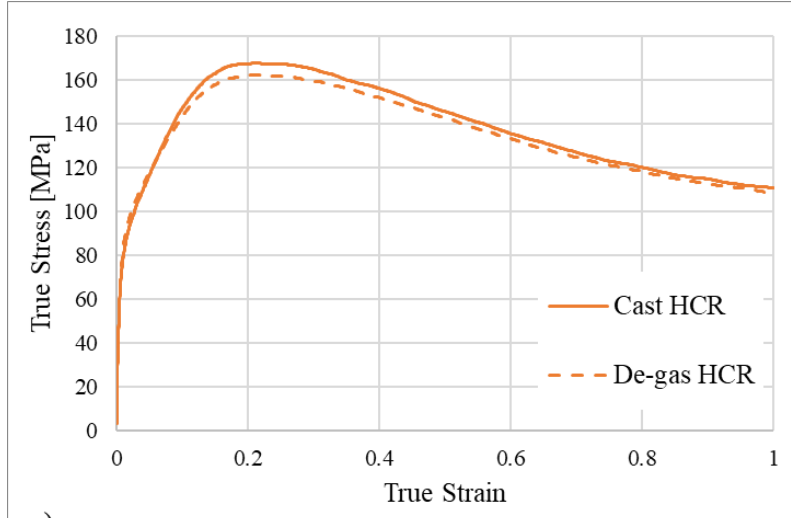

a)

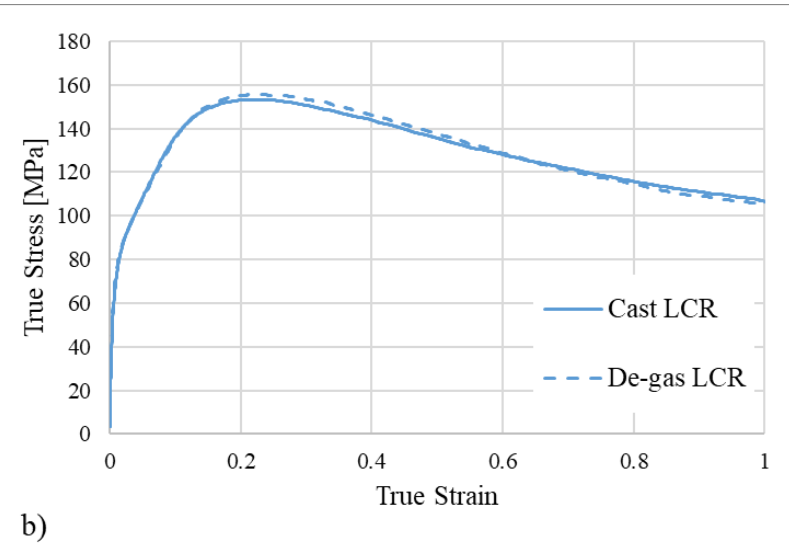

b)

Figure 5.20: The compressive stress-strain curves of wedge cast samples comparing degas material to as-cast material, for a) HCR and b) LCR, at a strain rate of $1 \mathrm{~s}^{-1}$ and a temperature of $300^{\circ} \mathrm{C}$.

conditions studied. An increase in cooling rate showed an increase in peak stress and change in work hardening rates, both ahead of, and following, the peak stress. These tests were performed under temperatures of $250^{\circ} \mathrm{C}, 300^{\circ} \mathrm{C}$, and $350^{\circ} \mathrm{C}$, and strain rates of $0.01 \mathrm{~s}^{-1}, 0.1 \mathrm{~s}^{-1}$ and $1.0 \mathrm{~s}^{-1}$. A plot of the peak and steady state stress for each material and deformation condition is shown in Figures $5.21 \mathrm{a}$ and b. A repeatability study was performed on de-gas LCR material $(n=5)$, showing a standard deviation of less than 2 at the peak stress and less than 1 at the steady-state stress, though it is suggested by Gleeble that the accuracy is within $\pm 3 \%$ of the peak stress. Using either of these error margins, the trends described are apparent. 


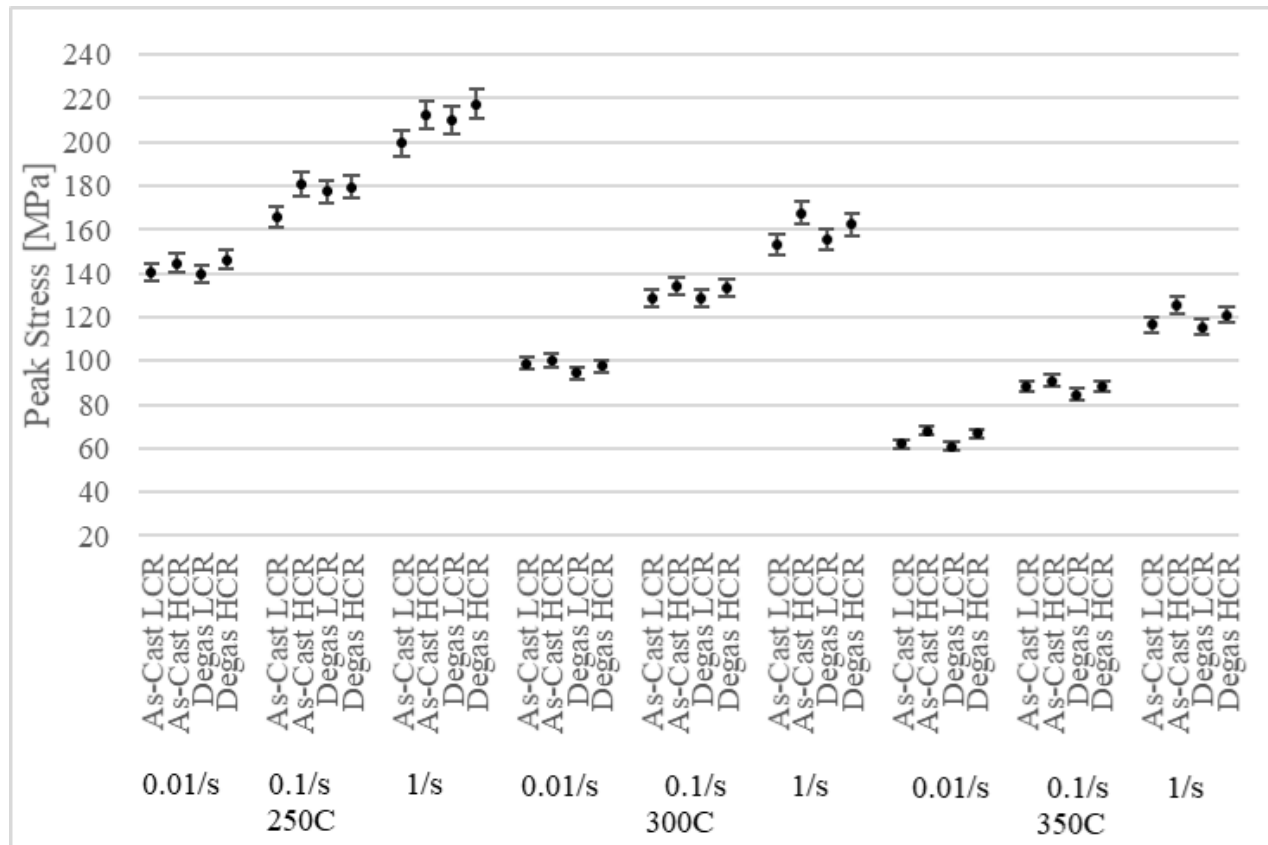

a)

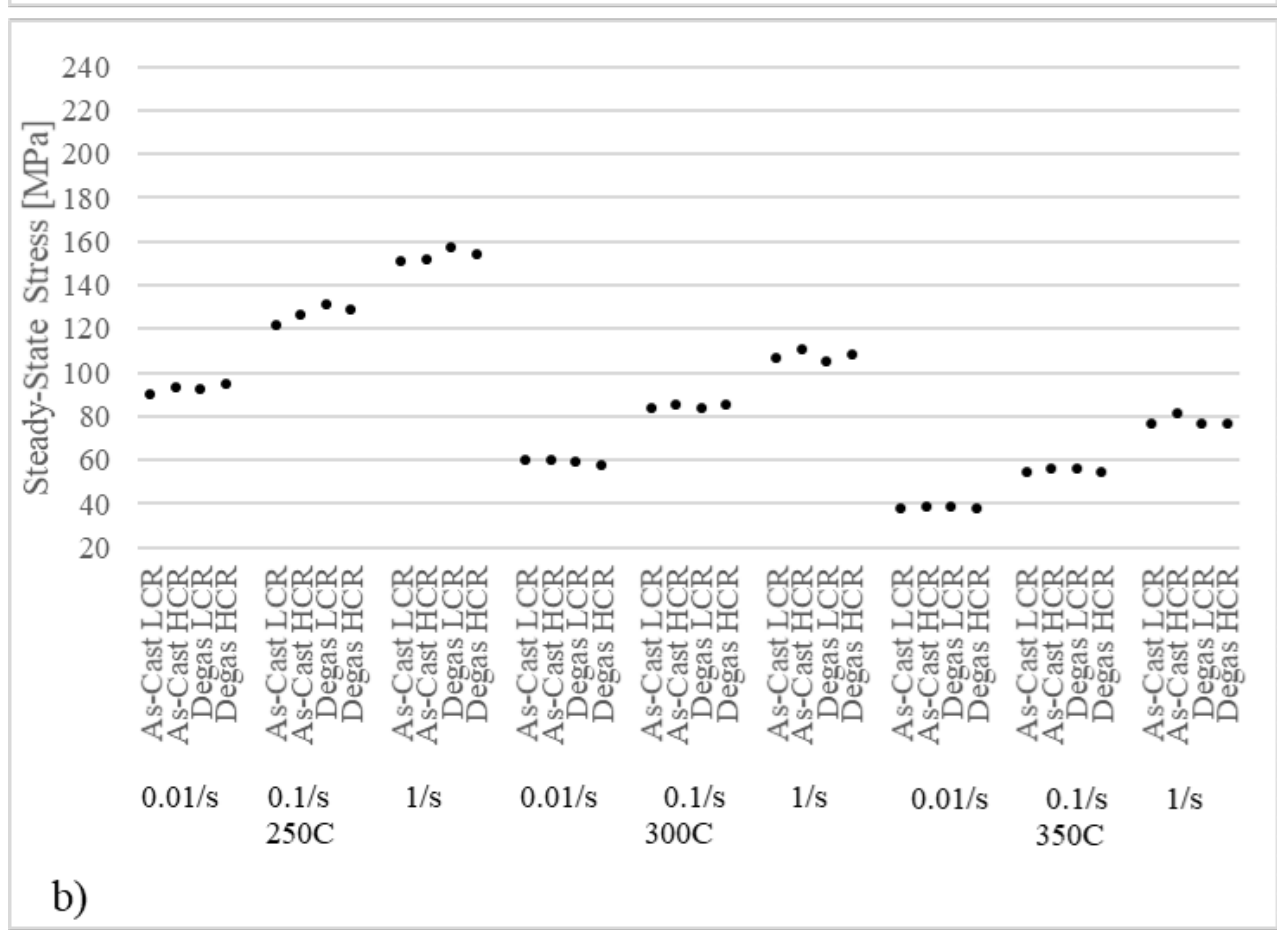

Figure 5.21: Measurements of (a) the peak stress and (b) the steady-state stress, for LCR and HCR castings of both as-cast and de-gaøsedge cast samples. The error bars represent $\pm 3 \%$ of the peak stress. 
To compare this research with the other research already presented in the literature, the Zener-Holloman parameter is calculated (hereby $\mathrm{Z}$ parameter), using material from the $\mathrm{HCR}$ and LCR wedge castings. The $\mathrm{Z}$ parameter presents the combined effect of both temperature and strain rate in one parameter, to easily study their effect on the compressive stress. The $\mathrm{Z}$ parameter is calculated using the following equation, where $\mathrm{Q}$ is the activation energy, $\mathrm{R}$ is the universal gas constant equal to $8.314 \frac{\mathrm{J}}{\mathrm{K} \cdot \mathrm{mol}}$, $\mathrm{T}$ is the deformation temperature in Kelvin and $\dot{\varepsilon}$ is the strain rate.

$$
Z=\dot{\varepsilon} \exp \frac{Q}{R T}
$$

A value for the activation energy, $Q$, is calculated to be $125 \mathrm{~kJ}$ using the method described in [77. Since the compression testing results between as-cast and de-gas are similar for most deformation conditions, only one value is calculated. The same value was calculated for both HCR and LCR material using this method. The Z parameter is calculated for each combination of temperature and strain rate that was tested, and is plotted against the peak stress seen during testing. Values from the current work can be compared to what is found in the literature in Figure 5.22 [49, 78]. Values from the work by $\mathrm{Su}$ et al. [49] and Li et al. [78] were extrapolated from published flow curves to the best of the authors ability, and are therefore to be used for comparison only as the accuracy cannot be guaranteed. This comparison focuses only on extruded material, since pre-forging grain refinement via extrusion is a common practice for reducing the compressive stress and improving forgeability of this alloy [8]. Calculation of the $\mathrm{Z}$ parameter does not account for strain, therefore it is common to select a given strain for consistency. Since this comparison encompasses many deformation conditions and materials however, the peak stress and the stress at a strain of 0.7 is used. A strain of 0.7 was selected on the availability of flow curve data from the mentioned literature and is not necessarily the steady state stress. The flow curves published for extruded material were seen to soften much earlier than the cast material in this research, so selecting of one strain value would make any comparison ineffective. Since the as-cast and de-gas material had comparable values of compressive stress, both as-cast and de-gas results were combined into each of the HCR and LCR plots. Each data point on this plot represents the temperature and strain rate of a compression test, and the corresponding peak stress (Figure 5.22 a) or stress at a strain of 0.7 (Figure 5.22 that was measured. 


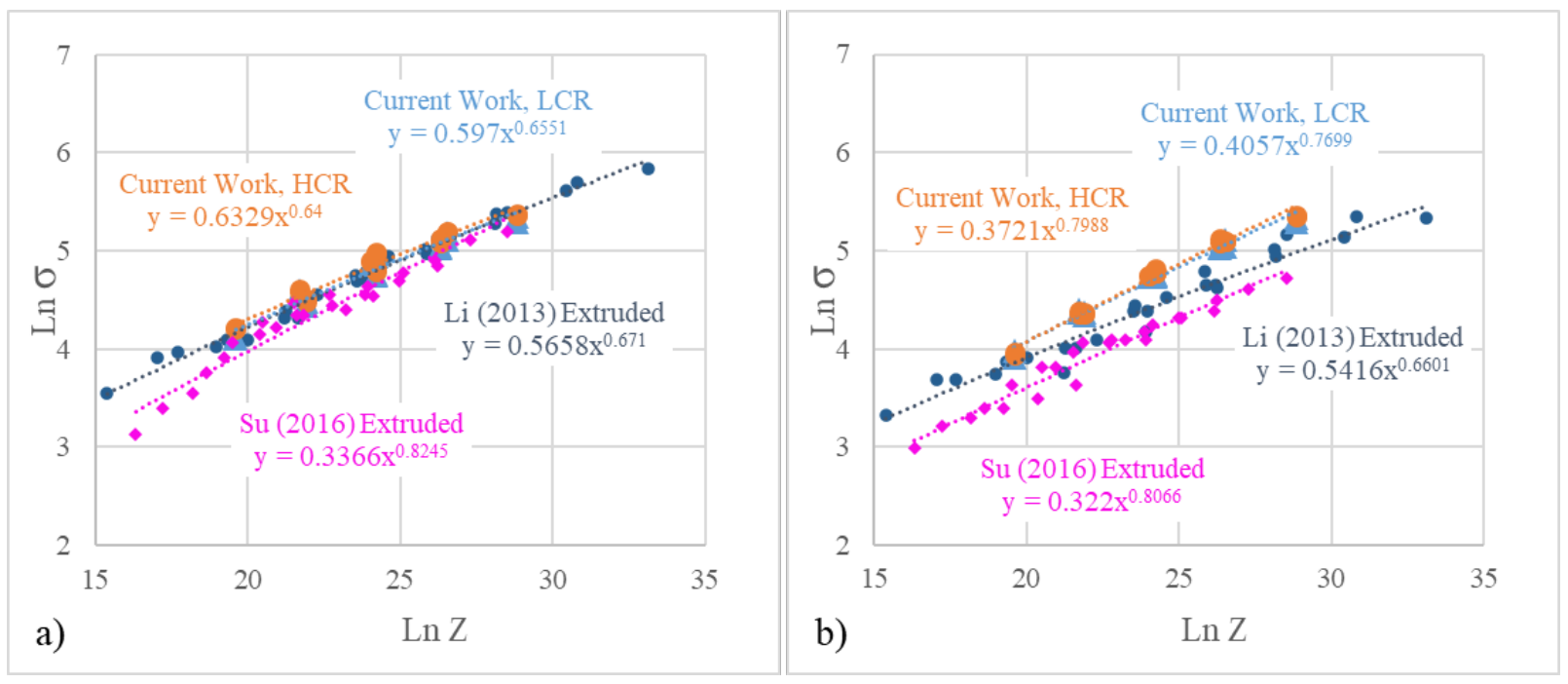

Figure 5.22: The natural logarithm of the calculated $\mathrm{Z}$ parameter plotted against the natural logarithm of the a) maximum true stress, and b) true stress at a strain of 0.7 , comparing results from the HCR and LCR wedge casting with values in literature. Data extrapolated from $[49,76]$.

The current works are in reasonable agreement with what is published in the literature for the AZ80 alloy. For a given combination of strain rate and deformation temperature, the influence of casting cooling rate appears much lesser than that of a pre-forging deformation process, such as extrusion, when attempting to lower the compressive stress. In the cast material, it is the material with the finer grain size (HCR) that has a higher peak stress both at the peak stress and at a strain of 0.7. The research on extruded AZ80 that are shown all have lower peak stress values for each corresponding $\mathrm{Z}$ value when compared to the cast material in this research. It has been shown that extruded material can reach the peak stress at an earlier strain than cast material, indicating an earlier onset of DRX, owing to their fine grain size [31]. Extruded materials also show a more rapid softening following the peak stress, indicating either faster DRX kinetics or a preferential texture for slip system activation [31]. This is evident in Figure $5.22 \mathrm{~b}$, as the extruded material measures much lower of a compressive stress than the as-cast material. Since the LCR cast material showed a lower peak stress than the HCR material, despite a larger grain size, the lower peak stress in the extruded materials is attributed to the easier activation of deformation mechanisms by a preferential texture. The lath precipitates present in the cast material also influence the onset of dynamic recrystallization [74], which may explain the higher peak stress and higher strain required to reach the peak stress in the cast material. 
Finally, the HCR and LCR wedge cast samples are evaluated on their forgeability based on their propensity to crack under higher strains, over all of the deformation conditions tested. While difficult to quantify, the occurrence of cracking during compression testing may be indicative of a higher risk of cracking during forging, where even higher strains will be seen. An example of these cracked samples is shown in Figure 5.23.

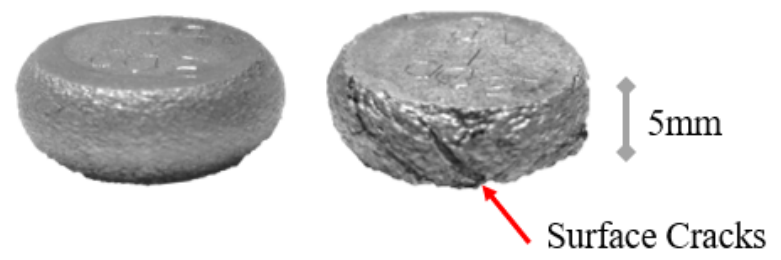

Figure 5.23: Examples of a de-gas AZ80 HCR sample which did not experience surface cracking (left), and a de-gas AZ80 LCR sample which did show surface cracking (right), after compression at $300^{\circ} \mathrm{C}$ and a strain rate of $1 \mathrm{~s}^{-1}$ to a strain of 1.0 .

Each sample was evaluated, and the results are summarized in Table 5.1, where samples that did not show visual signs of cracking are marked with a check mark. The de-gas samples are more favorable for forging, as they showed fewer deformation conditions where cracking was observed. Further, by this comparison, HCR samples proved more favorable for forging in both the as-cast and de-gas materials. It is noted that deformation conditions with a higher $\mathrm{Z}$ value (i.e. higher strain rate and/or lower temperature) are more likely to induce cracking in the test samples. It is believed that porosity is the most significant contributor to crack propensity in these samples, since it is the LCR as-cast samples which see the highest amount of cracking. It is possible however, that some cracking could occur due to the larger eutectic $\mathrm{Mg}_{17} \mathrm{Al}_{12}$ regions which are seen in the LCR material, since having a fine and dispersed intermetallic is more favorable for ductility [12]. 
Table 5.1: A summary of the qualitative surface crack evaluation, for as-cast and de-gas wedge cast material, of HCR and LCR conditions, for each temperature and strain rate tested.

\begin{tabular}{|c|c|c|c|c|c|c|c|c|}
\hline & \multicolumn{3}{|c|}{ As-cast } & \multicolumn{4}{|c|}{ De-gas } \\
\hline & & \multicolumn{3}{|c|}{ Strain Rate } & & \multicolumn{3}{|c|}{ Strain Rate } \\
\hline & & $0.01 \mathrm{~s}^{-1}$ & $0.1 \mathrm{~s}^{-1}$ & $1 s^{-1}$ & & $0.01 s^{-1}$ & $0.1 \mathrm{~s}^{-1}$ & $1 s^{-1}$ \\
\hline \multirow{5}{*}{ LCR } & \multirow{3}{*}{$\begin{array}{l}250^{\circ} \mathrm{C} \\
300^{\circ} \mathrm{C} \\
350^{\circ} \mathrm{C}\end{array}$} & $\mathbf{X}$ & $\mathbf{X}$ & $\mathbf{X}$ & \multirow{3}{*}{$\begin{array}{l}250^{\circ} \mathrm{C} \\
300^{\circ} \mathrm{C} \\
350^{\circ} \mathrm{C}\end{array}$} & $\mathbf{x}$ & $\mathbf{X}$ & $\mathbf{X}$ \\
\hline & & $x$ & $x$ & $x$ & & $\checkmark$ & $\checkmark$ & $x$ \\
\hline & & $X$ & 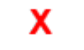 & $x$ & & $\checkmark$ & $\checkmark$ & $\checkmark$ \\
\hline & & & rrain $\mathrm{Ra}$ & & & & train $\mathrm{Rz}$ & \\
\hline & & $0.01 \mathrm{~s}^{-1}$ & $0.1 \mathrm{~s}^{-1}$ & $1 s^{-1}$ & & $0.01 \mathrm{~s}^{-1}$ & $0.1 \mathrm{~s}^{-1}$ & $1 s^{-1}$ \\
\hline \multirow{3}{*}{ HCR } & $250^{\circ} \mathrm{C}$ & $\checkmark$ & $x$ & $x$ & \multirow{3}{*}{$\begin{array}{ll} & 250^{\circ} \mathrm{C} \\
& 300^{\circ} \mathrm{C} \\
350^{\circ} \mathrm{C}\end{array}$} & $\checkmark$ & $\checkmark$ & $x$ \\
\hline & $300^{\circ} \mathrm{C}$ & $\checkmark$ & $x$ & $x$ & & $\checkmark$ & $\checkmark$ & $\checkmark$ \\
\hline & $350^{\circ} \mathrm{C}$ & $\checkmark$ & $\checkmark$ & $\checkmark$ & & $\checkmark$ & $\checkmark$ & $\checkmark$ \\
\hline
\end{tabular}

\subsubsection{Effect of Homogenization}

To study the effect of homogenization treatment prior to the deformation of AZ80, samples from both the as-cast wedge casting, and the air cooled cylinder castings were used. The wedge cast samples included both HCR and LCR samples, to show the effect of cooling rate combined with homogenization, on the compressive stress and crack propensity. Due to their abundance, the air cooled cylinder cast samples were used for a detailed investigation of the microstructure evolution of both cast and homogenized conditions. In material from either casting process, the effect of homogenization is made most apparent after the peak stress in the compressive true stress-true strain curve, during the dynamic softening stage. This effect is shown in Figure 5.24, where the work hardening rate is plotted alongside the compressive stress against the strain, for both as-cast and homogenized samples from the air cooled cylinder, deformed at $300^{\circ} \mathrm{C}$ and a strain rate of $0.1 \mathrm{~s}^{-1}$. In the homogenized samples, the peak stress occurs at a lower strain than in the as-cast samples. This is a result of earlier occurrence of dynamic recrystallization in the homogenized material, which is responsible for the softening effect seen in the compressive stress curve. The homogenized material also experiences a higher amount dynamic softening compared to the as-cast material, lowering the compressive stress at a much higher rate. At the steady state stress, the homogenized material remains lower than the as-cast material. A homogenization treat- 


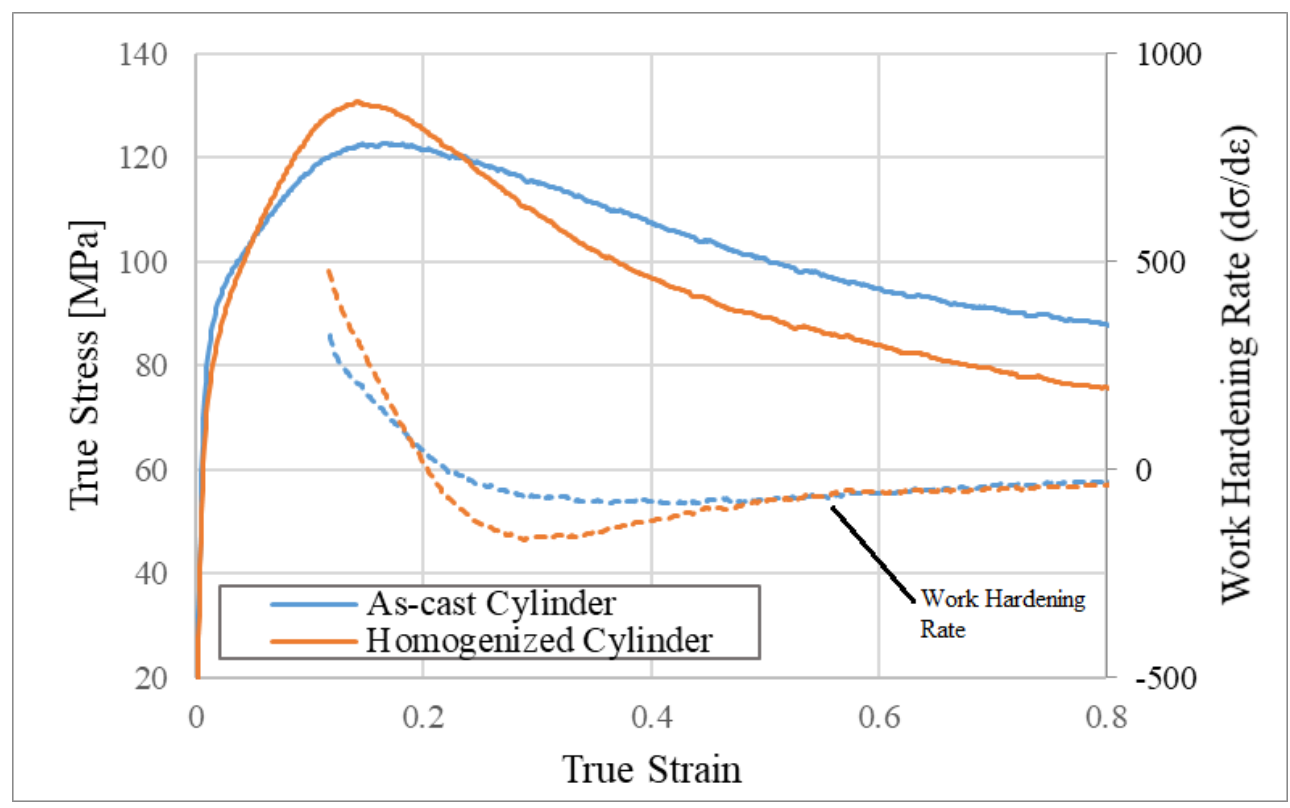

Figure 5.24: True stress-true strain curves for as-cast and cast-homogenized air cooled cylinders, compressed at $300^{\circ} \mathrm{C}$ and a strain rate of $0.1 \mathrm{~s}^{-1}$.

ment is often applied prior to deformation, with the intent of lowering the compressive stress, and therefore lowering the required forging load. This effect is well documented for alloys AZ31 [43, 44], and AZ61 [45]. In the cylinder however, the peak compressive stress is actually increased in the homogenized material. In high strain rate tests on AZ31, Prasad et al. [43] measured a higher compressive stress in homogenized samples, though this was attributed to fracture of the as-cast samples. The explanation behind the apparent increase in peak stress in the homogenized material in this research is instead better understood as a decrease in compressive stress in the cast cylinder material. Referring to the microstructure presented in Figure 5.10 a and c, the cylinder casting has a high amount of discontinuous precipitates near the grain boundaries, which are known to promote the formation of DRX grains. Therefore, the homogenized material measures a higher peak compressive stress, as it lacks the discontinuous precipitates near the grain boundaries necessary for early onset of DRX. This effect was seen in all deformation conditions tested, shown in Appendix B.

HCR and LCR samples from the as-cast wedge casting were also prepared with the same homogenization treatment and tested in compression. Both cooling rates were tested in their as-cast and homogenized states, at a deformation temperature of $300^{\circ} \mathrm{C}$, and at strain rates of $1 \mathrm{~s}^{-1}, 0.1 \mathrm{~s}^{-1}$, and $0.01 \mathrm{~s}^{-1}$. The results of these compression tests are shown in Figure 
5.25. Similar to the cylinder material, the homogenized samples experience a higher de-
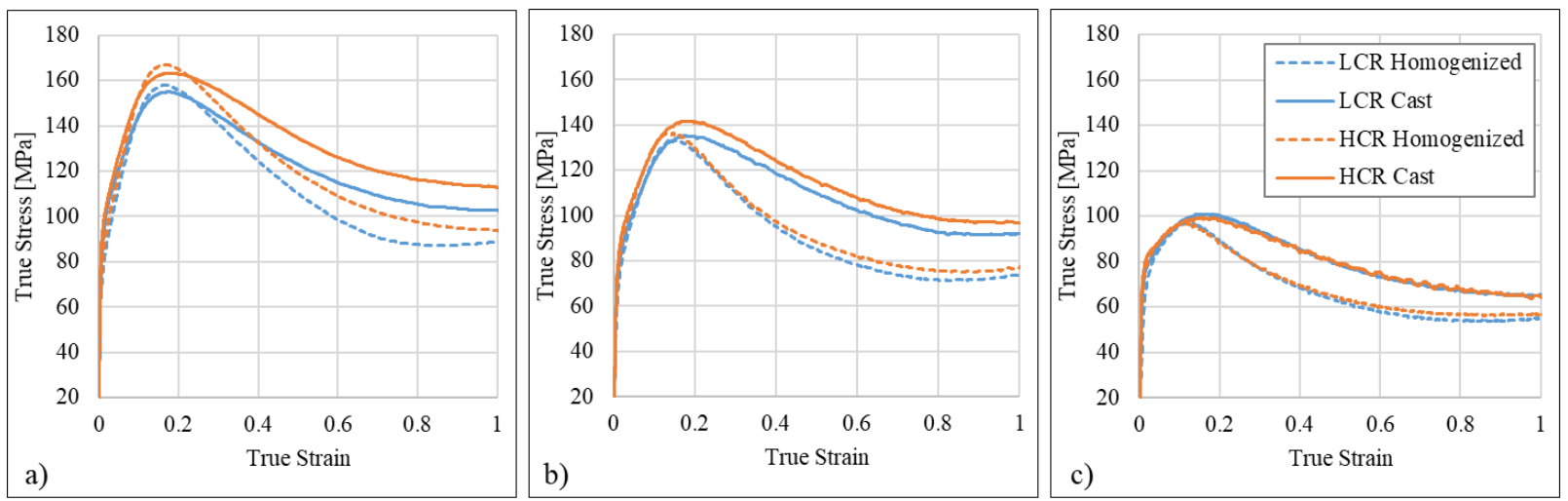

Figure 5.25: The compressive true stress-true strain curves for as-cast and homogenized LCR and HCR material: a) $300^{\circ} \mathrm{C}_{\text {and }} 1 \mathrm{~s}^{-1}$, b) $300^{\circ} \mathrm{C}$ and $0.1 \mathrm{~s}^{-1}$, and c) $300^{\circ} \mathrm{C}$ and $0.01 \mathrm{~s}^{-1}$.

gree of dynamic softening than the as-cast samples. The peak compressive stress remains greater in the higher cooling rate material even after the samples have been homogenized, and this effect is more apparent at higher strain rates for both cast and homogenized conditions. Therefore, the higher peak stress in the HCR samples must be a result of refined grain size, and not intermetallic morphology. The Z parameter was also calculated for the homogenized material, to show how the effect of deformation parameters may differ between cast or homogenized material. These results are plotted in Figure $5.26 \mathrm{a}$ and b, showing the relationship between the $\mathrm{Z}$ parameter and the peak stress, and the stress at a strain of 0.7 , respectively. The effect of homogenization at the peak stress is not significant for the wedge cast material. At higher strains however, the homogenization treatment shows a significant reduction in compressive stress, similar to the comparison between ascast material in this study, and extruded material in literature.

An interesting distinction from the compressive stress curves for the cylinder casting in Figure 5.24 however, is that the wedge cast material does not experience an increase in peak stress after homogenization. Only at the highest strain rate of $1 \mathrm{~s}^{-1}$ does the homogenized material have a peak stress exceeding that of the cast material, however in both LCR and HCR conditions this difference is not statistically significant. To understand this, the cast microstructure of these samples before homogenization must be compared. A comparison of the wedge cast and cylinder cast samples that were used for this study, may be seen in Figure 5.27. The microstructure of the wedge cast sample does contain $\mathrm{Mg}_{17} \mathrm{Al}_{12}$ phases, however there are no discontinuous precipitates near to the grain boundaries, much like the 


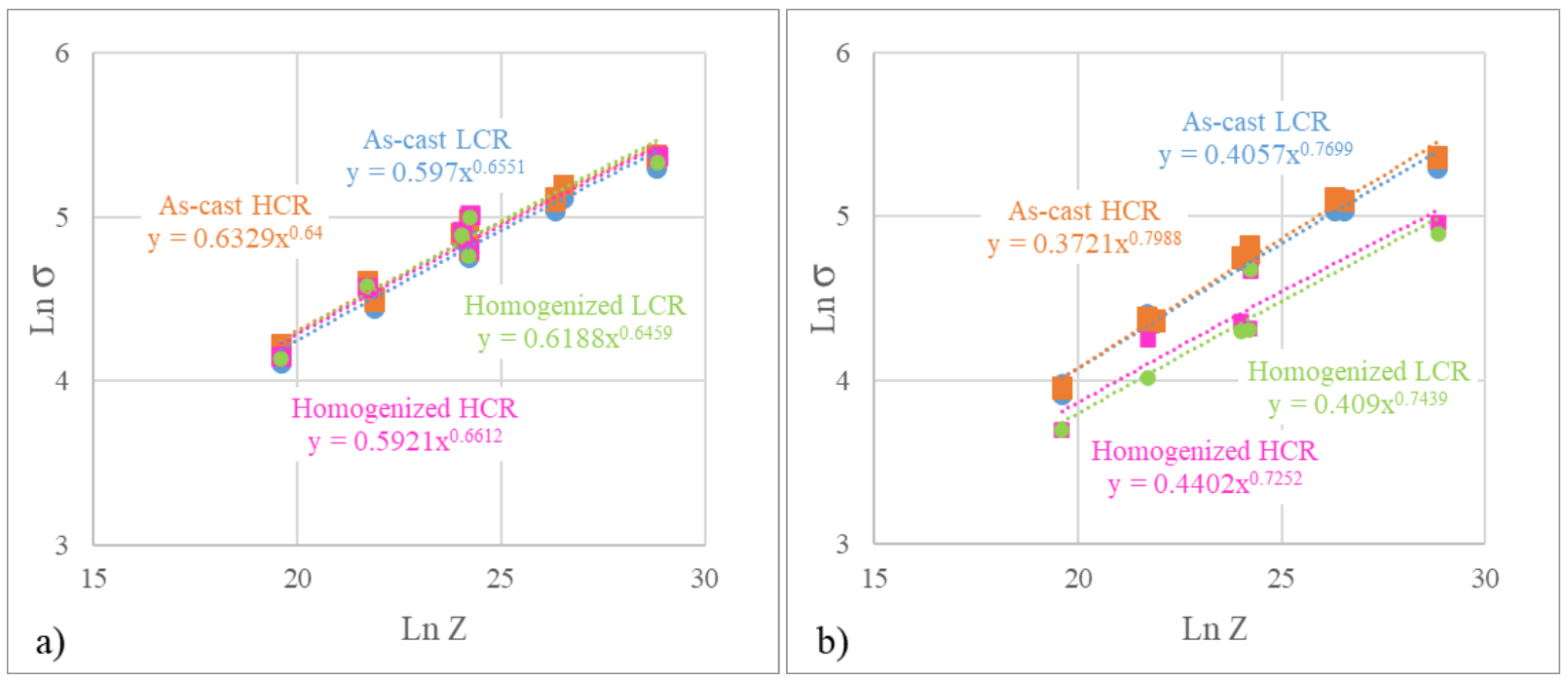

Figure 5.26: The natural logarithm of the calculated Z parameter plotted against the natural logarithm of the a) maximum true stress, and b) true stress at a strain of 0.7 , for cast and homogenized LCR and HCR wedge cast material.
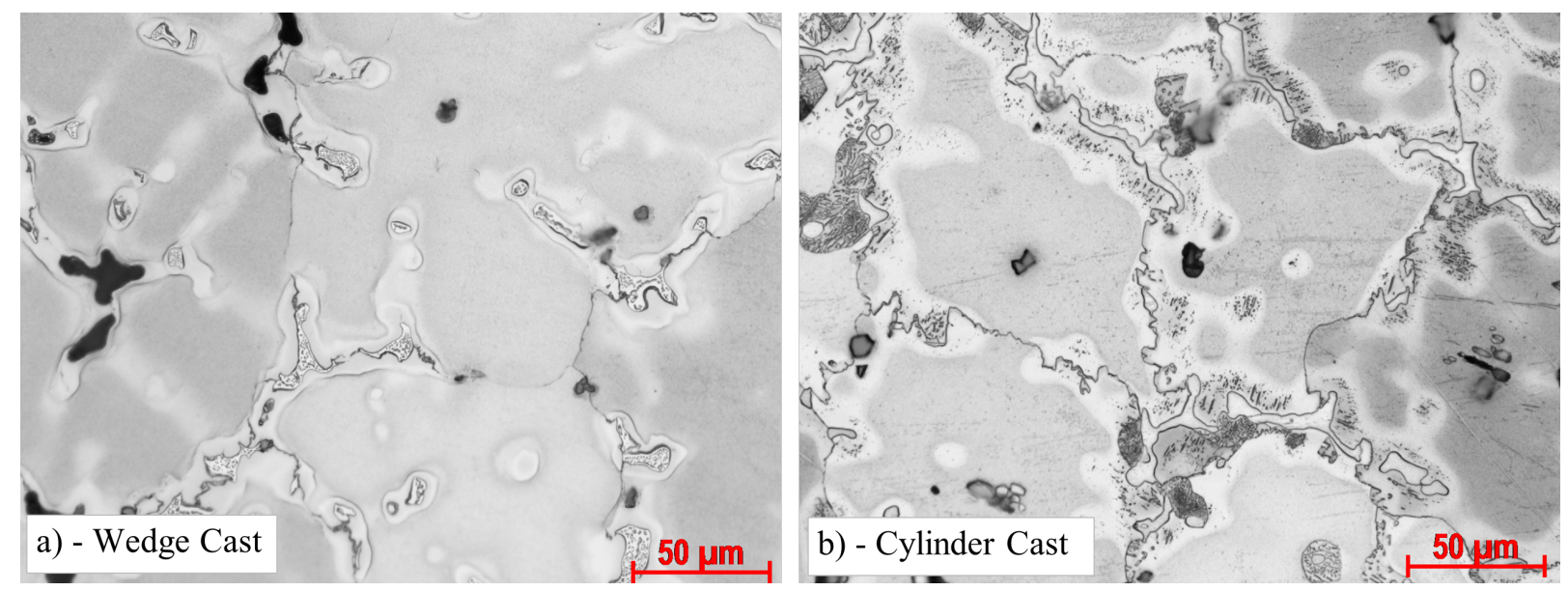

Figure 5.27: Optical microstructures of a) LCR as-cast wedge cast AZ80, and b) air cooled cylinder cast AZ80.

homogenized microstructure presented in 5.11. It is believed that the lack of discontinuous $\mathrm{Mg}_{17} \mathrm{Al}_{12}$ precipitates in the wedge cast sample are responsible for the different response to homogenization. As described for the phenomena in Figure 5.24, discontinuous $\mathrm{Mg}_{17} \mathrm{Al}_{12}$ 
precipitates, such as the ones seen in the cylinder cast material, can promote dynamic recrystallization [74, which can lower the compressive stress. When the compressive true stress-true strain curves are plotted alongside one another, as in Figure 5.28, it is clear that the wedge cast material has a higher peak compressive stress than the cylinder cast material. After homogenization however, these values are very comparable, indicating that this difference in compressive stress is a result of the difference in $\mathrm{Mg}_{17} \mathrm{Al}_{12}$ morphology. Therefore, homogenization may be an effective method at reducing the compressive stress in AZ80 as with other alloys, though may be dependent on the precipitate morphology of the initial cast microstructure.

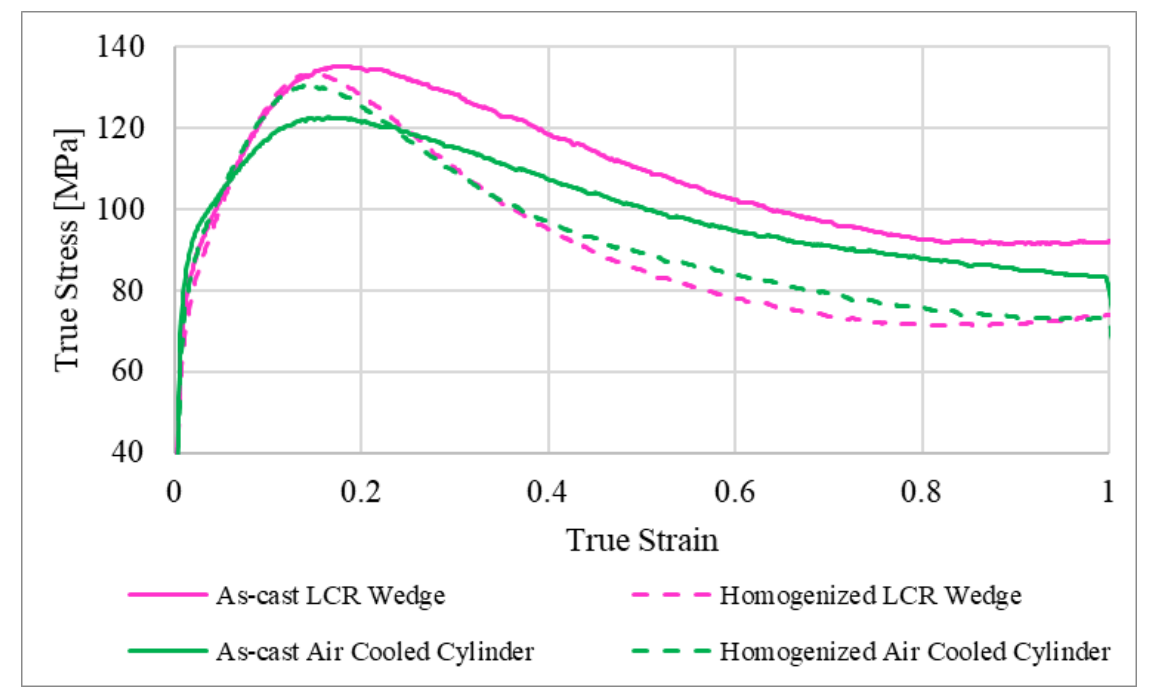

Figure 5.28: Compressive true stress-true strain curves for the as-cast and homogenized samples of the LCR wedge and air cooled cylinder castings, deformed at a strain rate of $0.1 \mathrm{~s}^{-1}$ and a temperature of $300^{\circ} \mathrm{C}$.

The cracking of homogenized samples was also studied, for de-gas LCR and HCR wedge material. Due to the limited samples available, only two temperatures and two strain rates were tested. The results of the crack observation on homogenized samples are shown in Table 5.2. compared to the previous result from the de-gas wedge cast material. It is evident that homogenization had no influence on the sample cracking during deformation. This means that cracking is likely more influenced by porosity in the cast structure than the intermetallic volume fraction or morphology, since the intermetallic phase was in solution with the $\alpha-\mathrm{Mg}$ phase in the homogenized samples. 
Table 5.2: A summary of the qualitative surface crack evaluation, for de-gas and homogenized material, of HCR and LCR conditions, for each temperature and strain rate tested.

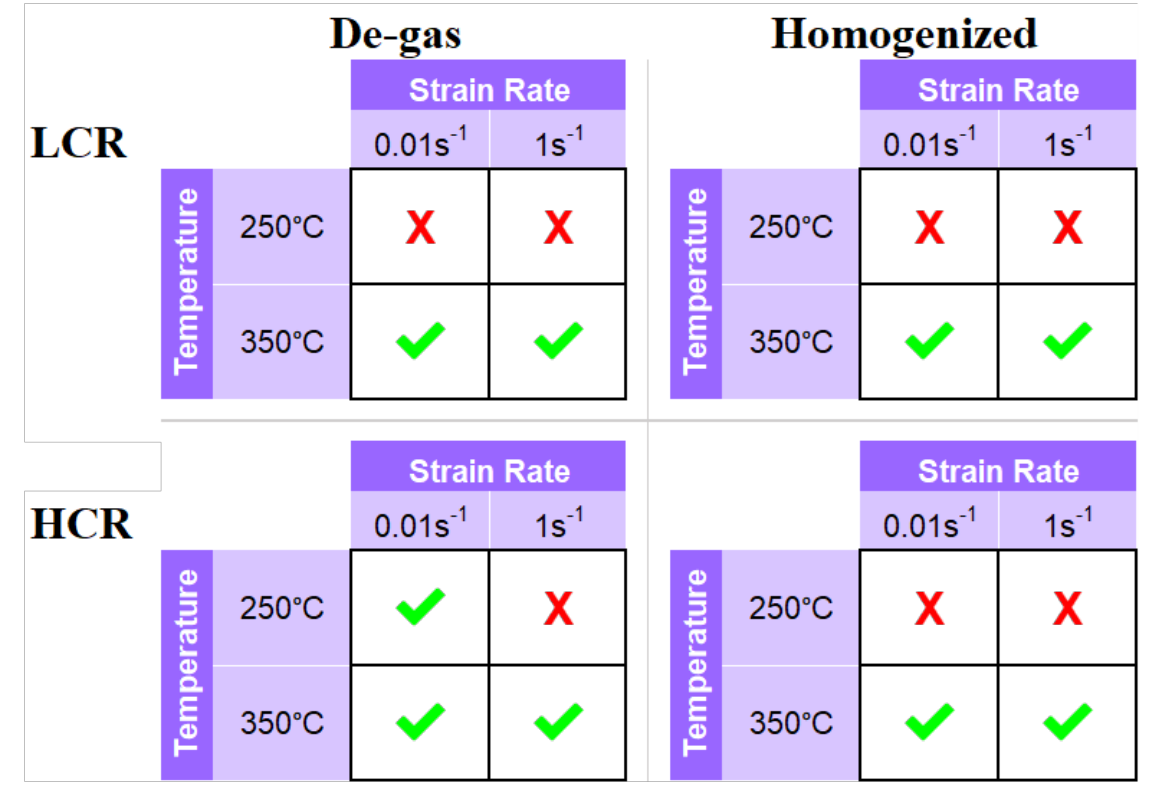

\subsubsection{Evolution of Cast and Homogenized Microstructure}

A microstructure study was performed on deformed samples for the as-cast and homogenized air cooled cylinder castings, at various levels of strain, to better understand the deformation mechanisms and evolution of the microstructure in compression. Samples were analyzed at strains of $0.15,0.4$, and 1.0 , after compression at $300^{\circ} \mathrm{C}$ and a strain rate of $0.01 \mathrm{~s}^{-1}$. The compressive true stress-true strain curves for these samples, with microstructure images in the undeformed state and at the aforementioned strains, are shown in Figure 5.29. The microstructures of these samples can be seen in better detail in Figures 5.30 and 5.31 for cast and homogenized samples, respectively. 


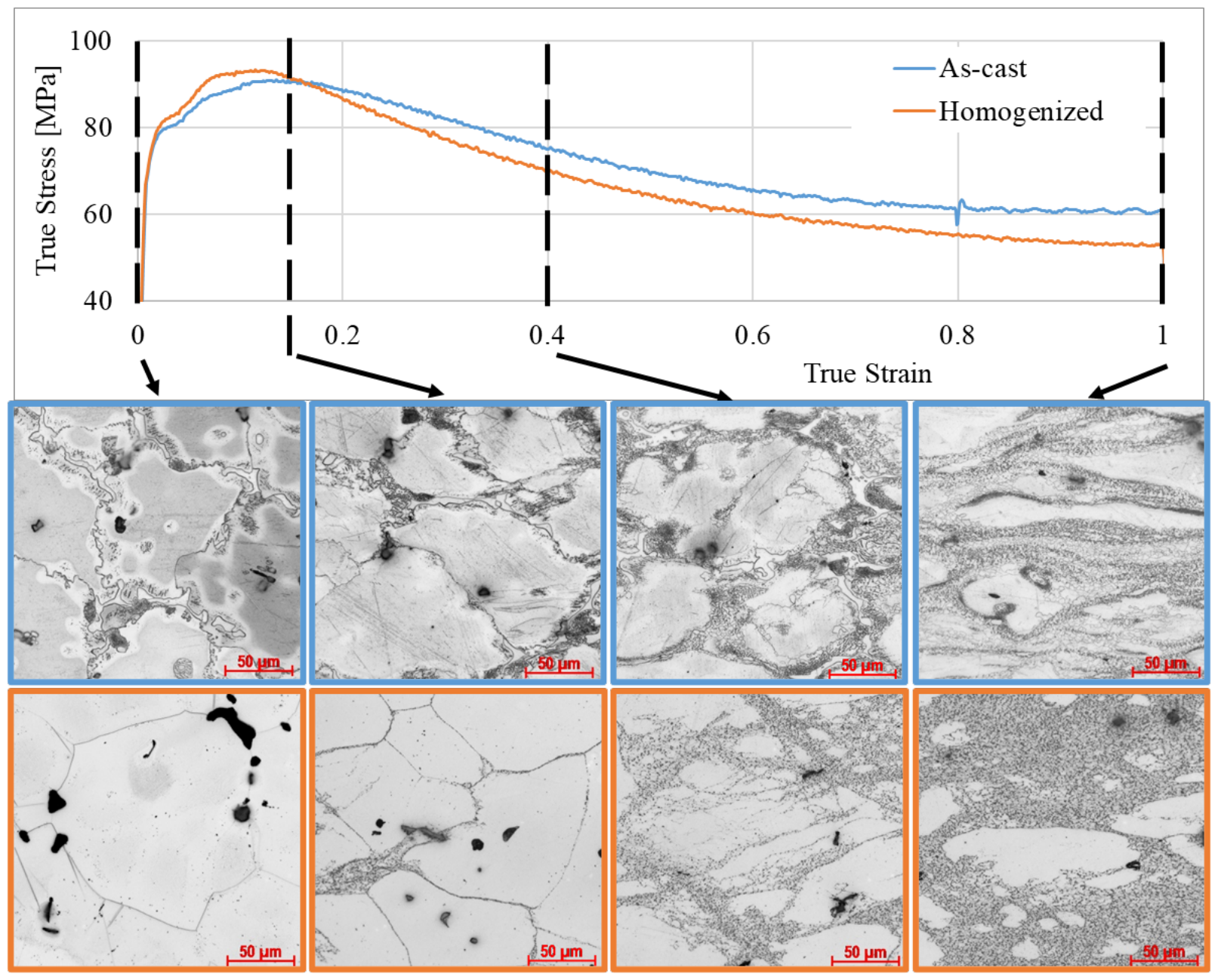

Figure 5.29: Compressive true stress-true strain curves for the as-cast and homogenized cylinder cast samples, compressed at a temperature of $300^{\circ} \mathrm{C}$ and a strain rate of $0.01 \mathrm{~s}^{-1}$. The strain at which each image is taken is shown by vertical dashed lines on the plot. 

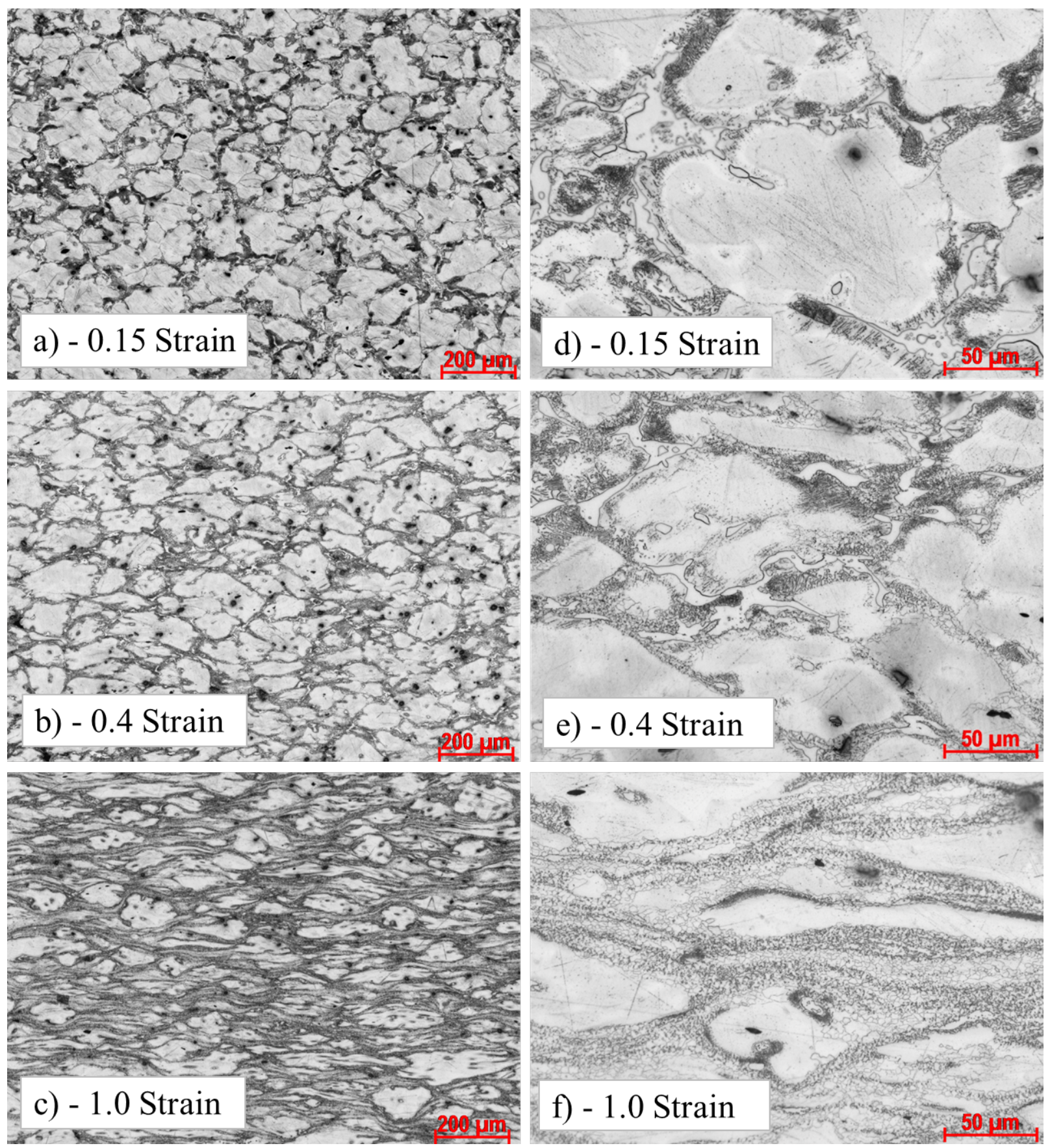

Figure 5.30: Optical microstructure of the cast deformed samples from the cylinder casting: a) 0.15 strain $100 \mathrm{x}$ magnification, b) 0.4 strain $100 \mathrm{x}$ magnification, c) 1.0 strain $100 \mathrm{x}$ magnification, d) 0.15 strain 500x magnification, e) 0.4 strain 500x magnification, and f) 1.0 strain 500x magnification. 

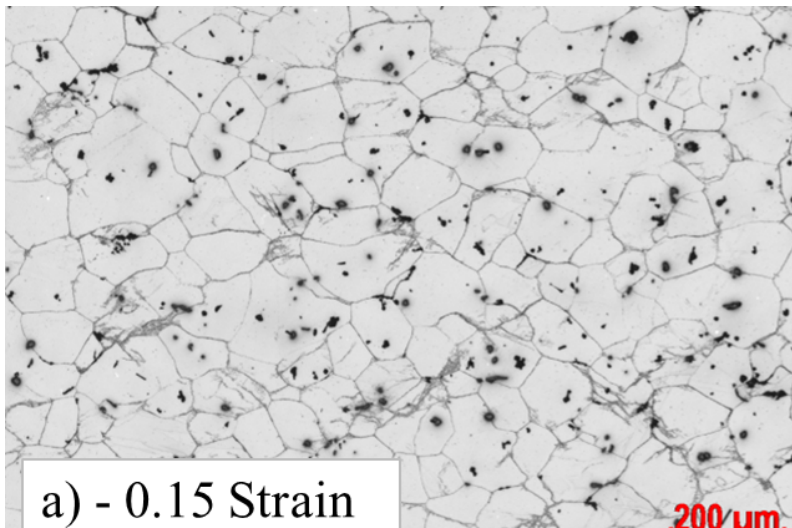

$200 \mathrm{um}$
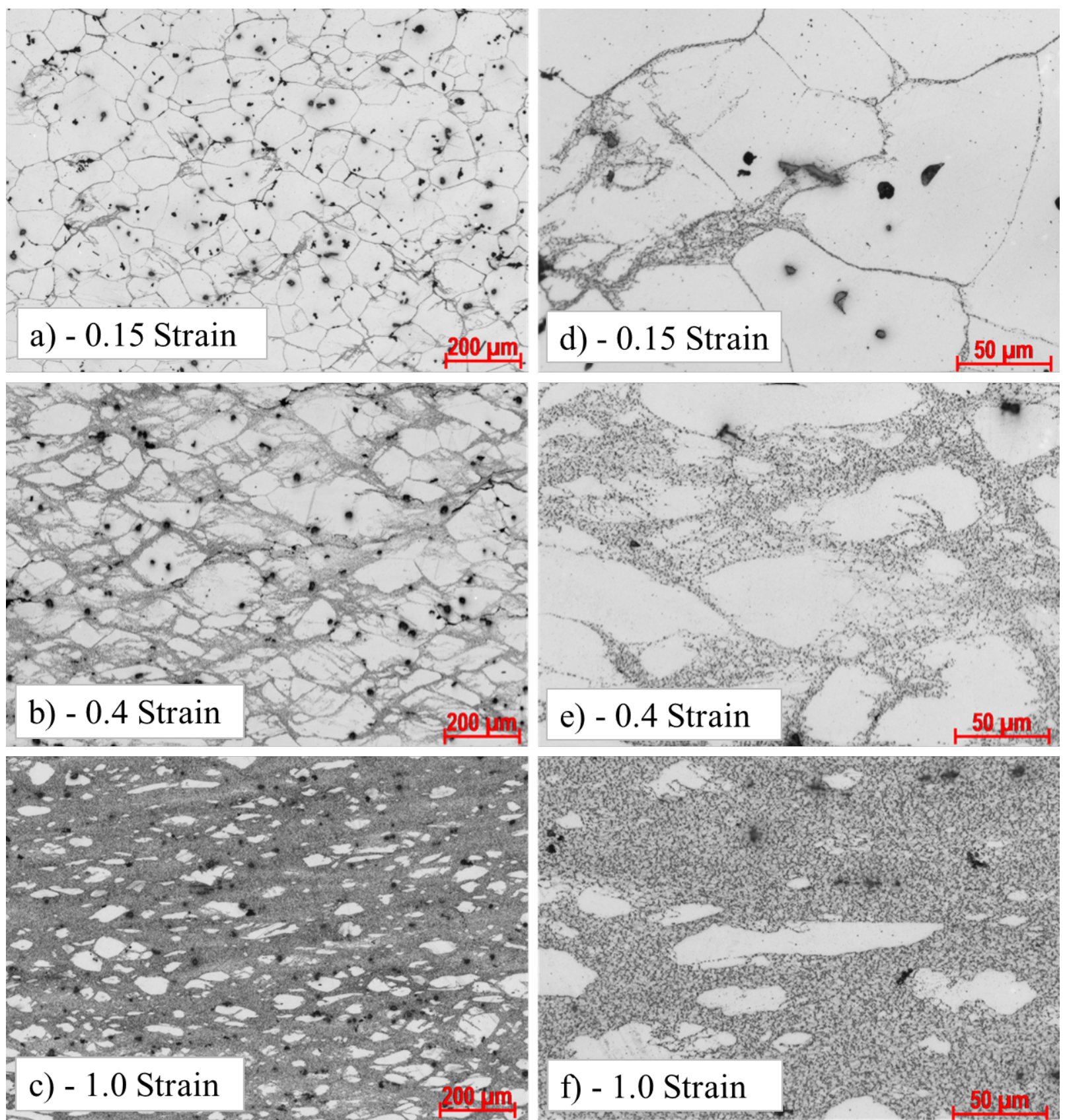

Figure 5.31: Optical microstructure of the homogenized deformed samples from the cylinder casting: a) 0.15 strain 100x magnification, b) 0.4 strain 100x magnification, c) 1.0 strain 100x magnification, d) 0.15 strain 500x magnification, e) 0.4 strain 500x magnification, and f) 1.0 strain 500x magnification. 
The cast microstructure does not show much evidence of deformation at a strain of 0.15 , however some DRX grains can be observed in Figure $5.30 \mathrm{~d}$, at the grain boundaries. At a strain of 0.4 , the grains are noticeably more compressed, and a significant amount of DRX has occurred. Similar to the 0.15 strain sample, these DRX grains appear at the grain boundaries, but also among the discontinuous precipitates near the grain boundaries. Finally, the sample which was deformed to a strain of 1.0 shows a bi-modal grain structure. There is a high fraction of very fine DRX grains, however there are still many large grains which have not been recrystallized. The high magnification image of Figure 5.30: shows that many of the DRX grains are similar in size, but comparing to the sample at 0.4 strain, some DRX grain growth has since occurred. DRX formation at the discontinuous lamellar precipitates is thought to occur in these samples, since the presence of these precipitates diminishes with an increase in strain, along with an increase in percentage of DRX grains. The microstructure of homogenized deformed samples is unlike that of the cast material. At a strain of 0.15 , the occurrence of DRX is more apparent, with regions near the grain boundaries already showing recrystallization. At a strain of 0.4 , a similar trend is seen where recrystallized grains are most apparent at the grain boundaries. At a strain of 1.0, there is a high volume fraction of DRX grains, and a bi-modal grain structure. The percentage of the microstructure which has become DRX grains was measured for cast and homogenized samples, at strains of 0.4 and 1.0, using the technique described in Section 4.3.2. The results are plotted in Figure 5.32 .

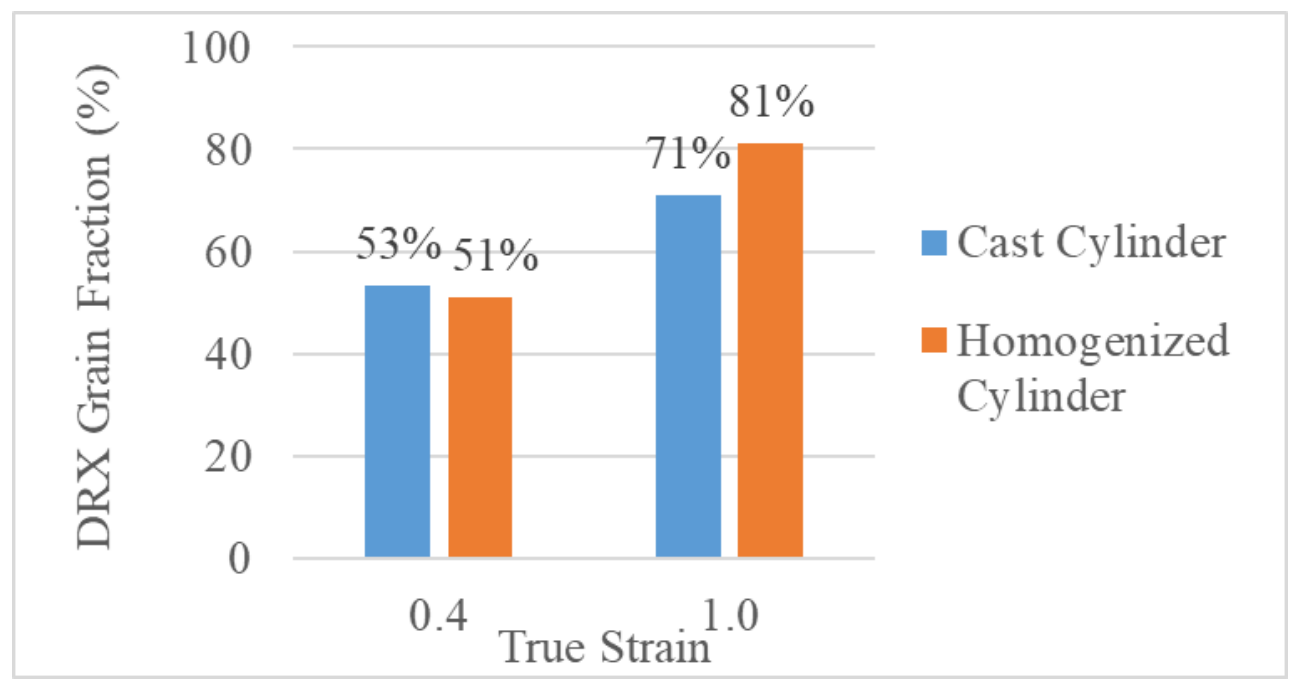

Figure 5.32: The percentage of area of DRX grains for cast and homogenized cylinder samples, at a deformation temperature of $300^{\circ} \mathrm{C}$ and a strain rate of $0.01 \mathrm{~s}^{-1}$. 
Despite measuring a similar amount of recrystallization at a strain of 0.4 , there is significantly more recrystallization at higher strains than in the cast samples. It is believed that the volume fraction of DRX grains in the as-cast material at a strain of 0.4 is less than what was measured. Since this analysis was done only by filtering regions of the image by brightness, it may be that some of what was measured to be DRX grains may actually have been lamellar precipitates. Visually comparing Figure 5.30e and 5.31e confirms that the homogenized sample should have a higher fraction of DRX grains than that of the as-cast sample. At the strain of 1.0 for the homogenized material, there are very few remaining grains which have not recrystallized, many of such grains are also smaller in size than that of the cast sample. The reason behind this increase in DRX occurrence in the homogenized samples has been well studied, and is a result of the dissolution of the continuous precipitates present in the cast microstructure. In the cast samples, continuous precipitates near the grain boundaries can pin DRX grains, restricting both the amount of DRX grains that form and their growth [45, 74]. Twinning is also observed in the homogenized sample at strains of 0.15 and 0.4 , and some DRX has occurred along the twin boundary. Twinning may have also occurred in the cast sample, however since there was typically less DRX in the cast sample, it is possible that the twins are simply not visible, as they are only apparent in the homogenized sample from DRX occurring at their boundaries.

The porosity was also measured at each level of strain, to understand the amount of forging that would be necessary to eliminate porosity effects on the mechanical properties. The results of these measurements are shown in Figure. 5.33

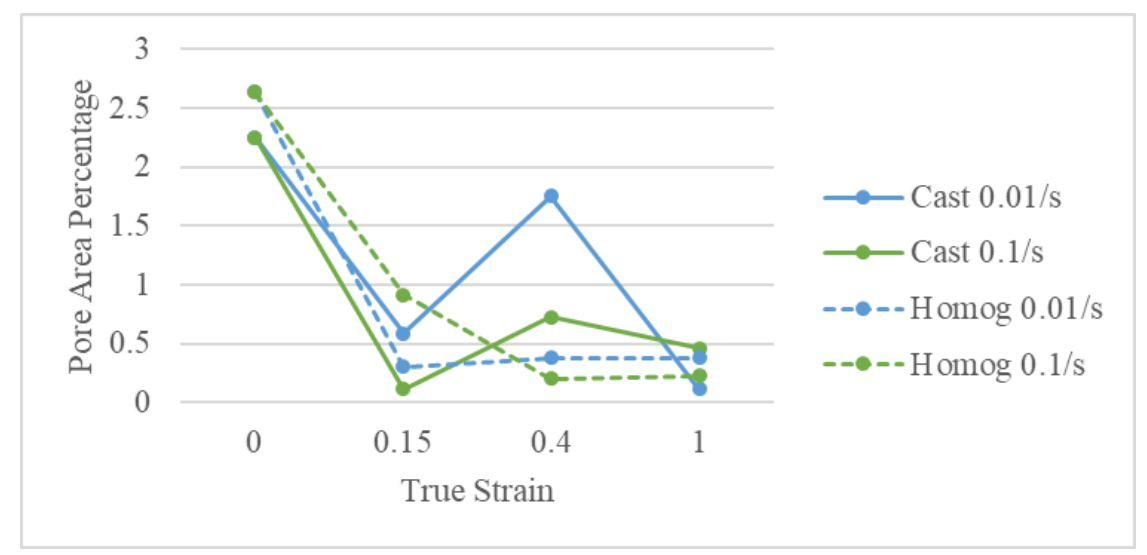

Figure 5.33: The evolution of porosity volume estimated by measured 2D pore area with increasing strain, for both the cast and homogenized LCR cylinder samples, at strain rates of $0.01 \mathrm{~s}^{-1}$ and $0.1 \mathrm{~s}^{-1}$. 
The amount of porosity in both the cast and homogenized samples was similar prior to deformation. After deforming only to a strain of 0.15 , the apparent porosity is reduced, as the pores are closing during compression. Further deformation does not appear to have as significant of an effect on further reduction of porosity. It is possible that the remaining percentage of porosity at a strain of 1.0 is due to the inaccuracies of this measurement method. Since the areas are only selected by shade of colour in the image, it is possible that some of what is measured as porosity is actually intermetallic particles. Since this method only measures one cross-sectional area of the sample and not the entire volume, it is not fully representative of the porosity, but provides an estimate. This may explain for the high measured porosity at a strain of 0.4 for the cast sample deformed at a strain rate of $0.01 \mathrm{~s}^{-1}$, where the image may have been taken on an area that had particularly high local porosity. 


\section{Conclusions and Future Work}

\subsection{Conclusions}

This research is part of a Natural Sciences and Engineering Research Council of Canada's Strategic Partnership Grant. The intent of this project is to produce an automotive suspension control arm for a Ford Fusion car, through casting and forging of the AZ80 alloy. This research investigated the elevated temperature deformation behaviour of the AZ80 alloy, with consideration of the initial microstructure of the casting. Much of this work concentrated on the influence of the casting process on the cast microstructure, and how that microstructure subsequently influences the compressive flow stress at elevated temperatures. The main findings of this research are as follows:

1) The microstructure of cast AZ80 becomes more refined when it is cast with a high cooling rate during solidification. As-cast samples with a cooling rate of $25^{\circ} \mathrm{C} / \mathrm{s}$ saw a SDAS and grain size of $17 \mu \mathrm{m}$ and $118 \mu \mathrm{m}$ respectively, and when the cooling rate was approximately $3^{\circ} \mathrm{C} / \mathrm{s}$, the SDAS and grain size measured $27 \mu \mathrm{m}$ and $201 \mu \mathrm{m}$ respectively. Much of the grain size effects are found to occur during the earlier stages of solidification, however. During later stages of solidification, nearer to the melting temperature of the $\mathrm{Mg}_{17} \mathrm{Al}_{12}$ phase, a slowing of the cooling rate will result in a less divorced eutectic morphology, and more precipitated $\mathrm{Mg}_{17} \mathrm{Al}_{12}$ along the grain boundaries. This phenomenon can occur even in lower cooling rate castings if the cooling rate is slowed further during later stages of solidification.

De-gassing of the melt prior to casting, through addition of hexachloroethane, was an effective method for reducing the gas porosity that was seen in the castings. The de-gassing addition is not believed to have any other influence on cast microstructure, relating to either grain size or intermetallic morphology.

2) Effective dissolving and sufficient diffusion of the $\mathrm{Mg}_{17} \mathrm{Al}_{12}$ phase was achieved by the homogenization heat treatment, performed at $420^{\circ} \mathrm{C}$ for 24 hours. It is unclear if the sample was fully homogenized (i.e. evenly dispersed solute within the matrix), as the microstructure was only analyzed by optical microscope, however the material has become solutionized, as all of the precipitated and eutectic $\mathrm{Mg}_{17} \mathrm{Al}_{12}$ is no longer visible. Some grain growth was observed during homogenization; however it is very small in comparison to the difference between HCR and LCR wedge castings, and therefore is not believed to have any effect on the results.

3) Cast AZ80 which has a more refined grain structure (i.e. smaller SDAS or grain size), 
will result in a higher peak compressive stress during hot deformation. This effect is most significant at high values of the $\mathrm{Z}$ parameter, and while the effect is still present at lower $\mathrm{Z}$ values, there is not as significant of a difference between the compressive stress of coarse and fine grain structures. The effect of the SDAS/grain size remains even after homogenization, indicating that this elevated stress with refined grain structures is not a result of different intermetallic volume fraction or morphology, which may also occur with a change in cast cooling rate. At higher levels of strain, where the stress is nearing a steady state condition, the compressive stress is comparable between samples, regardless of their initial grain structure. It is believed that at this point, significant enough deformation and recrystallization has occurred that there is no remaining effect of the initial microstructure.

At high strains during hot deformation, samples which are cast with more porosity will experience more visible cracking after deformation. The addition of the hexachloroethane de-gassing agent is effective at reducing the gas porosity during casting, however it cannot eliminate shrinkage porosity. Samples which had been de-gassed were observed to have fewer visible surface cracks after deformation than the as-cast samples. Samples cast with a higher cooling rate also showed less cracking than the lower cooling rate samples, however this is a result of the high amount of shrinkage porosity that can occur during the wedge casting process. These effects are also sensitive to the deformation strain rate and temperature, as cracking was more prominent at higher values of the $\mathrm{Z}$ parameter. Cracking was not found to be related to the volume fraction or morphology of $\mathrm{Mg}_{17} \mathrm{Al}_{12}$, as samples which had undergone homogenization treatment were still found to crack under many of the same deformation conditions as the HCR and LCR as-cast and samples. While the de-gassing of the melt was effective at reducing porosity, there was no observed effect on the compressive stress after de-gassing.

4) The microstructure evolution of the AZ80 alloy during hot deformation is highly dependent on the volume fraction and morphology of the precipitated $\mathrm{Mg}_{17} \mathrm{Al}_{12}$ phase. Samples which have a higher amount of discontinuous lamellar precipitates near the grain boundaries will have a lower peak compressive stress, due to the promoted DRX grain formation at these precipitates. Samples which have had their $\mathrm{Mg}_{17} \mathrm{Al}_{12}$ phase dissolved by homogenization will see an increase in the volume fraction of DRX grains during deformation. This is due to the lack of continuous $\mathrm{Mg}_{17} \mathrm{Al}_{12}$ precipitates, which are known to pin DRX grains [45, 74]. The higher volume fraction of DRX grains results in a slight reduction of the peak compressive stress, a lower strain required to reach the peak stress, and rapid dynamic softening following the peak stress. This is evident in the microstructures, as the homogenized samples show a higher fraction of DRX grains than the as-cast samples throughout deformation following the peak stress. However, in castings with a high amount 
of discontinuous lamellar precipitates in the microstructure prior to homogenization, the peak compressive stress may increase following homogenization, as there are fewer sites to promote DRX grain formation with the lamellar $\mathrm{Mg}_{17} \mathrm{Al}_{12}$ phase brought into solution.

5) When creating a casting for the forging pre-form, it is recommended that a forging preform be cast with a high cooling rate, such that the casting will have a more refined grain structure. While a more refined grain size will incur an increase in the peak compressive stress during forging, it will be much less susceptible to cracking during forging. This will allow higher strains, and a broader range of acceptable deformation temperatures and strain rates. Depending on the measured mechanical properties of the forged samples however, a forging temperature and rate may be selected which might allow use of a lower cooling rate cast material. In this case, the load required of the forging press may be lessened. Since the forged parts will begin as cast pre-forms, it is reccomended that they are forged to a strain of 0.4 or greater, as this will eliminate most of the porosity seen in the cast structure, while simultaneously giving a fair amount of grain refinement. Homogenization treatment might be beneficial toward reducing the compressive stress and subsequent forging press load, depending on the microstructure of the as-cast pre-form. Since not all of the material in a forging will be reaching the peak stress at once, and since the decrease in compressive stress in homogenized material following the peak stress is much more substantial than any increase in the peak stress that was seen, it is thought that homogenization will reduce the forging press load. While a higher number of recrystallized grains is seen in the homogenized material after deformation due to the $\mathrm{Mg}_{17} \mathrm{Al}_{12}$ phase being in solution, in practice, the forgings are held at their deformation temperature for a longer duration prior to deformation than in the compression test, and therefore some precipitation of the $\mathrm{Mg}_{17} \mathrm{Al}_{12}$ phase may occur. It is not known the extent of precipitation that may occur, or the effect it may have on the forging behaviour, since the forging conditions are currently not known. Finally, it is important to consider that the compression tests are of an open-die compression and are loaded uni-axially. In a closed-die forging, such as the one required for control arm forgings, the material is in a more complex stress state, and may not behave exactly as seen in the idealized compression test.

\subsection{Future Work}

Based on the analysis of these results, with consideration for the goals of the project and the knowledge surrounding AZ80, there are several areas that require further study in order to fully understand the phenomena responsible for the results that were seen. The proposed future works are as follows: 
1) This work showed an apparent increase of $\mathrm{Mg}_{17} \mathrm{Al}_{12}$ precipitates in the areas immediately surrounding the grain boundaries, for samples which were deformed at a lower strain rate. It is believed that this precipitation is responsible for the increased volume fraction of DRX grains that were seen when compressed at a lower strain rate. It is of interest to conduct analysis on these samples using EBSD, to measure their size and volume fraction more accurately. Further, this analysis should be conducted on homogenized material as well, to understand if the same effect of strain rate is seen. The homogenized material compressed at the low strain rate of $0.01 \mathrm{~s}^{-1}$ in this research did not show any precipitation, which is understandable as the homogenized material presumably will have less concentration of aluminum near the grain boundaries. With the current optical microscopy results however, it is difficult to determine if the homogenized samples experienced more DRX at lower strain rates.

2) The current research showed some relationship between the presence of the $\mathrm{Mg}_{17} \mathrm{Al}_{12}$ phase in the microstructure and the sample's electrical conductivity, during homogenization. It is of interest to further study this correlation, though also during ageing/precipitation of the $\mathrm{Mg}_{17} \mathrm{Al}_{12}$ phase. During forging, the pre-form and the die must be heated and held at the forging temperature for a period, until there are no thermal gradients in the material. It has been shown that possible precipitation can occur within minutes in homogenized material [76], especially with higher energy from deformation. Therefore it is likely that the homogenized material will undergo precipitation before forging. If the conductivity can reliably be correlated to precipitate fraction, it could be used prior to forging, to measure how much of the $\mathrm{Mg}_{17} \mathrm{Al}_{12}$ phase has precipitated during heating.

3) The amount of cracking seen during deformation was largely related to the porosity in the castings. A reduction in gas porosity was seen with the addition of the de-gas agent, and a reduction in shrinkage porosity was seen with an increase in the cast cooling rate, owing to the wedge cast mould configuration. In both conditions of reduced porosity, the visible cracking under high strains was reduced. However it is not believed that the porosity was the only explanation, as there was also a large difference in grain size between the high and low cooling rate samples. A similar study on cracking should be performed on material of varying grain sizes, but without any effects of shrinkage or gas porosity. 


\section{References}

[1] National Highway Traffic Safety Administration Department of Transportation. 2017 and Later Model Year Light-Duty Vehicle Greenhouse Gas Emissions and Corporate Average Fuel Economy Standards; Final Rule. Federal Register Vol 77, No. 199 Pg 62623-63200, 2012.

[2] Lynette W Cheah. Cars on a diet: the material and energy impacts of passenger vehicle weight reduction in the US. PhD thesis, Massachusetts Institute of Technology, 2010.

[3] MW Andure, SC Jirapure, and LP Dhamande. Advance automobile material for light weight future - a review. In IJCA Proceedings on International Conference on Benchmarks in Engineering Science and Technology, pages 15-22, 2012.

[4] Mustafa Kemal Kulekci. Magnesium and its alloys applications in automotive industry. The International Journal of Advanced Manufacturing Technology, 39(9-10):851-865, 2008.

[5] Zhong Yang, JP Li, JX Zhang, GW Lorimer, and JAMSEL Robson. Review on research and development of magnesium alloys. Acta metallurgica sinica (English letters), 21(5):313-328, 2009.

[6] S Kalpakjian and SR Schmid. Manufacturing processes for engineering materials-5th edition. agenda, 12:104, 2014.

[7] Andrew Gryguc, Sugrib K Shaha, Seyed Behzad Behravesh, Hamid Jahed, Mary Wells, B Williams, and X Su. Monotonic and cyclic behaviour of cast and cast-forged az80 mg. International Journal of Fatigue, 104:136-149, 2017.

[8] CA Sager, I Yakubtsov, W MacDonald, S Shook, B Diak, and M Niewczas. Physical metallurgy of mg az80 alloys for forging applications. Mater. Soc. Annu. Meet, 12:405410, 2009.

[9] DH StJohn, AK Dahle, Trevor Abbott, MD Nave, and Ma Qian. Solidification of cast magnesium alloys. Magnesium Technology, 2003:95-100, 2003.

[10] Hai-ping Cao and Magnus Wessén. Effect of microstructure on mechanical properties of as-cast mg-al alloys. Metallurgical and materials transactions A, 35(1):309-319, 2004 . 
[11] IA Yakubtsov, BJ Diak, CA Sager, B Bhattacharya, WD MacDonald, and M Niewczas. Effects of heat treatment on microstructure and tensile deformation of $\mathrm{mg}$ az80 alloy at room temperature. Materials Science and Engineering: A, 496(12):247-255, 2008.

[12] Mui Kheng Yeoh, XingHe Tan, Philip Hong Ning Cheang, Teik-Cheng Lim, and Richard Wai Onn Kwok. Effect of solutionizing time on improving the microstructure and mechanical properties of aged az80 mg alloy. Journal of Materials Engineering and Performance, 28(11):6836-6852, 2019.

[13] D Mackie, JD Robson, PJ Withers, and M Turski. Characterisation and modelling of defect formation in direct-chill cast az80 alloy. Materials Characterization, 104:116$123,2015$.

[14] Michael Grimm, Andreas Lohmüller, Robert F Singer, and Sannakaisa Virtanen. Influence of the microstructure on the corrosion behaviour of cast mg-al alloys. Corrosion Science, 155:195-208, 2019.

[15] S Lun Sin, D Dubé, and R Tremblay. Characterization of al-mn particles in az91d investment castings. Materials Characterization, 58(10):989-996, 2007.

[16] Carsten Potzies and Karl Ulrich Kainer. Fatigue of magnesium alloys. Advanced Engineering Materials, 6(5):281-289, 2004.

[17] K. Shiozawa, J. Kitajima, T. Kaminashi, T. Murai, and T. Takahashi. Low-cycle fatigue deformation behavior and evaluation of fatigue life on extruded magnesium alloys. Procedia Engineering, 10:1244-1249, 2011. 11th International Conference on the Mechanical Behavior of Materials (ICM11).

[18] Kazuaki Shiozawa, Tomoki Kashiwagi, Tutomu Murai, and Tooru Takahashi. Fatigue behaviour and fractography of extruded az80 magnesium alloys in very high cycle regime. Procedia Engineering, 2(1):183-191, 2010.

[19] A Gryguć, SB Behravesh, SK Shaha, H Jahed, M Wells, B Williams, and X Su. Multiaxial cyclic behaviour of extruded and forged az80 $\mathrm{mg}$ alloy. International Journal of Fatigue, 127:324-337, 2019.

[20] Makoto Fujita, Nobuo Sakate, Shoji Hirahara, and Yukio Yamamoto. Development of magnesium forged road wheel. JSAE review, 16(3):299-301, 1995. 
[21] Hoda Dini. As-cast AZ91D Magnesium Alloy Properties-Effect of Microstructure and Temperature. PhD thesis, Jönköping University, School of Engineering, 2015.

[22] Zhang Guangjun, Long Siyuan, and Cao Fenghong. Effects of aluminum content on the microstructure and mechanical properties of az magnesium alloys. Special Casting E Nonferrous Alloys, 9:848-850, 2009.

[23] F Yavari and SG Shabestari. Effect of cooling rate and al content on solidification characteristics of az magnesium alloys using cooling curve thermal analysis. Journal of Thermal Analysis and Calorimetry, 129(2):655-662, 2017.

[24] Matthew S Dargusch, Ketil Pettersen, Kazuhiro Nogita, Mark D Nave, and Gordon L Dunlop. The effect of aluminium content on the mechanical properties and microstructure of die cast binary magnesium-aluminium alloys. Materials transactions, 47(4):977-982, 2006.

[25] Pouya Sharifi. Structure-property relationships of magnesium alloys. Master's thesis, 2012.

[26] CH Caceres, CJ Davidson, JR Griffiths, and CL Newton. Effects of solidification rate and ageing on the microstructure and mechanical properties of az91 alloy. Materials Science and Engineering: A, 325(1-2):344-355, 2002.

[27] F-W Bach, A Roßberg, M Schäperkötter, M Schaper, L Walden, and J Weber. Today's sheet metal materials and their forming properties. Materialwissenschaft und Werkstofftechnik: Entwicklung, Fertigung, Prüfung, Eigenschaften und Anwendungen technischer Werkstoffe, 35(7):423-430, 2004.

[28] Adrien Chapuis and Julian H Driver. Temperature dependency of slip and twinning in plane strain compressed magnesium single crystals. Acta Materialia, 59(5):1986-1994, 2011.

[29] Marcel Graf, Madlen Ullmann, and Rudolf Kawalla. Influence of initial state on forgeability and microstructure development of magnesium alloys. Procedia Engineering, 81:546-551, 2014.

[30] FA Slooff, JS Dzwonczyk, J Zhou, J Duszczyk, and L Katgerman. Hot workability analysis of extruded az magnesium alloys with processing maps. Materials Science and Engineering: A, 527(3):735-744, 2010. 
[31] Paresh Prakash, Amir Hadadzadeh, Sugrib Kumar Shaha, Mark A Whitney, Mary A Wells, Hamid Jahed, and Bruce W Williams. Microstructure and texture evolution during hot compression of cast and extruded az80 magnesium alloy. In Magnesium Technology 2019, pages 89-94. Springer, 2019.

[32] WANG Qiang, Zhi-Min Zhang, Xing Zhang, and Jian-Min Yu. Precision forging technologies for magnesium alloy bracket and wheel. Transactions of Nonferrous Metals Society of China, 18:s205-s208, 2008.

[33] Yun Teng Liu, Ji Xue Zhou, Di Zhang, Tao Lin, Yu Liu, Chang Wen Tian, and Yuan Sheng Yang. Influence of initial microstructure on the hot working flow stress of mg-3al-1zn alloy. In Materials Science Forum, volume 898, pages 86-90. Trans Tech Publ, 2017.

[34] AG Beer and MR Barnett. Influence of initial microstructure on the hot working flow stress of mg-3al-1zn. Materials Science and Engineering: A, 423(1-2):292-299, 2006.

[35] Dominik Kobold, Tomaž Pepelnjak, Gašper Gantar, and Karl Kuzman. Analysis of deformation characteristics of magnesium az80 wrought alloy under hot conditions. Journal of Mechanical Engineering, 12(56):823-832, 2010.

[36] A Gryguc, SK Shaha, SB Behravesh, H Jahed, M Wells, and B Williams. Compression behaviour of semi-closed die forged az80 extrusion. In Characterization of Minerals, Metals, and Materials 2017, pages 361-369. Springer, 2017.

[37] Lifei Wang, Ehsan Mostaed, Xiaoqing Cao, Guangsheng Huang, Alberto Fabrizi, Franco Bonollo, Chengzhong Chi, and Maurizio Vedani. Effects of texture and grain size on mechanical properties of az80 magnesium alloys at lower temperatures. Materials $\mathcal{G}$ Design, 89:1-8, 2016.

[38] S Aliakbari Sani, GR Ebrahimi, and AR Kiani Rashid. Hot deformation behavior and dynamic recrystallization kinetics of az61 and az61+ sr magnesium alloys. Journal of Magnesium and Alloys, 4(2):104-114, 2016.

[39] Pavel Lukáč and Zuzanka Trojanová. Influence of grain size on ductility of magnesium alloys. Materials Engineering, 18(3):110-114, 2011.

[40] JP Weiler, JT Wood, RJ Klassen, R Berkmortel, and G Wang. The effect of grain size on the flow stress determined from spherical microindentation of die-cast magnesium am60b alloy. Journal of materials science, 40(22):5999-6005, 2005. 
[41] P Sharifi, Y Fan, JP Weiler, and JT Wood. Predicting the flow stress of high pressure die cast magnesium alloys. Journal of alloys and compounds, 605:237-243, 2014.

[42] Choong Do Lee and Kwang Seon Shin. Effects of precipitate and dendrite arm spacing on tensile properties and fracture behavior of as-cast magnesium-aluminum alloys. Metals and Materials International, 9(1):21-27, 2003.

[43] YVRK Prasad and KP Rao. Effect of homogenization on the hot deformation behavior of cast az31 magnesium alloy. Materials \&f Design, 30(9):3723-3730, 2009.

[44] Tsz Wun Wong, Amir Hadadzadeh, Michael J Benoit, and Mary A Wells. Impact of homogenization heat treatment on the high temperature deformation behavior of cast az31b magnesium alloy. Journal of Materials Processing Technology, 254:238-247, 2018.

[45] Horng-yu Wu, Jie-chen Yang, Feng-jun Zhu, and Hsu-cheng Liu. Hot deformation characteristics of as-cast and homogenized az61 mg alloys under compression. Materials Science and Engineering: A, 550:273-278, 2012.

[46] Mu MENG, Hong-na QI, Jie REN, Xue-wei ZHENG, and Seng JIANG. Deformation microstructure and properties of az80 alloy with different initial status. Journal of Plasticity Engineering, page 05, 2015.

[47] Deng Ziyu, Shang Linlin, Zhang Xuefei, and Cui Jianzhong. Effects of homogenization treatment on microstructure and high temperature deformation behavior of as-cast az80 magnesium alloy. Special Casting $\&$ Nonferrous Alloys, page 03, 2009.

[48] Y Cai, L Wan, ZH Guo, CY Sun, DJ Yang, QD Zhang, and YL Li. Hot deformation characteristics of az80 magnesium alloy: Work hardening effect and processing parameter sensitivities. Materials Science and Engineering: A, 687:113-122, 2017.

[49] Zexing Su, Li Wan, Chaoyang Sun, Yun Cai, and Daijun Yang. Hot deformation behavior of az80 magnesium alloy towards optimization of its hot workability. Materials Characterization, 122:90-97, 2016.

[50] Paresh Prakash. Microstructure and texture evolution during hot deformation of AZ80 magnesium alloy. PhD thesis, 2019.

[51] John Campbell. Stop pouring, start casting. International Journal of Metalcasting, $6(3): 7-18,2012$. 
[52] John Campbell. Castings. Elsevier, 2003.

[53] Whiting L. V. Sadayappan K. Sahoo M., Sahu S. American Foundry Society, 2015.

[54] WD Griffiths and N-W Lai. Double oxide film defects in cast magnesium alloy. Metallurgical and materials transactions A, 38(1):190-196, 2007.

[55] David Schwam, John F Wallace, Tom Engle, and Qingming Chang. Gating of permanent molds for aluminum casting. Technical report, Case Western Reserve Univ., Cleveland, OH (United States), 2004.

[56] X Dai, X Yang, J Campbell, and J Wood. Effects of runner system design on the mechanical strength of al-7si-mg alloy castings. Materials Science and Engineering: A, 354(1-2):315-325, 2003.

[57] John Campbell. Concise castings: a casting workshop lecture. American Foundry Soc., 2010.

[58] MAA Khan and AK Sheikh. A comparative study of simulation software for modelling metal casting processes. International Journal of Simulation Modelling, 17(2):197-209, 2018.

[59] I Vasková, D Fecko, and L' Eperješi. Comparison of simulation programs magmasoft and novaflow\&solid in terms of results accuracy. Archives of foundry engineering, 11(1):51-54, 2011.

[60] Kai Ho and Robert D Pehlke. Metal-mold interfacial heat transfer. Metallurgical Transactions B, 16(3):585-594, 1985.

[61] Y Nishida, W Droste, and S Engler. The air-gap formation process at the casting-mold interface and the heat transfer mechanism through the gap. Metallurgical Transactions $B, 17(4): 833-844,1986$.

[62] H Hao, DM Maijer, MA Wells, SL Cockcroft, D Sediako, and S Hibbins. Development and validation of a thermal model of the direct chill casting of az31 magnesium billets. Metallurgical and Materials Transactions A, 35(12):3843-3854, 2004.

[63] J Sengupta, SL Cockcroft, DM Maijer, MA Wells, and A Larouche. On the development of a three-dimensional transient thermal model to predict ingot cooling behavior during the start-up phase of the direct chill-casting process for an aa5182 aluminum alloy ingot. Metallurgical and Materials Transactions B, 35(3):523-540, 2004. 
[64] Weihong Zhang, Gongnan Xie, and Dan Zhang. Application of an optimization method and experiment in inverse determination of interfacial heat transfer coefficients in the blade casting process. Experimental thermal and fluid science, 34(8):1068-1076, 2010.

[65] Liqiang Zhang, Luoxing Li, Hui Ju, and Biwu Zhu. Inverse identification of interfacial heat transfer coefficient between the casting and metal mold using neural network. Energy conversion and management, 51(10):1898-1904, 2010.

[66] Charles Moosbrugger. Engineering Properties of Magnesium Alloys. ASM International, 2017.

[67] ZY Chen, SQ Xu, and XH Dong. Deformation behavior of aa6063 aluminium alloy after removing friction effect under hot working conditions. Acta Metallurgica Sinica (English Letters), 21(6):451-458, 2008.

[68] Amir Hadadzadeh and Mary A Wells. Analysis of the hot deformation of zk60 magnesium alloy. Journal of magnesium and alloys, 5(4):369-387, 2017.

[69] R Ebrahimi and A Najafizadeh. A new method for evaluation of friction in bulk metal forming. Journal of Materials Processing Technology, 152(2):136-143, 2004.

[70] J Luan, C Sun, X Li, and Q Zhang. Constitutive model for az31 magnesium alloy based on isothermal compression test. Materials Science and Technology, 30(2):211219, 2014 .

[71] Astm e112-13, standard test methods for determining average grain size, astm international, west conshohocken, pa, 2013, www.astm.org.

[72] Eli Vandersluis and Comondore Ravindran. Comparison of measurement methods for secondary dendrite arm spacing. Metallography, Microstructure, and Analysis, 6(1):89-94, 2017.

[73] Rahul R Kulkarni, Nityanand Prabhu, Peter D Hodgson, and Bhagwati P Kashyap. Phase dissolution of $\gamma$-mg 17 al 12 during homogenization of as-cast az80 magnesium alloy and its effect on room temperature mechanical properties. In Magnesium Technology 2012, pages 543-548. Springer, 2012.

[74] Paresh Prakash, Dwayne Toscano, Sugrib Kumar Shaha, Mary A Wells, Hamid Jahed, and Bruce W Williams. Effect of temperature on the hot deformation behavior of az80 magnesium alloy. Materials Science and Engineering: A, 794:139923, 2020. 
[75] Andrew Gryguc. Fatigue of Forged AZ80 Magnesium Alloy. PhD thesis, 2019.

[76] SW Xu, N Matsumoto, S Kamado, T Honma, and Y Kojima. Effect of mg17al12 precipitates on the microstructural changes and mechanical properties of hot compressed az91 magnesium alloy. Materials Science and Engineering: A, 523(1-2):47-52, 2009.

[77] MR Barnett. Influence of deformation conditions and texture on the high temperature flow stress of magnesium az31. Journal of Light Metals, 1(3):167-177, 2001.

[78] Hui-zhong Li, Xiao-yan Wei, Jie Ouyang, Jun Jiang, and LI Yi. Hot deformation behavior of extruded az80 magnesium alloy. Transactions of Nonferrous Metals Society of China, 23(11):3180-3185, 2013. 
APPENDICES 


\section{A Casting Moulds and Castings}

Detailed images of the casting moulds and the castings are presented in this section.
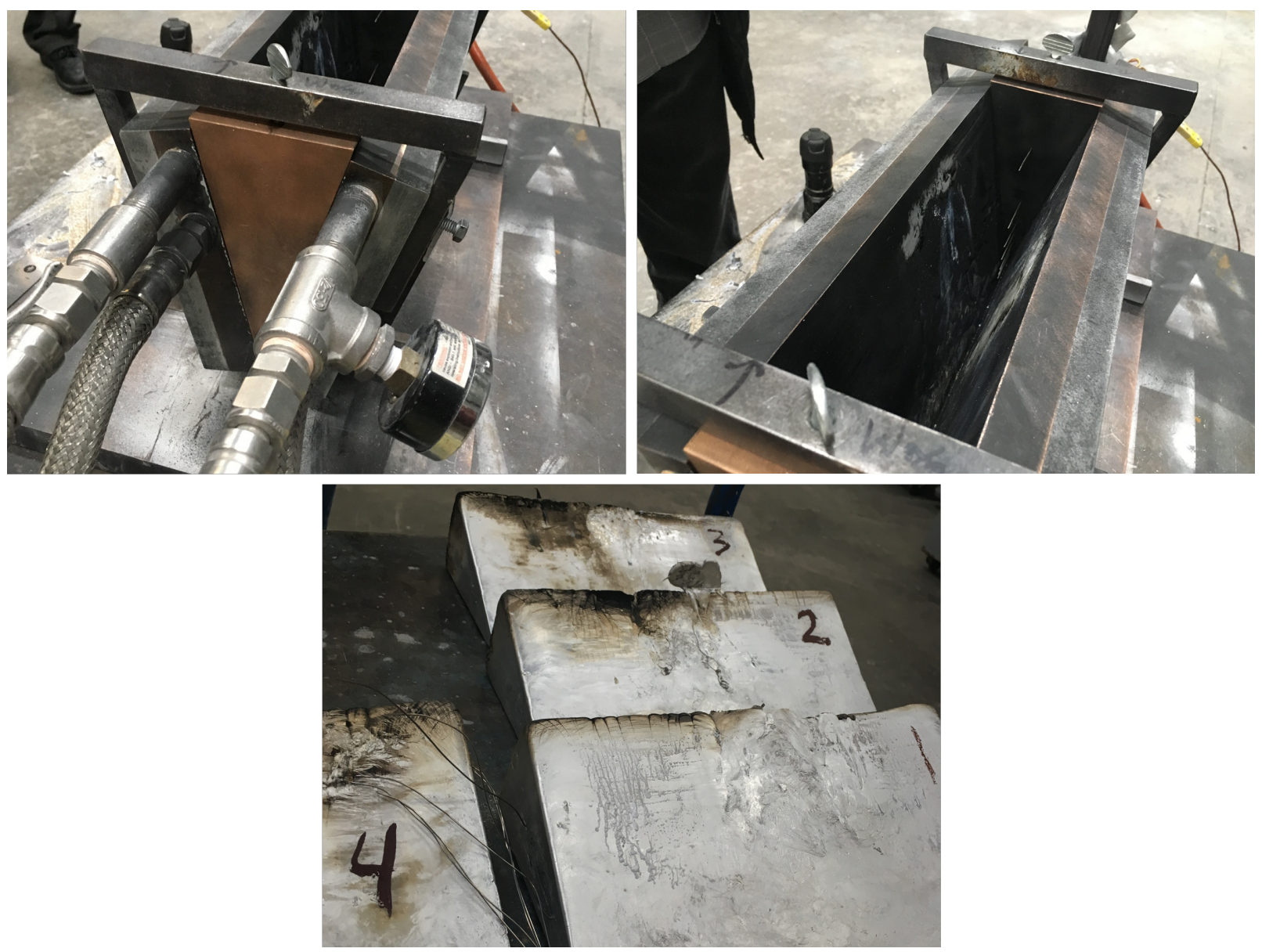

Figure A.1: Detailed images of the wedge casting mould, showing water cooling lines, thermocouples inside the mould, and the cast wedges. 

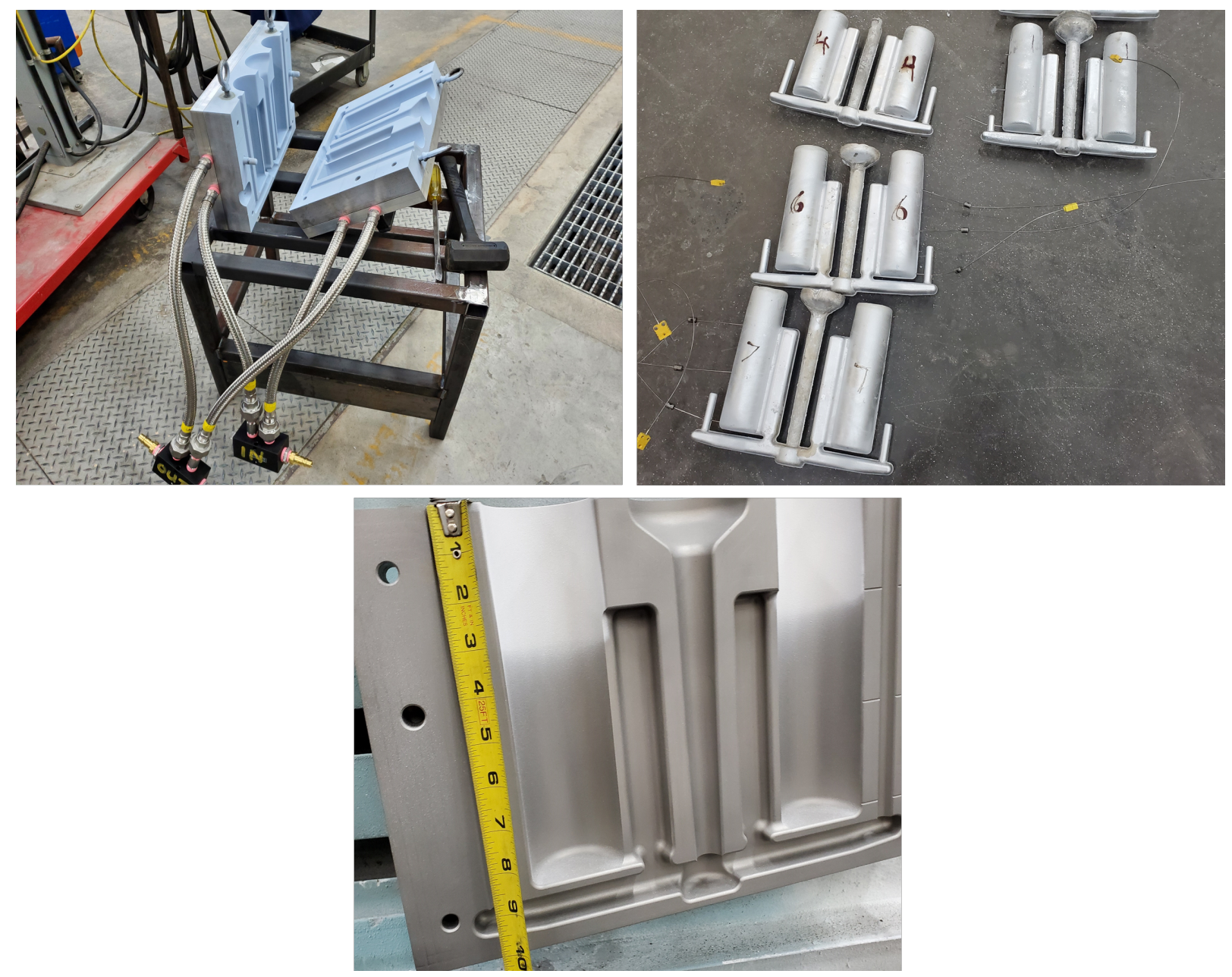

Figure A.2: Detailed images of the cylinder casting mould, showing water cooling lines, detailed mould geometry and approximate size, and the casting. Images courtesy of Peter Newcombe at CANMETMaterials. 


\section{B Compressive Stress Curve Data}

\section{Compressive true stress-true strain curves for all defor- mation conditions tested, wedge cast material}

The plots of compressive true stress-true strain for all deformation conditions tested for the low and high cooling rate wedge cast samples are presented in this section.
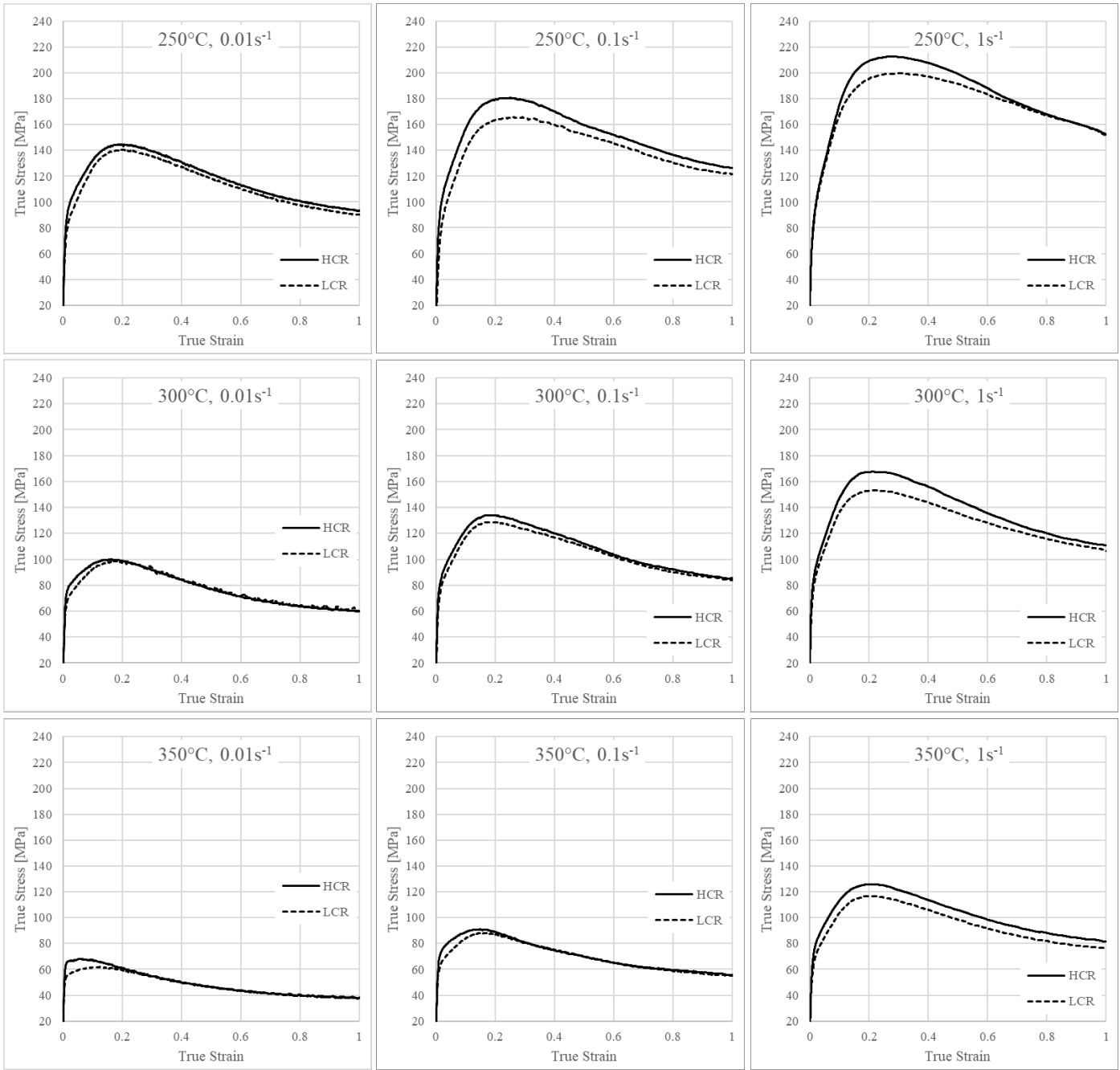

Figure B.1: Compressive true stress-true strain curves for the as-cast material. 

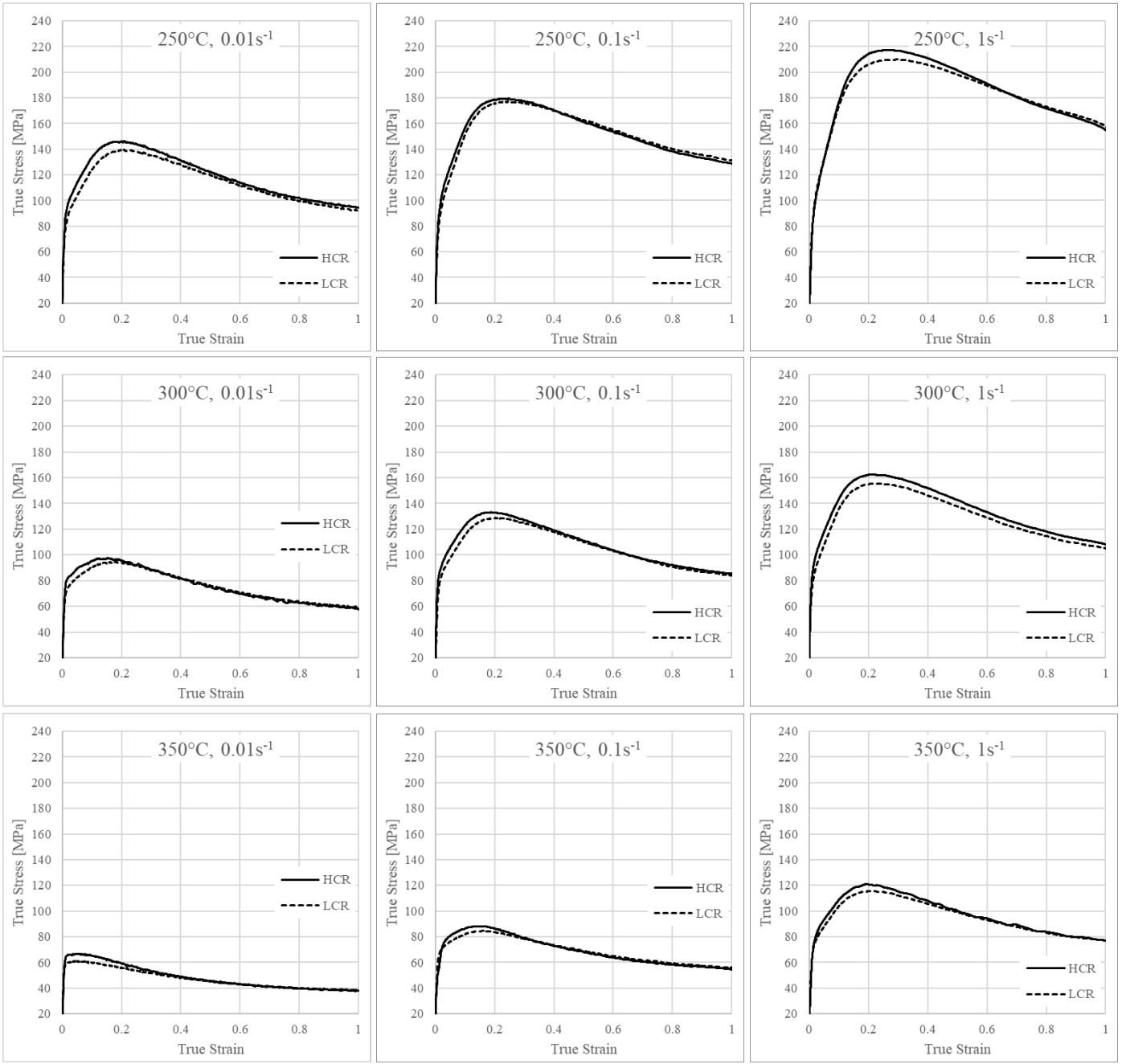

Figure B.2: Compressive true stress-true strain curves for the de-gas material.

\section{Compressive true stress-true strain curves for all defor- mation conditions tested, cylinder cast material}

The plots of compressive true stress-true strain for all deformation conditions tested for the cylinder cast material, in as-cast and homogenized states, are presented in this section. 


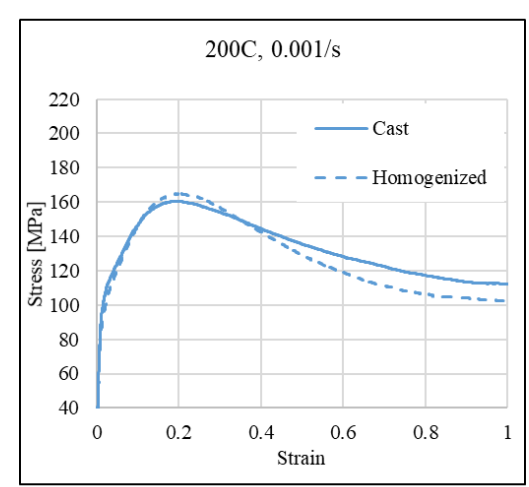

Increasing Strain Rate
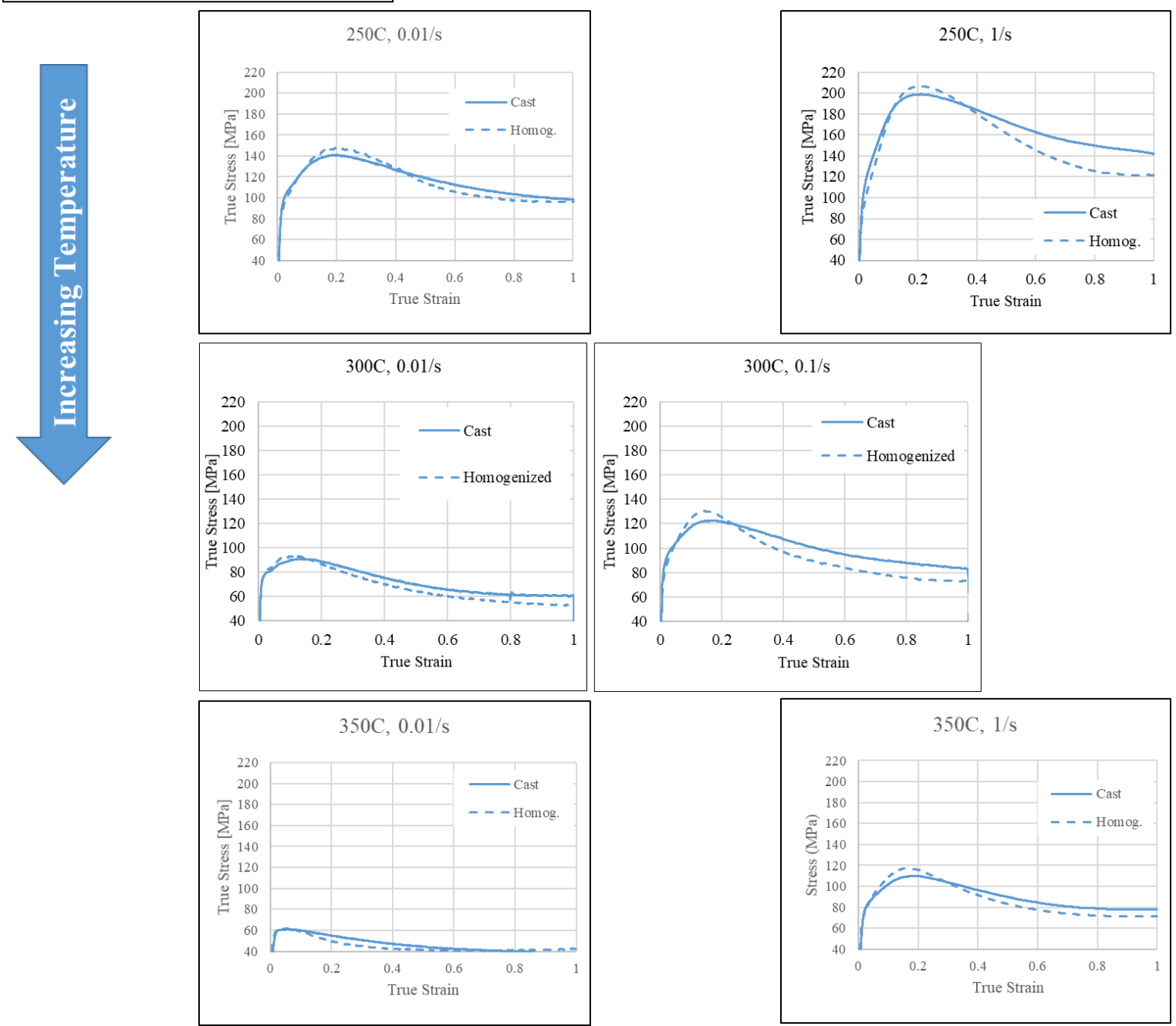

Figure B.3: Compressive true stress-true strain curves for the cast and homogenized cylinder material 


\section{Metallographic Analysis}

\section{Grain Size and Secondary Dendrite Arm Spacing Mea- surements}

The grain size was measured on images that were taken at 50x magnification, using 5 lines drawn in different directions.

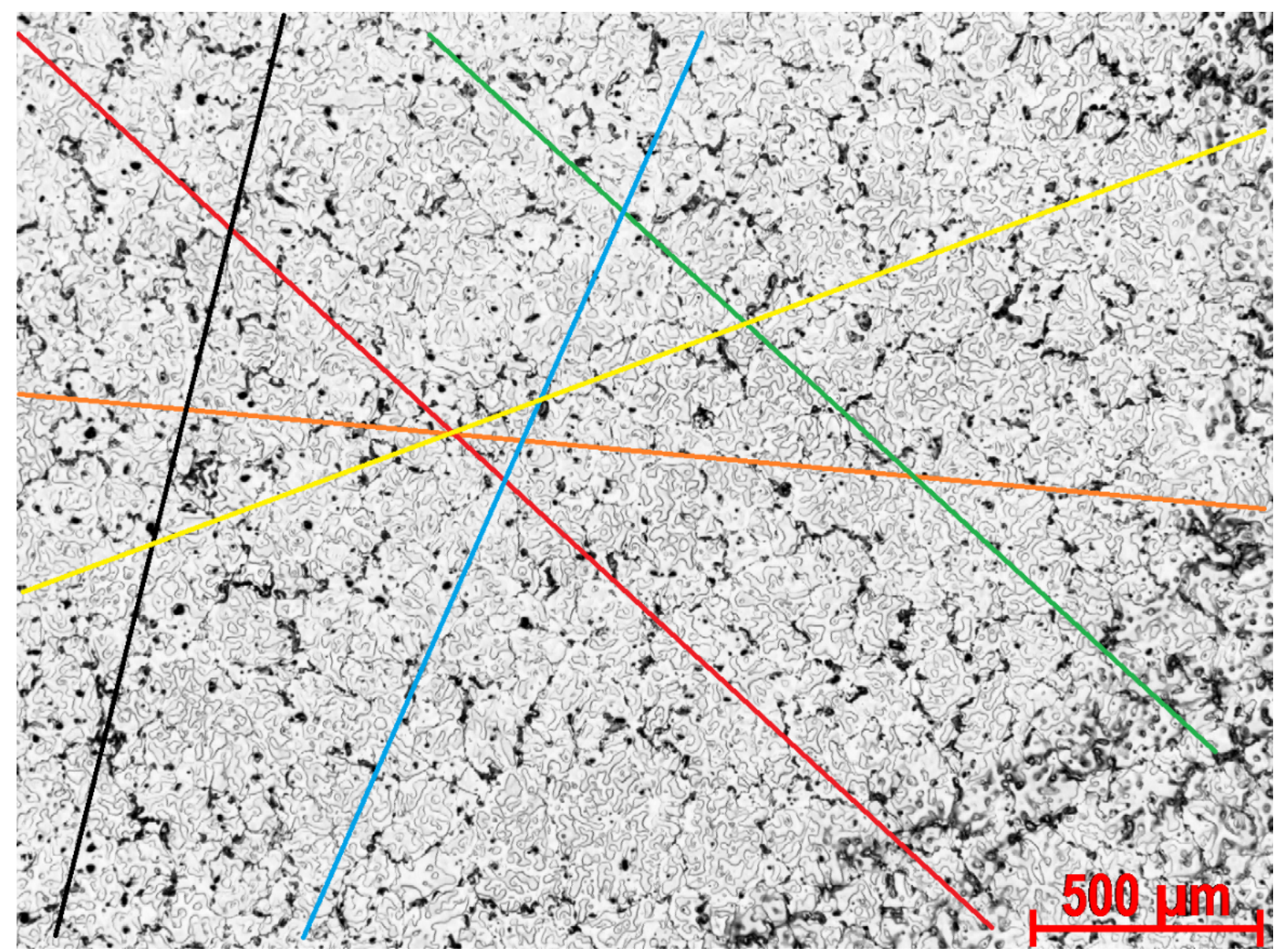

Figure C.1: An example of the lines drawn on the sample images for grain size measurement. The sample is an as-cast LCR sample, at 50x magnification.

The length of each line was measured, and the number of grain boundaries which each line 
intercepts were recorded. The results of this example are shown in Table C.1.

Table C.1: The line length and grain boundary intercepts recorded, and calculated grain size, for the as-cast LCR wedge casting.

\begin{tabular}{|c|c|c|c|c|c|c|c|}
\hline As-cast LCR & Line Colour & Orange & Red & Black & Green & Blue & Yellow \\
\hline \multirow[t]{4}{*}{$50 \mathrm{x}$} & Length of Line $(\mu \mathrm{m})$ & 2678.54 & 2837.31 & 2032.38 & 2294.48 & 2106.04 & 2836.14 \\
\hline & Number of Grain Boundaries & 11 & 14 & 10.5 & 13.5 & 12 & 13 \\
\hline & Average Grain Size & 243.503 & 202.665 & 193.56 & 169.961 & 175.503 & 218.165 \\
\hline & Total Average Grain Size & 200.56 & & & & & \\
\hline
\end{tabular}

\section{Identification and Measurement of DRX grains}

As described in Section 4.3.2, the DRX grains were measured using a similar method to that of the porosity, by filtering areas of an image based on colour, ensuring that no porosity, un-recrystallized grains, or other particles, were selected. An example of an image with a high amount of DRX grains is shown in Figure C.2.

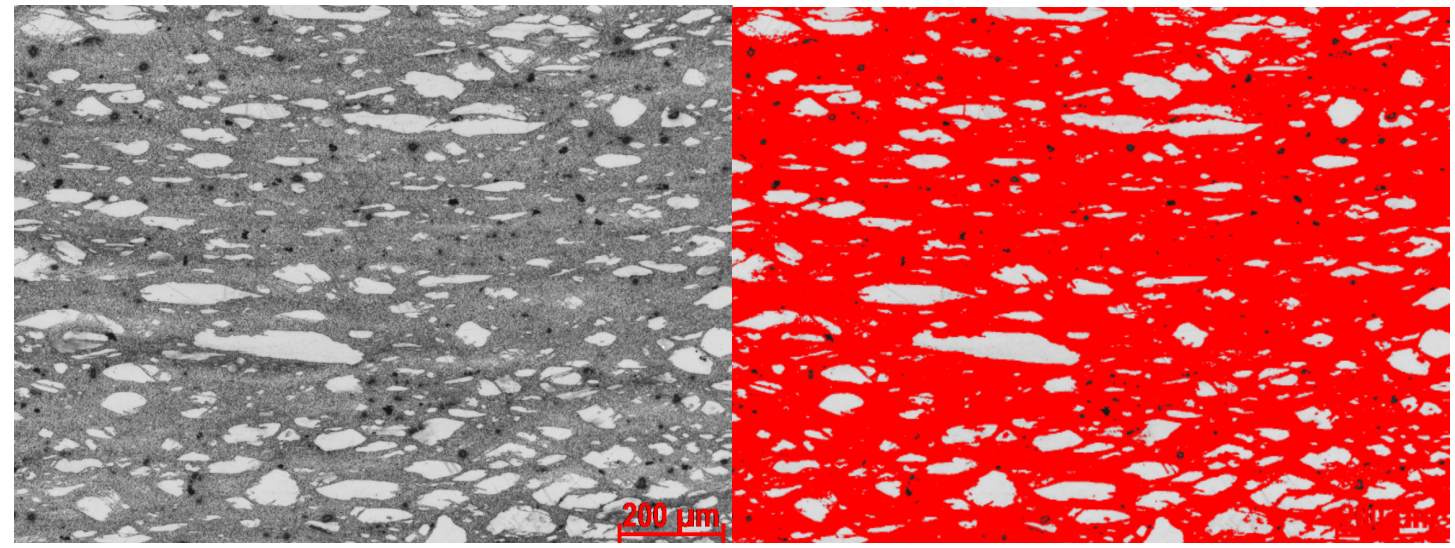

Figure C.2: An example of an image with a high amount of DRX grains, and how they appear after selection using ImageJ. 